\title{
Embodied Visions in William Blake's Visions of the Daughters of Albion
}

\author{
by \\ Rosalind Atkinson \\ A thesis submitted to Victoria University of Wellington in fulfilment of the \\ requirements for the degree of Master of Arts in English Literature
}

Victoria University of Wellington

Te Whare Wānanga o te Ūpoko o te Ika a Māui 2015 


\section{Contents}

Table of Illustrations ..................................................................................iv

Acknowledgements.........................................................................................

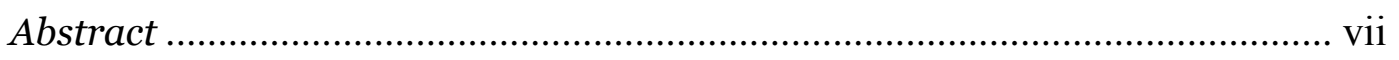

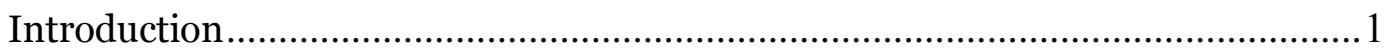

A Japanese Blake: Tezuka Osamu and William Blake ........................................4

Modesty and Sexual Embodiment in Wollstonecraft and Blake ..........................38

Embodied Perception and Visions Criticism...................................................... 78

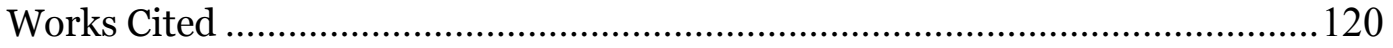




\section{Table of Illustrations}

Figure 1. Bernard Leach, cover design for Shirakaba ............................................. 9

Figure 2. Bernard Leach, screen inspired by “The Tyger” ...................................... 9

Figure 3. Blake, fragment of America a Prophecy cancelled plate a ..................... 15

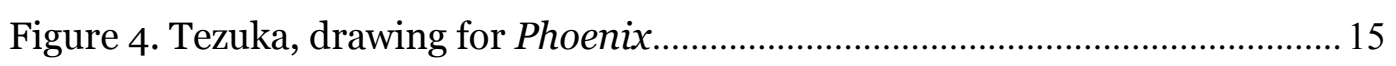

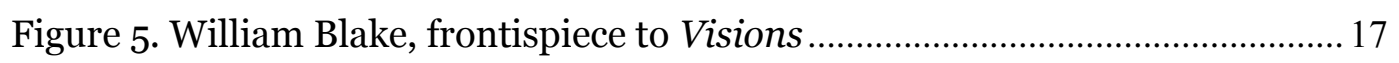

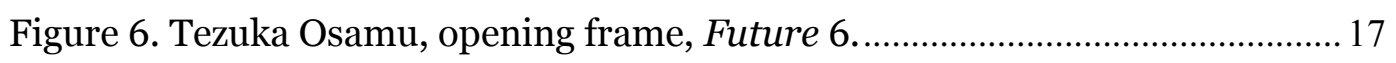

Figure 7. Tezuka Osamu, Doctor Saruta inspects his creations ............................... 18

Figure 8. Tezuka Osamu, Bradbury melts in agony .............................................. 19

Figure 9. Tezuka Osamu, Saruta reads The Sorrows of Young Werther ............... 20

Figure 10. Tezuka Osamu, the Phoenix appears ……............................................... 22

Figure 11. Tezuka Osamu, the Phoenix introduces herself ...................................... 23

Figure 12. Tezuka Osamu, conversation with Phoenix ........................................... 24

Figure 13. Tezuka Osamu, Saruta's vision of the cosmos........................................ 25

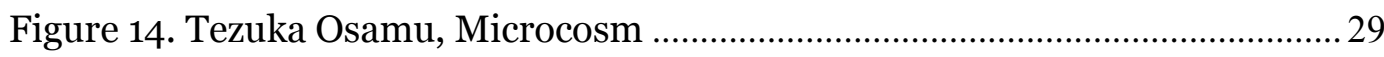

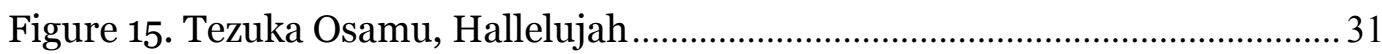

Figure 16. Tezuka Osamu, Apocalypse .................................................................... 34

Figure 17. William Blake, engraving for Original Stories from Real Life ...............53

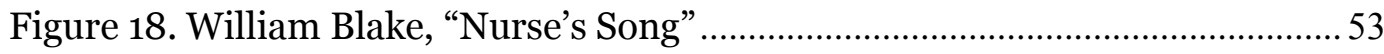

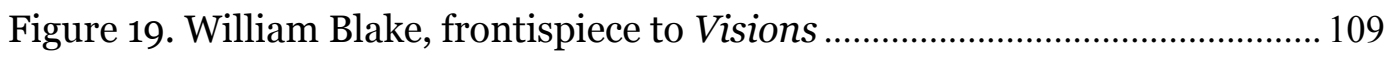

Figure 20. William Blake, detail from title page of Visions .................................. 115 


\section{Acknowledgements}

I am grateful for the support of a Victoria University of Wellington Master's Scholarship, and the assistance of the Karis Boyd Scholarship. My thanks to the Faculty of Humanities and Social Sciences for a postgraduate research grant which enabled me to present a version of the first chapter of this thesis at the 2014 NASSR "Romantic Connections" Conference in Tokyo, and facilitated research at the Tezuka archives in Hyōgo and the Japan Folk Craft Museum. I am grateful for assistance from the School of English, Film, Theatre and Media Studies' "Romantic Voyagers" fund, and to the encouragement of Heidi Thomson which made attendance at this conference possible.

Thank you Pip, Emma, Tara, Daniel, Emily and Andrew for your contributions and loving support.

And my gratitude to Heidi Thomson and Dougal McNeill for their expert and generous supervision of this thesis. 


\begin{abstract}
William Blake characterised an abstract as "A murderer of its own Body," an attempt to impose stable mastery on an unstable reality (E153). In this project I read Blake's illuminated poem, Visions of the Daughters of Albion, from the 'unstable' perspective of 'Embodied Visions,' based on my hypothesis that readings of the poem have often been distorted by the imposition of binary divisions that are undermined within the work itself. I approach Visions in three chapters: firstly I align Blake's work Japanese manga artist Tezuka Osamu (19281989), tracing the construction of Blake in Japan, and how this can occasion new perspectives; secondly I read Visions with Mary Wollstonecraft's A Vindication of the Rights of Woman, placing both texts in response to oppressive sexual prescriptions of the 1790s, in order to chart where they concur and diverge; and finally I examine the effect of dualistic critical frames on readings of Visions, arguing that we must read the sections exploring perception as continuous with the rest of the poem in order to appreciate Blake's engagement with an embodied reality.
\end{abstract}




\section{Introduction}

William Blake describes his embodied, poetic project as "Giving a body to Falshood that it may be cast off for ever. | ... piercing Apollyon with his own bow! (Jerusalem 12.13, E155). Embodiment is crucial to exposing the forms of oppression Blake's works contest, an anatomy of the present revealing the ravages of current practices. Too often, Blake's illuminated poems have been read as disembodied mythical allegories, rather than active engagements with specific forms of "Falshood" Blake saw around him in late-eighteenth-century and earlynineteenth-century London.

This has been the case with Blake's illuminated poem Visions of the Daughters of Albion (1793), where dualistic critical frameworks have been imposed upon a poem that actively undermines such frames. For a student reading accounts of this poem, as one critic noted, "[t]here is sometimes the impression given that different critics are reading different poems, all with the same title" (Moss 10). My approach to Visions seeks to return to the body of the text, from which many of these imaginings have taken flight. As Peter Otto notes, Blake's art engages with the world with a recognition that "our emotions, imaginations, and sense-making procedures are deeply implicated in the production of [what Blake refers to as] the fallen world," and that "[r]eaders therefore inevitably take part" in its dynamics $(17,18)$. My project of gaining a perspective on the poem without impositions is impossible, but the goal is to fail well: to examine this one poem as a complicated, sometimes irresolvable chaos of 'embodied visions' rather than immaterial fantasy.

My framework of embodiment is different from some existing approaches in that I focus on the relation between the body and the various cultural practices designed to transcend it, whether within the poem itself or played out in the critical reception, rather than an examination of Blake and information about the body. 'Embodied Visions' is the framework which I propose yields exciting and 
rich perspectives on Visions, rather than the poem being used to prove a thesis of embodiment in Blake's work more broadly.

In order to examine and unsettle received understandings of Visions, I have chosen to read the poem from three distinct viewpoints which challenge the construction of Blake as a poet of transcendence. Firstly, I examine Blake's work in a radically different context by reading it alongside twentieth-century manga artist Tezuka Osamu's Phoenix: A Tale of the Future. The construction of a Japanese Blake, and the resulting correspondences with Tezuka, destabilise critical assumptions about Blake's work, making room for fresh perspectives on embodiment in Blake's work. The aim is not to sever Blake from his context, but rather to gain critical distance, and thus insight into what dualistic frameworks may have been imposed upon his poetry. What emerges is the possibility of poetry that is visionary, but not at the expense of the material, and embodied, but not at the expense of vision.

In order to continue this argument from a different direction, I turn to the often discussed influence of Mary Wollstonecraft's Vindication of the Rights of Woman on Blake's Visions, examining the portrayal of modesty in both works. I explore what emancipation might mean in relation to the repressive sexual norms of the 1790s, in order to ground Visions in the cultural forces against which it rails. Again, reading these two authors together analogically reveals not polarised opposition but fruitful and vital discussion, with embodiment at the centre of the tension between the two. The resulting version of Blake allows for detailed consideration of Oothoon, and sexual embodiment in Visions, deepening the challenge to dualistic readings.

Finally, I chart the changing fortunes of those sections of the poem dealing with perception, examining Locke's writing alongside Blake's "piercing” criticism of idealist and materialist practices. I use Locke's Essay Concerning Human Understanding (1689) to again question divisive binaries, relating shifts in treatments of the epistemological sections of Visions to the assumptions and strategic omissions of various critical frameworks. Having examined different 
'Blakes' in this and the preceding chapters, this chapter analyses the critical legacy to see why certain assumptions have been made, and how these affect a reading of the poem. In dealing with one poem from these related viewpoints, there is inevitably a degree to which these accounts circle one another and overlap. However by approaching Blake's work from different cultural, temporal, geographical, gendered, generic and philosophical standpoints, alternative ways of reading have space to be considered. I argue that when these chapters are taken together, they demonstrate the limitations of divisive frameworks, allowing instead for an unstable, always incomplete version of Visions, which can nevertheless be read as part of Blake's multiple, incisive conversations with cultural forces around him, revealing their lived effects through poetic embodiment. 'Embodied Visions,' I will show, describes not only a material process, an argument, a solution, a strategy and a perspective found within the poem, but also a fruitful and illuminating to read it. 


\section{A Japanese Blake: Tezuka Osamu and William Blake}

The Ancient Poets animated all sensible objects

William Blake, The Marriage of Heaven and Hell, plate 11

William Blake, wrote his contemporary Robert Hunt, was an "unfortunate lunatic," his works "a futile endeavour by bad drawings to represent immaterially ${ }^{1}$ by bodily personifications" (qtd. in Bentley 283). Blake's conflations of "the visible and invisible world," Hunt asserted in the Examiner, were "impossibilities... surpassing any recorded in the Tales of Genii [sic]" (qtd. in Bentley 259). This embodied elision of the mind-body divide was identified by Hunt and other reviewers as the most offensively irrational aspect of Blake's work, and Hunt connects this with specifically Eastern disorder.

Peter Otto discusses Blake's figure of Nebuchadnezzar as a critique of colonial empire, arguing that Blake's representation of the fallen tyrant challenges the attempts of radicals and conservatives "to transcend the dangerous, purportedly Eastern, realm of the body" ("Sublime Torments” 261). Blake’s artwork, Otto suggests, exposes the impossibility of these attempts, thereby creating possibilities for "an art that would undo the opposition" that "in Western, colonial discourses is often used to divide East from West" ("Sublime Torments" 261). Such a division and privileging of an orderly Western empire of the mind over a disorderly, usually feminised body of the East has been used to interpret Blake's works since their inception. In this chapter, I consider whether it is possible to read Blake outside of these divisive Western categories. Are there

\footnotetext{
${ }^{1}$ Bentley writes "obviously a misprint for “immateriality”" (283).
} 
contexts that might suggest different configurations of embodiment in Blake's works?

To consider these questions, I trace what Steve Clark and Masashi Suzuki call, in The Reception of Blake in the Orient, "the long and distinguished Japanese tradition of reception" (2). ${ }^{2}$ This reception history gives us an unexpected Blake, which I focus by bringing Blake's Visions of the Daughters of Albion ${ }^{3}$ and The Marriage of Heaven and Hell into conversation with twentieth-century manga artist Tezuka Osamu (1928-1989) and his Phoenix: A Tale of the Future (1968). 4 Rather than assuming a pre-existing, universal Blake, this chapter argues that a Japanese Blake is rather an original construction, notably different to the Western poet, which can however "more than hold its own against the current AngloAmerican orthodoxies" (Clark and Suzuki 11).

Examining this 'Japanese Blake' may seem strange given Blake's reputation as a "notorious non-traveller" (Clark and Suzuki 1). Blake mentions "bright Japan" (E170) once each in Milton and in The Four Zoas, and eight times in Jerusalem, each time to indicate a geographical limit, for example "Japan | Where the Red Sea terminates the World" (Jerusalem 89.38-39, E249). These mentions are remarkable given the distance of Japan from the British popular imagination. Despite "popular Orientalism during the late eighteenth century and the early nineteenth attain[ing] a vogue of considerable intensity" (Said 118), Annette Keogh notes how "[d]uring the long eighteenth century, Japan represents a singularly foreign destination, both linguistically and experientally, for European travellers” (171). Edo Japan's sakoku or 'closed country' edicts

\footnotetext{
${ }^{2}$ My references to Japanese names are in the Japanese order of family name followed by given name, except as here, when authors have published their works in the reversed English language order, in which case I follow their indication.

3 References to Visions refer to the Huntington Library facsimile and transcription of copy E. All other citations of Blake's works refer to Erdman's Complete Works, hereafter 'E'. 4 My discussion draws exclusively on the English language translation of Phoenix, in which images have been mirrored and rearranged to conform to a left-to-right reading order rather than the original Japanese right-to-left. Further research would require engagement with Tezuka's work in the original Japanese language and orientation.
} 
restricted interchange with Europe to extremely limited contact via the Dutch trading station in Nagasaki. Until the Tokugawa shogunate ended in 1868, the best text available on Japan was Engelbert Kaempfer's erratic 1727 History of Japan, and literary mentions were few and far between. ${ }^{5}$ Robert Markley notes the indistinctness of Swift's fleeting reference to Japan in 1726, arguing that "Japan resists representation precisely because it controls the cultural and economic terms of its encounters" (255). When Japan was mentioned, it was commonly appended to China to evoke tyranny, such as John Thelwall's reference in 1796 to "the despotisms of China, and Japan" (qtd. in Kitson 27).

Although I will outline a Japanese construction of Blake, rather than Blake's construction of Japan, it is worth briefly considering what Blake's passing mentions may suggest. Blake's reference to Japan as a neutral geographical marker, included with the other countries as part of "every Nation under heaven" (E169), supports Saree Makdisi's proposition that Blake "refused the discourse of exoticism" and Orientalism, a "political aesthetic that would enable and justify imperial conquest” (204). Makdisi relates this uninterest in the oppositions of Orientalism to antinomian tendencies which "stressed the continuity of European and Afro-Asiatic cultures" (204). This sits within a tradition of antinomian radicalism which has been illuminated in detail by the work of A. L. Morton, E. P. Thompson, David Worrall, John Mee, and Iain McCalman.

Others have argued that Blake's view of otherness was inevitably compromised. Tristanne Connolly reads Blake against Warren Hastings, former Governor-General of India, whose misconduct trial animated debates on the British Imperial project. Connolly argues that Blake's approach to Eastern alterity parallels Hastings' introduction to the East India Company's translation of Bhagvat-Geeta, as both "find[...] value in difference by making it the same," a universalist approach that was already overtaken by the new, more imperialistic,

5 A Literature Online search on the $1^{\text {st }}$ August 2014 shows 42 poetic texts, four drama, and 19 prose in English featuring any reference to 'Japan' in the period 1780-1837. 
utilitarian and profit oriented-i.e. modern-model of the Cornwallis era (153). This perspective on Blake as a complicit, out-of-date homogeniser concurs with Clark and Suzuki's argument that "prophecy against empire necessarily includes itself within a prophecy of empire" (2). Edward Larrissy, however, notes that Connolly's objections are "worth considering, though it might be asked whether or not Blake deliberately gives a Judeo-Christian vesture to his religious thought because of his insistence on the particularity of vision, which comprises the particular position of the visionary" ("Orient” 294).

Examining Japan's reception both of Blake's own strangeness, and the perspectives on otherness within his work itself, may help soften potential oppositions between visionary exceptionalism and inevitable complicity.

G. E. Bentley observed in 1990 that "there have been more publications about Blake in Japanese than in any other non-English language-perhaps more than in all other non-English languages combined" ("Empire" 16). What is notable about this reception "is the absence of certain preoccupations and dichotomies that structure and restrict the early-twentieth-century reception in Blake's own culture: madness-sanity, poetry-philosophy, accessibility-obscurity, orthodoxyheresy" (Clark and Suzuki 9).

Japan first encountered Blake and his poetry as text alone in the late Meiji period (1868-1912), beginning in 1893 with Bankoku Jimmei Jisho (A Dictionary of Famous Names), by novelist Yamada Bimyō. A few poems were translated during this period by leading literary figures, and Greek-born Irishman Lafcadio Hearn (also known as Koizumi Yakumo, of whom more below) lectured on Blake at Tokyo Imperial University, calling him 'The First Mystic' (Clark and Suzuki 10). However it wasn't until the Taishō period (1912-1926) that image reproduction technologies and Japanese avant-garde enthusiasm for Western art made the 
"Major Efflorescence" of Blake reception possible (Clark and Suzuki 7). By the second decade of the twentieth century Blake was known equally as a visual artist, and from this point on, his Japanese reception was characterised, unlike much Western criticism, by "no sense of inherent contradiction between thought and artwork" (Clark and Suzuki 11). Elinor Schaffer writes that "the delay in [Blake's] recognition at home [cannot] fully prepare one for the astonishingly fresh and focused impact on early-twentieth-century Japan” (301). Central to construction of this Japanese Blake was the humanist avant-garde journal Shirakaba (White Birch) journal, founded in 1910 by a small group of aristocratic literati. At the core of this group's enthusiasm for Blake were philosopher Yanagi Muneyoshi (18891961), also known as Yanagi Sōetsu, and his close friend, the British potter Bernard Leach (1887-1979).

Bernard Leach grew up in England with the romantic whimsy of Whistler's Orient: "From him," he wrote, "I must have caught some dream of Japan" (East and West 32). ${ }^{6}$ Yet his move to Japan to learn pottery, and instruct fellow Shirakaba group members in etching came after reading the prose of Lafcadio Hearn (de Waal 356). Hearn was an enigmatic figure who, like Leach, was credited by East and West alike with unique insight into Japan, despite his lack of Japanese language and engagement with a limited spectrum of society. His association of Japan with feminine sensibility has been variously celebrated or denigrated depending on how readers felt about Japan (Rie Askew, 53-60). Edmund de Waal notes how Hearn was "used as a marker for the rare Occidental who can 'understand' Japan-an inner, spiritualized, authentic Japan that is not accessible through empirical knowledge....That Leach's Japan, like Hearn's, should be so attractive in Japan itself is of great significance” (356). Why was "Leach's constant imaging of 'Orientals' as childlike, or mystical, or more attuned to the spiritual... mystically alive" so attractive to Yanagi and other members of Shirakaba? (de Waal 360-361). Leach lived with Yanagi for a month in China and 
a year in Japan and the two corresponded frequently. "We were drawn to each other silently and irresistibly," wrote Yanagi of Leach, bonding over "spiritual appetites," a romanticised image of Japan, and mingei or folk art (qtd. in de Waal 355). "Yanagi lit my lamp," Leach wrote (Introduction 89). Blake, whom Leach describes in Shirakaba as "unquestioningly... [his] best teacher" and "the greatest of all Englishmen," focused this nexus of concerns ("Notes" 462, 469). Leach introduced Yanagi and Shirakaba to Blake, and designed a cover for the journal's fourth volume based on Blake's 'The Tyger' (see figures 1 and 2).

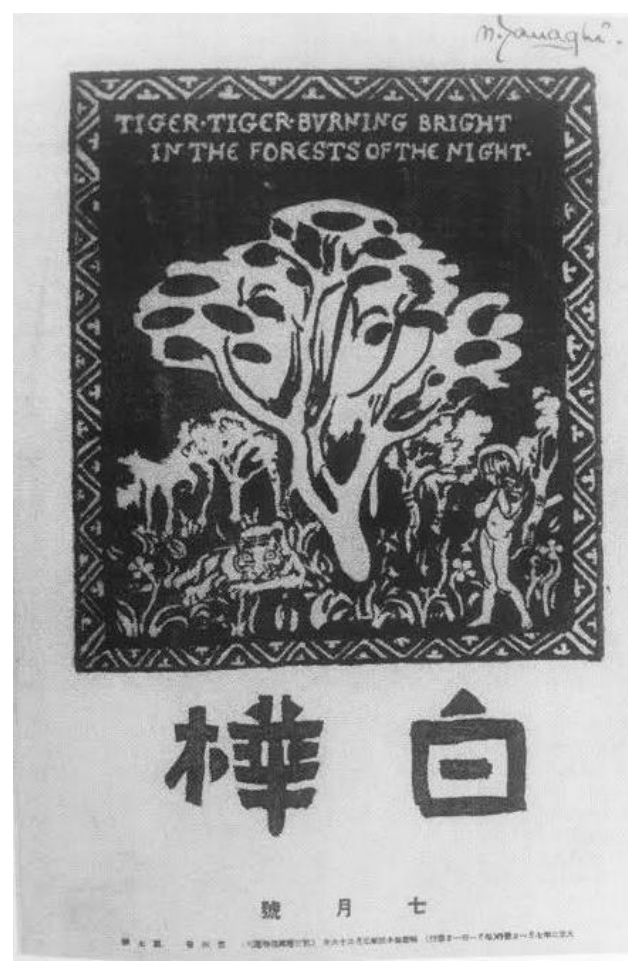

Figure 1. Bernard Leach, cover design for Shirakaba Vol. 4, Jan. 1913. The Japan Folk Crafts Museum, Tokyo; rpt in Clark and Suzuki 219.

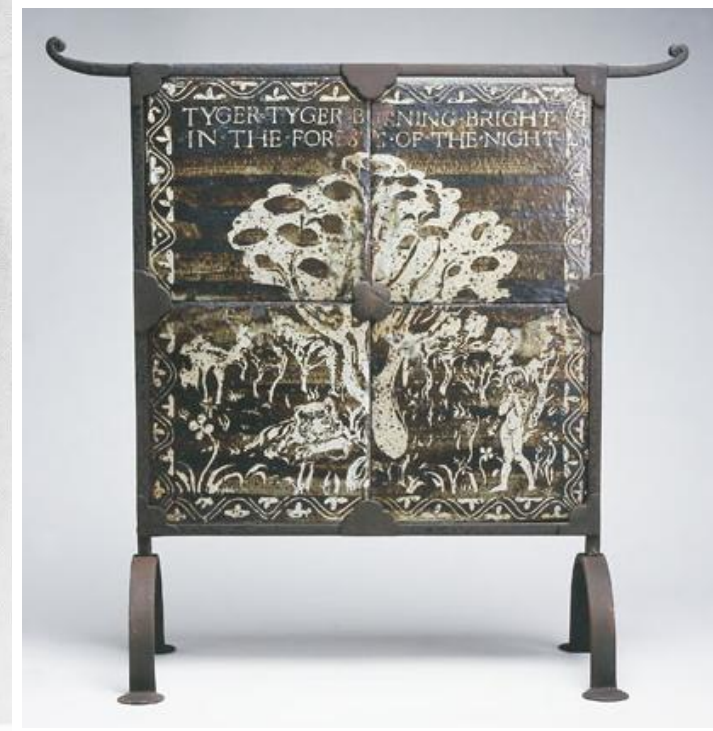

Figure 2. Bernard Leach, screen inspired by "The Tyger.” 1911. Stoneware tiles. Japan Folk Crafts Museum, Tokyo.

Yanagi describes this introduction in a letter to Leach in 1915:

I have lingered so long in the dual phenomenon of this world, and struggled against this tremendous Divorce-the duality of mind \& body, heaven \& hell, \& God \& man etc. etc. How to escape, or better to say 
emancipate, or how to unite, or organise these dualisms have been my constant endeavour for my intellectual as well as emotional demands. In those days I met Blake. (93)

Yanagi was instantly possessed, publishing a 137 page illustrated article on Blake in Shirakaba in 1914, followed by a 750 page biography later that year, that celebrated Blake's life and work together as a spiritual history. This acceptance is remarkable in a global context of reception, but may also give us pause. The Marriage was taken at the time in Britain, Ayako Wada notes, as "indubitable evidence of insanity," yet was embraced by Yanagi as "the authoritative work which deserves the highest throne of the English literary history in light of its... depth of truth manifested" (qtd. in Wada 165). As Kazuyoshi Oishi argues, Yanagi's ease "poses a serious question to the prevailing view of Yanagi as a legitimate interpreter of William Blake” (181). Seven years after Yanagi's monograph, T. S. Eliot praised Blake's poetry, but regretted that it "sadly lacked... a framework of accepted and traditional ideas which would have prevented him from indulging in a philosophy of his own" (156). Yanagi's enthusiasm suggests that he brought his own "framework of accepted... ideas" to Blake's works. Wada suggests that Yanagi found Blake "if not a simple figure, at least a reasonably accessible one," as a result of his study of Zen Buddhism with religious scholar Suzuki Daisetz (1870-1966, known in the West as D. T. Suzuki) (162). Leach commented that Yanagi "loved the East in the West" (qtd. in Wada 162), and Oishi argues that Yanagi used Blake to affirm his own ideas and identity, ignoring "the ideological ambiguity latent in [his] Blake-Buddhism equation” (183).

Oishi notes how rapid modernisation, civil unrest, and state repression in the late Meiji and early Taishō periods paralleled the Romantic period in Britain, arguing that Yanagi "depoliticized [Blake's] dangerously radical implications... containing the volatile, insurrectionary enthusiasm inherent in his religio-political message" into "a rather apolitical Buddhist philosophy" (192). "Cultivating our individuality," Yanagi wrote in Shirakaba in 1912, is "our one and only duty" (qtd. in Lucken par. 8). Certainly, Yanagi and Shirakaba were grounded in a culture of 
humanist individualism which emphasised unique genius, lifting Blake from his context and placing him alongside artists from Michaelangelo to the Impressionists, and frequently pairing him with Whitman due to their "profound harmony" (Leach 467). However this removal could give us "highly traditional readings of Blake as an oppositional and utopian figure," and may feed "the still powerful orthodoxy of a retreat from radical engagement into visionary otherworldliness" (Clark and Suzuki 1).

Oishi notes that Yanagi's reading of Blake emphasises the dissolution of mind-body dualisms (186), which could be one reason why subsequent Blake scholarship in Japan, aided by new technologies of image production, did not divide word from image in the way many Western accounts did (11). However this aspect of Japan's Blake may also be due to existing traditions that combined text and image. Donald Richie speculated that Japanese artists and academics found Blake's word-image combinations "strangely familiar," intelligible in a culture where poets such as Bashō drew and painted their poems (par. 3). Whether based on philosophy or material practices, the implication is that an act of recognition occurred, whereby the poetry and art of Blake at least partially resonated with and affirmed pre-existing beliefs. However an image of Japan was being coconstructed with a Japanese Blake. Both Leach and Hearn sought escape from what Hearn called "the monstrous machine-world of Western life" (qtd. in Askew 50) and Leach labelled "the rottenness of our Western life... our materialism" (463). Their images of Blake and Japan came from this escapist search, and influenced the constructions of Yanagi and others seeking a Japanese identity outside of modernism. Leach's complaint in Shirakaba that "even in England Blake has except by a very few penetrating minds, been regarded for 100 years as a madman" claims privileged identity and invites readers to join him in rejection of Western inadequacies (467). The legacy from Shirakaba and Yanagi is a Blake which elides many of the dualistic pitfalls mentioned earlier, yet is indebted to the Orientalism of Leach and Hearn, and the romantic imaging of Japan by Yanagi and Shirakaba. Makdisi argues that Blake's refusal of the "distinction between East and West-and hence self and other, material and immaterial," meant he was 
unable to be read through oppositional logics of the Enlightenment as "Western." If not Western, then his work "must, by th[is] logic...be Eastern instead, there being no room for other alternatives in such a highly dualistic worldview. This Blake, then is all the more a freak: a crazy 'distempered' Oriental” (244). Perhaps it is no wonder Blake found a fruitful reception in Japan when he was already 'non-western' according to the Orientalist categories shared by those who spread his work.

These beginnings shaped the continued reception of Blake's work, with Shirakaba exhibitions in 1915 and 1919, increasing discussion in a range of literary magazines, and a large exhibition in Kyoto in 1927 celebrating Blake's centenary (Clark and Suzuki 6). The latter gave rise to sustained scholarly interest from Doi Kochi, a wide-ranging humanities scholar often compared to Northrop Frye, and Jugaku Bunsho, a bibliographer and paper expert who with Yanagi published the journal Blake and Whitman, hand producing it with his wife at their own Kelmscott-like press. Blake’s was embraced across disciplines, by philosophers like Yanagi, Taishō period painters, and poets and novelists, notably Kenzaburo Ōe (Clark and Suzuki 6).7

\section{III}

In order to focus some of the questions that arise considering this Japanese Blake, the remainder of this chapter will examine Blake's works alongside those of twentieth-century Japanese manga artist Tezuka Osamu (19281989).

Tezuka is widely known as the 'God of Manga,' and like Blake, he adapted vocabularies from a wide variety of verbal and visual forms, creating a new medium in the process. As a result he has often been characterised as an isolated

7 For a full timeline of this further reception, see Clark and Suzuki's introduction to The Reception of Blake in the Orient. 
and visionary point of origin for the genre. But as with Blake, the insularity of this model, challenged by Itō Gō in Tezuka is Dead (2005), effaces his broader context. G. Clinton Godart traces Tezuka's acknowledged influences: his medical training, experiences during WWII, and encounter with Walt Disney (35-36). Without denying these influences, Godart relates Tezuka's ideas to Meiji era combinations of European Romanticism and Buddhist theory, noting the "striking" similarity between Tezuka's ideas and those of Lafcadio Hearn (42-43). This places Tezuka within the same intellectual currents as those within which a Japanese Blake took shape. Natsu Onoda Power traces how "images of the Orientalised Middle East, auto-orientalised Japan, as well as romanticised West [were] translated into Tezuka's comics" (iii). Blake had proven a useful ally in the construction of an image of Japan: Tezuka and Blake are connected by the use of European Romanticism and Buddhist philosophy to contest aspects of modernity in Japan. Yanagi later focused his opposition in the figure of the craftsman, founding the mingei (folk craft) movement.

IV

Susan Sontag claimed, "art is not only about something, it is something" (21). More than receptacles of related ideas, Blake and Tezuka's works are material practices: they demonstrate Blake's assertion that "my business is to Create" (E153). Blake's works are filled with images of physical, often noisy, creation. Prolific craftsmen, visionary writers, technical innovators outside the high art world, inspired workaholics: the creative similarities between Blake and Tezuka are striking.

As visual craftsmen, both artists craft narratives in shape, line and bodies. Such narratives evoke reactions that exceed our response to text or image alonethey are, in Blake's words, "addressed to...Spiritual Sensation \& but mediately to the Understanding" (E702). Just as "Man has no Body distinct from his Soul," the interdisciplinary materiality of Blake's illuminated books combines the abstract 
(words) with the sensory (images) (Marriage plate 4, E34). The printmaking process allows a seamless combination of the two, erasing any distinction between creation and execution. The results are an embodied experience, not just the report of one.

Blake and his wife Catherine together produced a huge volume of workprofessional engraving commissions, experimental prints, numerous handcoloured copies of illuminated books. Milton and Jerusalem alone involved 150 etched copper plates. Frederick Tatham claimed that on his deathbed Blake worked on a coloured print, exclaimed "it is the best I have ever finished," and then drew a portrait of Catherine, "sang loudly \& with true extatic energy" and died (qtd. in Bentley 682). Two hundred years later, Onoda Power writes: “'[p]rolific' does not even start to describe the sheer volume or breadth of Tezuka's work. During his lifetime, Tezuka published approximately 150,000 pages of manga in virtually every genre imaginable” (4). Head of Tezuka Productions Matsutani Takayuki reports Tezuka's deathbed words were "I'm begging you, let me work!” (289). Bentley inscribed Blake as an outsider, “a Stranger from Paradise in an alien world" (438), while Matsutani "truly came to believe 'Tezuka was a space alien'-it was the only way of explaining his extraordinary artistry" (288). The immense creative energy of both artists is undeniable, feeding myths of isolated genius.

Both Blake and Tezuka created works with great visual immediacy. Joseph Viscomi has shown that against the late-eighteenth-century fashion for drawings and sketches that appeared spontaneous, Blake's invention of relief etching eschewed the reproductive process of 'mixed method' engraving and instead captured the "autographic" artistic gesture first hand $(3-14,57)$. Blake's process enabled actual spontaneity of expression, as words and images could be drawn directly onto the plate (Viscomi 32-36). Tezuka's works are similarly innovative through his appropriation of cinematic techniques to express movement (Onoda Power 38). 
However both Blake and Tezuka combine this sense of rapidity with painstaking perfectionism. Blake's plates, margins and pages of his illuminated books were only roughly equal in size, meaning plates were probably registered by eye rather than exact registration marks (Viscomi 105). Irregularities were part of this process. Yet we also see instances of meticulous attention, such as the double etch and stop-out indicated by the flat areas around the text on the America fragment (figure 3). Furthermore, pithy aphorisms and generic swerves mask Frye's observation that "proportionately, Blake may be said to have blotted more lines than any other important poet of English literature” (6). Tezuka's works express a similar tension: the rapidity of an author who was producing an average of ten pages a day throughout his entire life (Matsutani 288), in a largely disposable medium, contrasts with the painstaking linework of many of his images-such as figure 4, below, showing "blotted out" twink lines around the form of the phoenix.

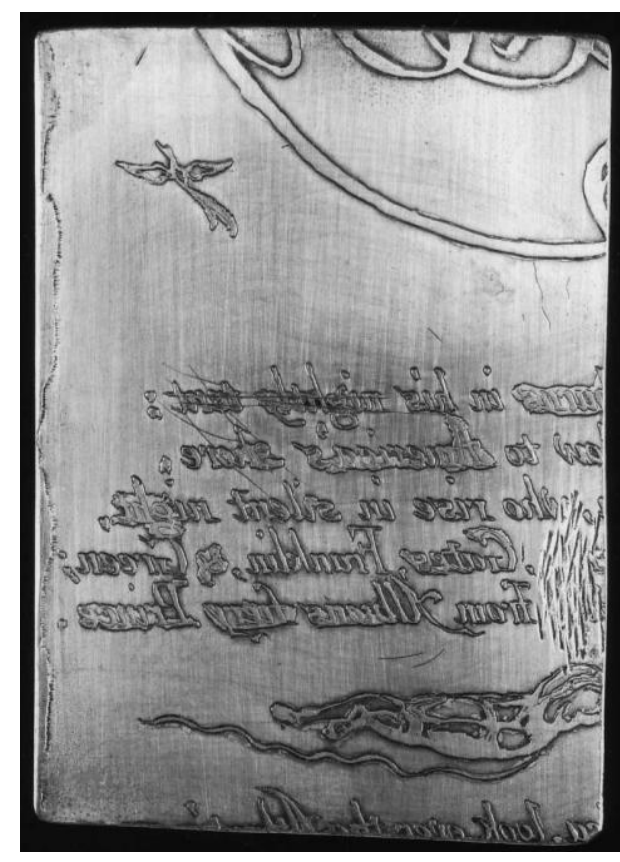

Figure 3. Blake, fragment of America a Prophecy cancelled plate a. Relief etched copper, $1793.82 \times 58 \mathrm{~mm}$. Lessing J. Rosewald Collection, Library of Congress; rpt. in Viscomi Q6

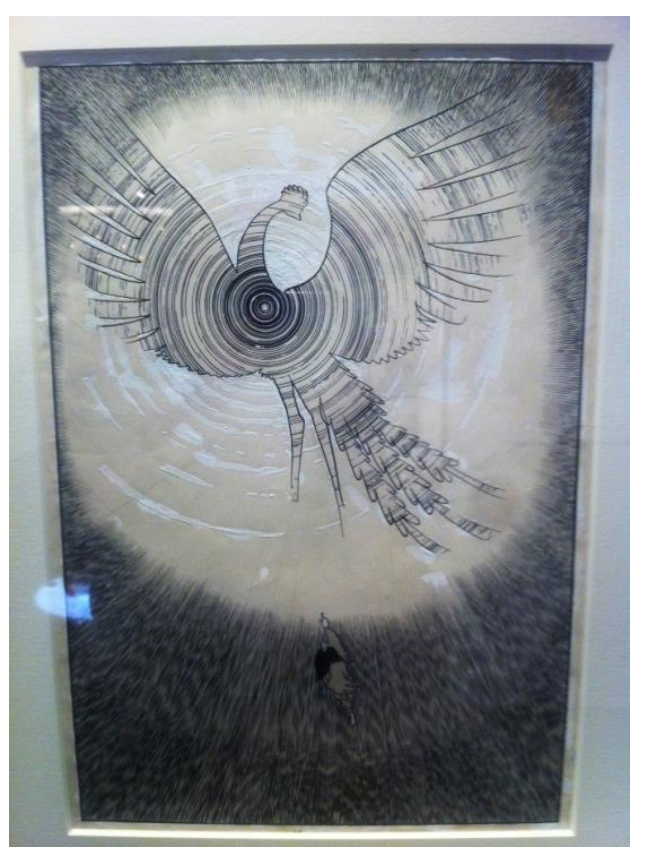

Figure 4. Tezuka, drawing for Phoenix. Photograph from Tezuka Osamu Museum, Takarazuka. 
Both artists refer to the physicality of their creative process, such as Blake's reference to "a Printing house in Hell" in the Marriage (plates 14-15), or Tezuka's references to himself as a manga artist within his own work (Future 231). Rachael Hutchinson suggests that Tezuka's "self-reflexive method" shows the reader that "his epic manga is only another story, created by a particular person, and that we should question his motives as well" (35). This recalls Blake's strategies to thwart the 'moral law' of second-hand assertions, including his own.

One such strategy was Blake's host of Biblical-sounding invented figures, as he believed that "what is not too explicit...rouzes the faculties to act" in the reader (E702, see Mee 27). Tezuka's extensive mythologies and their unexplained reincarnations of characters have a similarly disorienting effect. Tezuka kept a 'Star System' of his various 'actors' detailing not only their different roles and karmic rise and fall across otherwise unrelated works, but also their hourly rates and 'offstage' personalities (Onoda Power 66-88). As with Blake, the reader gets the sense "that all Tezuka's works, regardless of genre, topic, or style, are somehow connected" (Onoda Power 66).

I now turn to the "minute particulars" of several moments in the sciencefictional second volume, A Tale of the Future, of Tezuka's series Phoenix (first serialised as Hi no tori in 1967-68). Tezuka called this series his "life work" (288), and it has been praised as the "greatest masterpiece," "most intellectually challenging experiment" and "archetypal manga of Japan” (qtd. in MacWilliams 179). Blakean in ambition, the series begins at the dawn of civilisation, while the second volume stretches from the distant future into infinity. Eleven subsequent volumes oscillate between past and future, converging towards the present, although Tezuka's death in 1989 left the series unfinished. Future can be read as a space-age apocalyptic love story, or a metaphysical dystopia, or perhaps as an evolutionary parable, and it resonates with aspects of Blake's The Marriage of 
Heaven and Hell and Visions of the Daughters of Albion. The eponymous Phoenix, inspired by Stravinsky's Firebird (Tezuka 290), reappears throughout the series as the embodiment of what Tezuka called "life (seimei) itself... something cosmical" (qtd. in Godart 34).

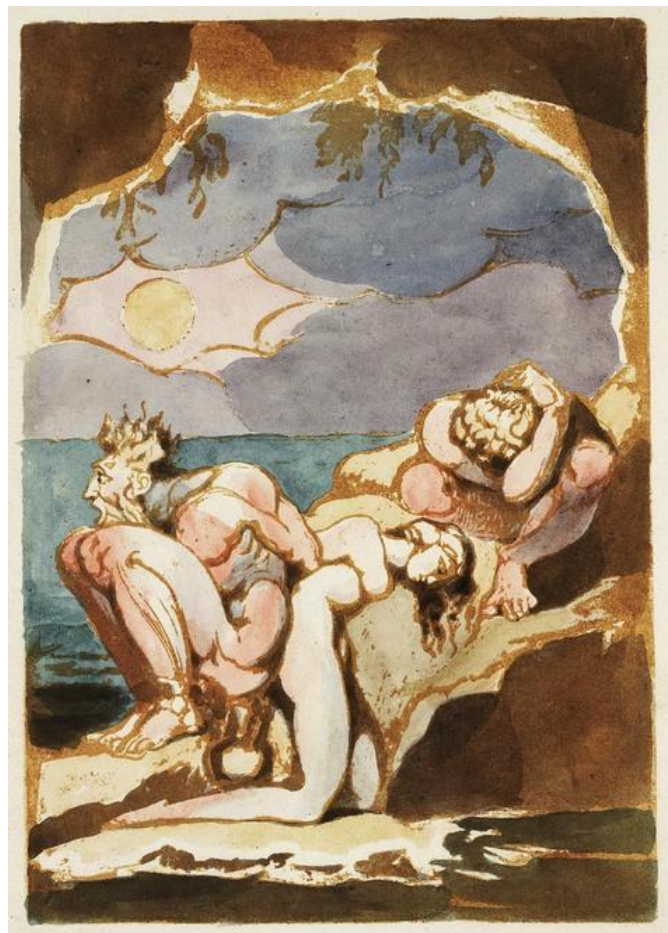

Figure 5. William Blake, frontispiece to Visions, copy E. 1793. Henry E.

Huntington Library and Art Gallery, San Marino; rpt. Blake Archive.

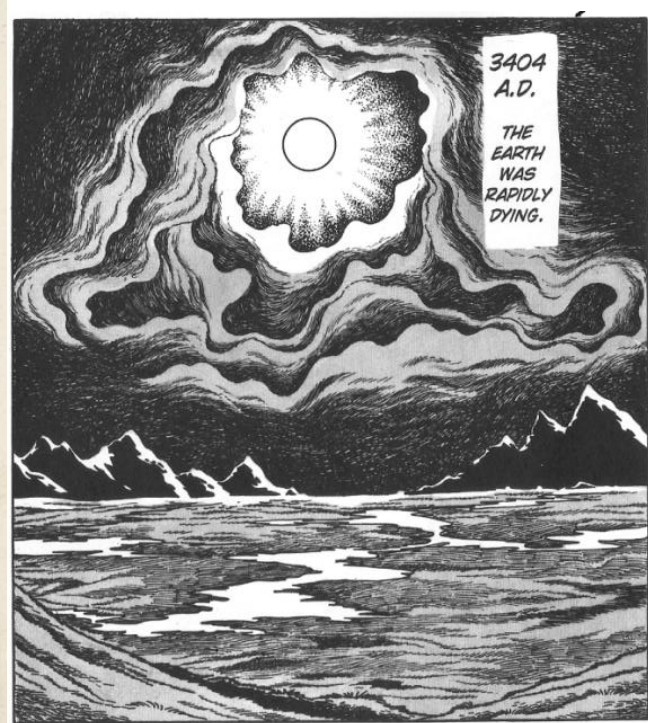

Figure 6. Tezuka Osamu, opening frame, Future 6.

Like Blake's Visions, Tezuka's Future opens with a grim landscape where Edvard Munch-like clouds surround the sun- "a bright shadow. Like an eye | In the eastern cloud" (Visions 2.35-36) (see figures 5 and 6). 
As the narrative advances, we meet lone scientist Dr Saruta, who is trying to populate the barren earth with animals grown in test tubes within his glass dome home (see figure 7).

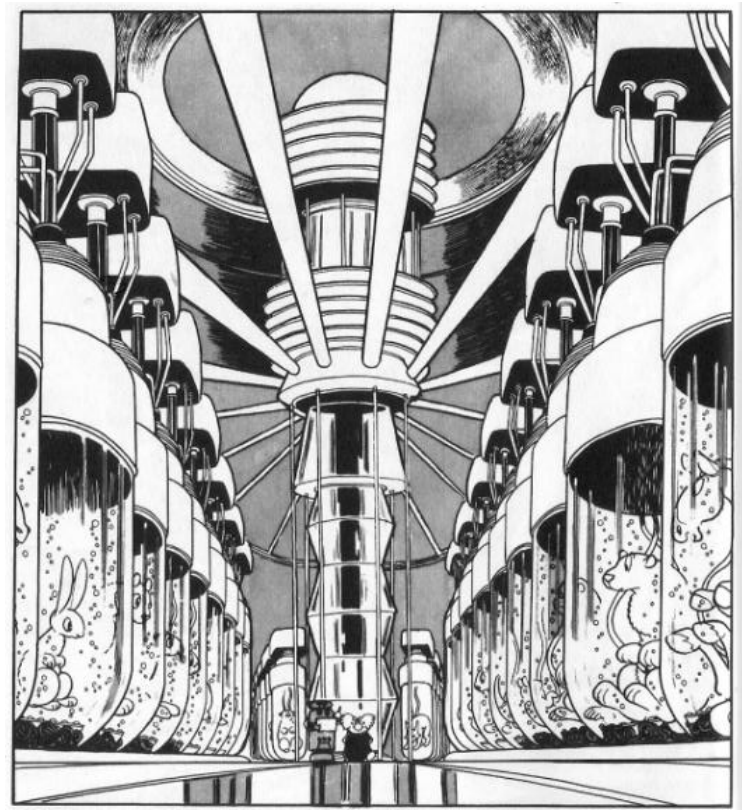

Figure 7. Tezuka Osamu, Doctor Saruta inspects his creations, Future 38.

Saruta walks amongst his "beautiful children" (39), greeting them by name in allusions to other science-fiction authors: "Oliver" is Symmes Chadwick Oliver (1928-1993), a U.S. anthropologist and writer whose SF texts "eulogise the earth" and express "a deeply felt longing for a non-urban life closely involved with nature" (Clute par. 1). "Lem” alludes to Polish author Stanisław Lem (1921-2006), who questioned human limitations and "the interweavings between biological and technological evolution" (Suvin and Clute par. 2); Wyndham to post-WWII UK writer John Wyndham Parkes Lucas Beynon Harris (1903-1969), author of The Day of the Triffids, The Chrysalids, and other dystopian fantasies (Clute par. 4); and Bradbury to Ray Bradbury (1920-2012), U.S. author of Fahrenheit 451. Tezuka references a global family of (at the time) contemporary science fiction writers who shared aspects of his critique of scientific progress. 
Saruta's desire to synthesise life explicitly references Mary Shelley's famous critique of scientific hubris, Frankenstein; Or, a Modern Prometheus (1818), when Saruta's most humanoid creation Bradbury, reads Goethe's The Sorrows of Young Werther (1774), the text from which Frankenstein's creature learns how to be human. Bradbury begs to be released from his test tube but when Saruta relents, his "son” melts in agony (42-43, figure 8).
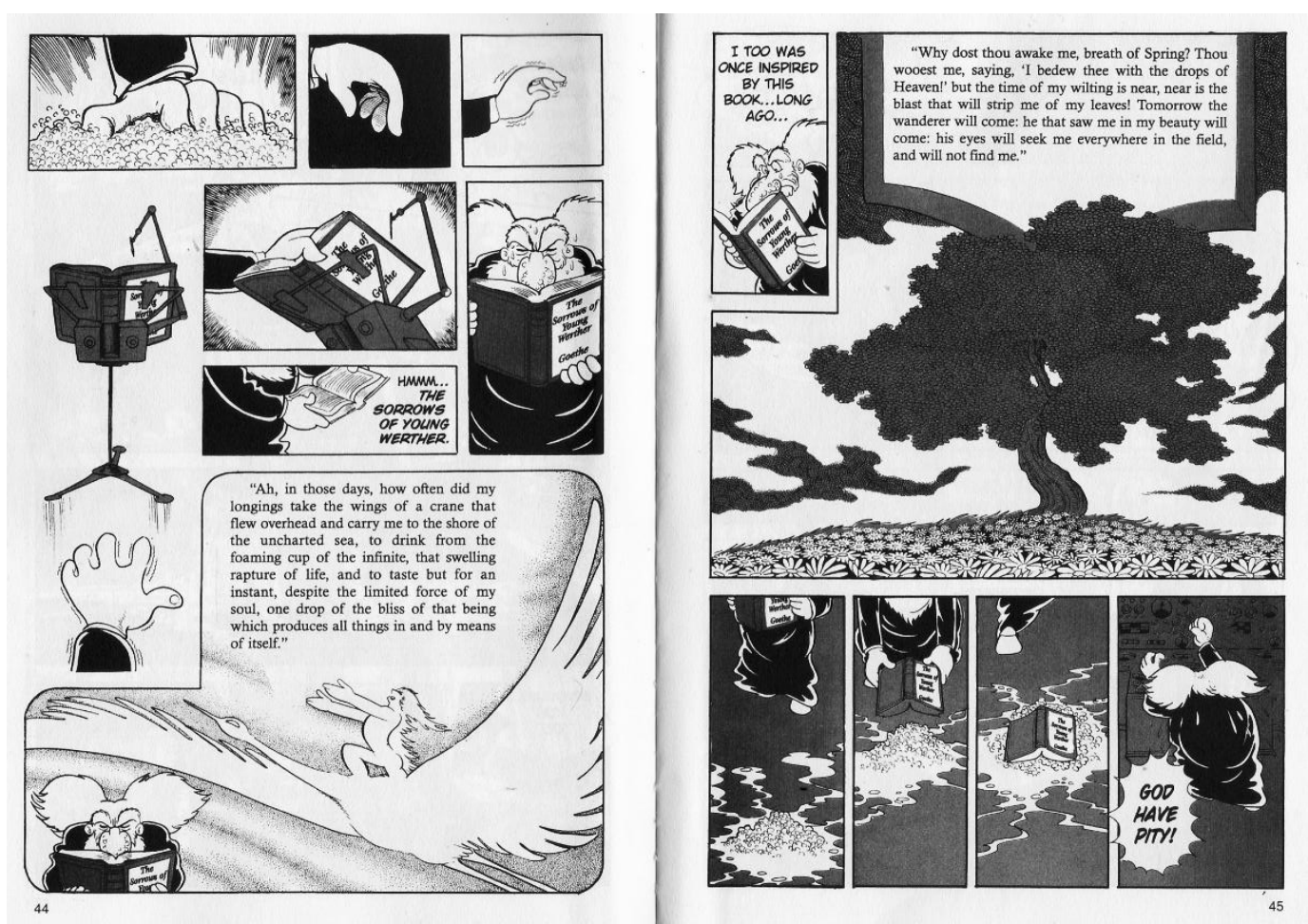

Figure 8. Tezuka Osamu, Bradbury melts in agony, Future 42-43. 

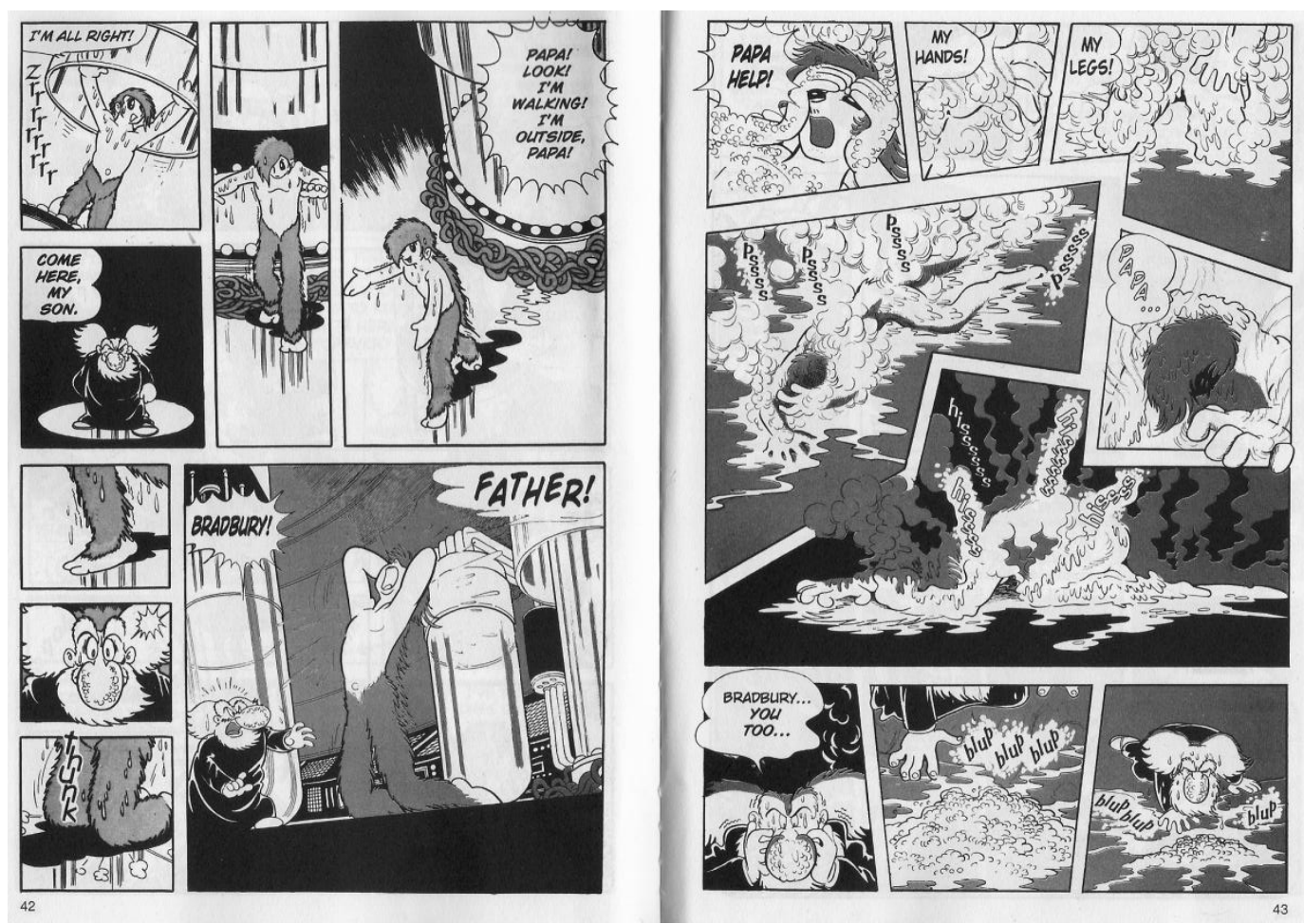

Figure 9. Tezuka Osamu, Saruta reads The Sorrows of Young Werther, Future 44-45.

An anguished Saruta turns to Bradbury's copy of Werther, which Tezuka quotes at some length (figure 9). The first passage derives from Goethe's text when Werther reflects upon his previous longings for sublimity amidst the beauty of his valley and its "ten thousand living creatures," a remembered state which he contrasts with his current awareness that "Nature, which has brought forth nothing that does not destroy both its neighbour and itself" (66). Tezuka then quotes a passage from the final section of Werther, where Werther reads to Lotte from his translation of Ossian, prefiguring "the time of [his] wilting” (Future 45). Ossian, the mythical Scottish bard whom mid-eighteenth-century poet James Macpherson claimed to have translated, was a key sources for Blake's Visions (Essick 36). In citing Goethe, Tezuka heightens Saruta's grief-as opposed to Victor Frankenstein's hatred and fear of his creation- and connects his selfdescribed "drama on the theme of life and death" with a global literary tradition, reinforcing the affinity between him and European Romanticism (qtd. in MacWilliams 179). Tezuka's non-parodic insertions of Werther may seem to share 
a feeling of generic incongruity with Goethe's own Ossianic digression at a climactic moment. We need to remember Tezuka's own ambitions-he had earlier adapted Faust and Crime and Punishment into manga, for example-and avoid generic assumptions as readers rising from how "in America [and other Western countries] comics [have been] stigmatized as a shallow entertainment for children" (Schodt, 52).

Saruta's venture places Future within the tradition of explorations of human creative powers and limits, from Prometheus to Frankenstein. But unlike Shelley, who condemned scientific overreaching by dramatising its results, Tezuka portrays the enterprise to create life as traumatic, but impossible. Dr Saruta's attempts to create life paradoxically cause only death. Despairing, Saruta pleads to learn "the secret of life... the key to the puzzle!" (47). Later, the character Masato also attempts to create life, making a series of robots and synthetic creatures before learning that he needs to leave biology to regenerate the planet by itself, even though this will take billions of years (232-237).

The appearance of the Phoenix in response to Saruta's plea further demonstrates the differences between Saruta and Victor Frankenstein. The following frames develop Saruta's character, and explore oppositions between nature and science, transcendence and materiality. 


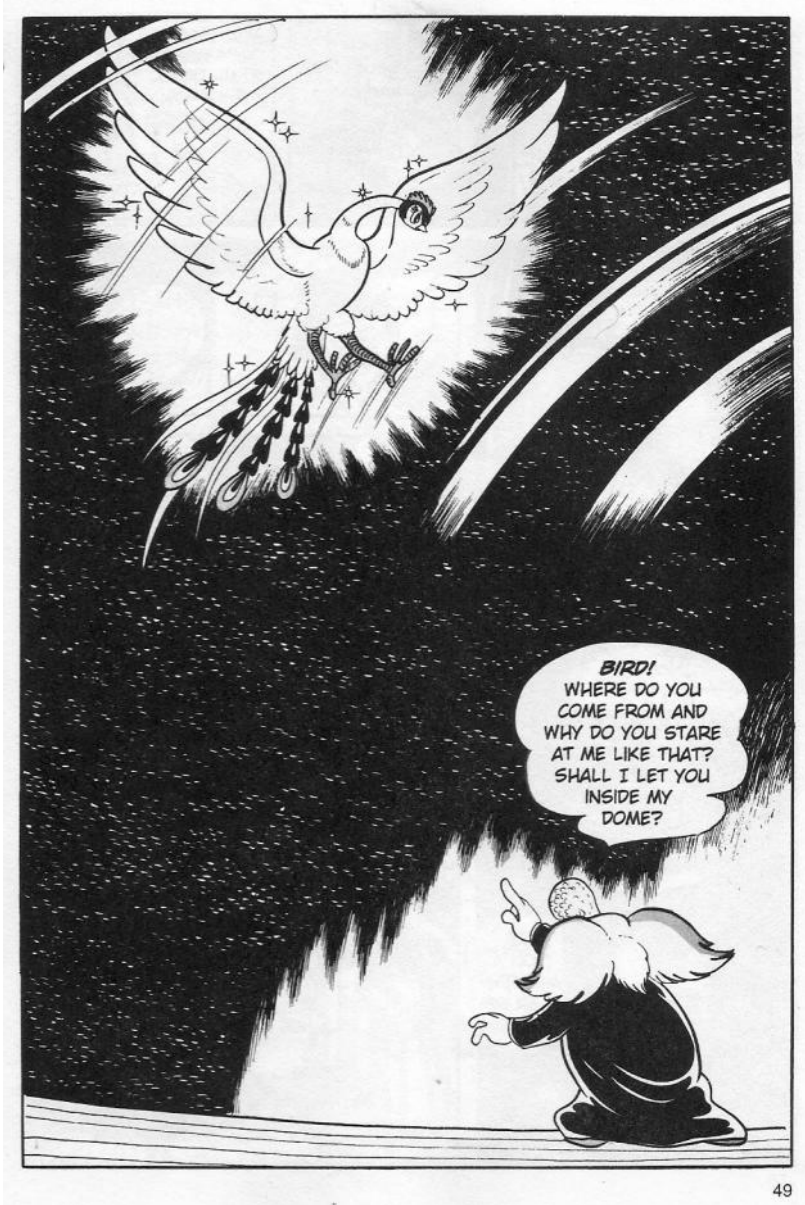

Figure 10. Tezuka Osamu, the Phoenix appears, Future 49.

The Phoenix appears before the distressed Doctor with the impact of a full page spread, each figure in a reciprocal blaze of light against the cosmic darkness outside. The scarcely visible glass dome divides them. The mirroring between Saruta's hair and the bird's wings, the comparable scale of the figures, the gestures towards one another, and Saruta's welcoming question- "shall I let you inside"establish a relationship of mutual interest (49, see figure 10). The doctor's methods to create life may be misguided, but as he later explains, his impulse is prompted by grief at the emptiness of the barren landscape, and desire to see it filled with living creatures again. This seems to differ from the archetypal figure of the hubristic scientist from Frankenstein to Doctors Faustus, Moreau, and Strangelove, for example, as Saruta appears as an eccentric yet sympathetic 
character, as seen in his protection of the main characters Masato and Tamami. However his later attempt to sacrifice Tamami to gain the secret of her alien cell structure reveals his obsessive nature and fundamental observance of the 'mad scientist' archetype. Despite this, Saruta is presented as deluded rather than malicious. The appearance of the phoenix faces a figure of science against a mystical figure of nature, but the encounter is not altogether hopeless.

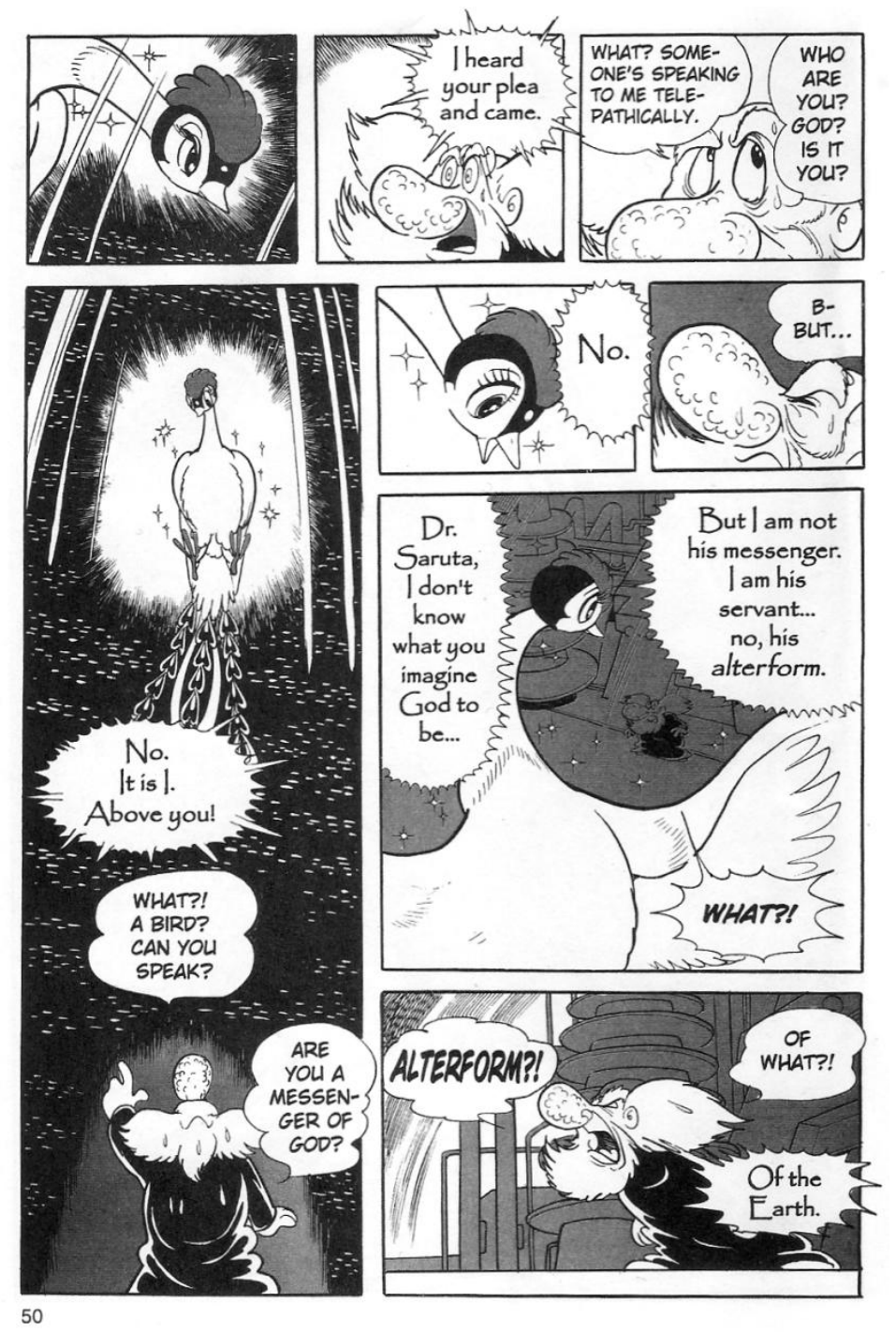

Figure 11. Tezuka Osamu, the Phoenix introduces herself, Future 50. 

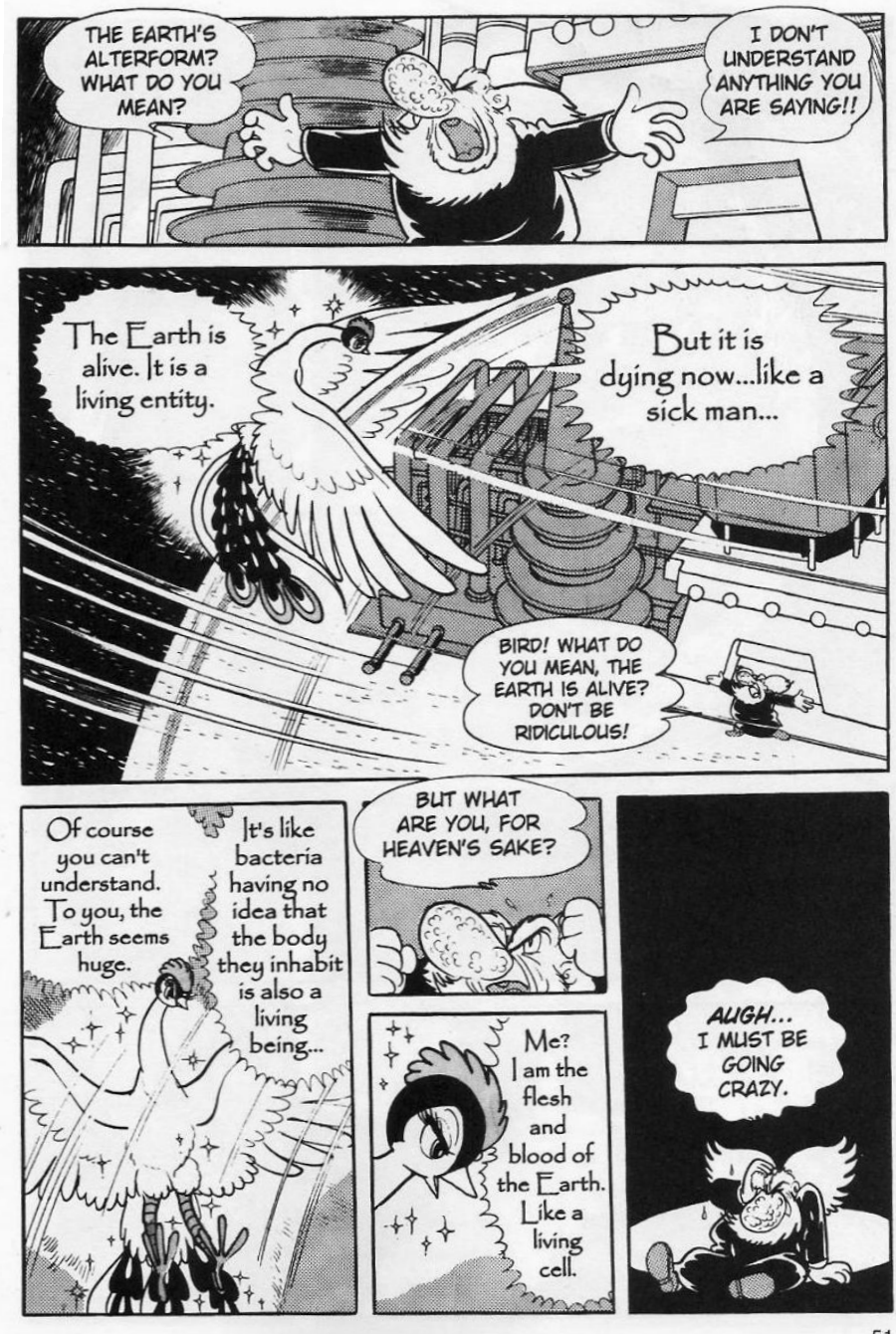

Figure 12. Tezuka Osamu, conversation with Phoenix, Future 51.

The following frames build upon the relationship between Saruta and the bird (see figures 11 and 12). Alternating angles and facial close-ups place Saruta and the phoenix in intimate conversation, telepathic speech bubbles overlapping the boundaries of their own frames into the physical and mental space of the other. The scientist questions the bird in an attempt to understand, but his confusion is expressed as frustrated curiosity, rather than violence or fear towards the unknown. His enquiries of an incomprehensible figure resonate with Blake's biblically patterned questions in Visions, and Saruta's outstretched arms on page 
51 , mirroring the phoenix's open wings, further reinforce this motif of supplication.

This gesture of openness is also evident in Blake's work as a sign of emancipation, such as the open-armed figure of “Albion Rose” or Oothoon's airborne gesture on the concluding plate of Visions. When Saruta collapses at the foot of the page, it is not the phoenix he mistrusts, but his own perceptions-"I must be going crazy," he says (151). Yet his dark night is spotlit, and on the following page this circular form expands into an eyeball-like vision of the earth as a living thing (figure 13). Tezuka implies that this vision is only available to Saruta once he questions his existing ideas. His open-armed science shares both a posture and a willingness to keep questioning with Visions' heroine, Oothoon.
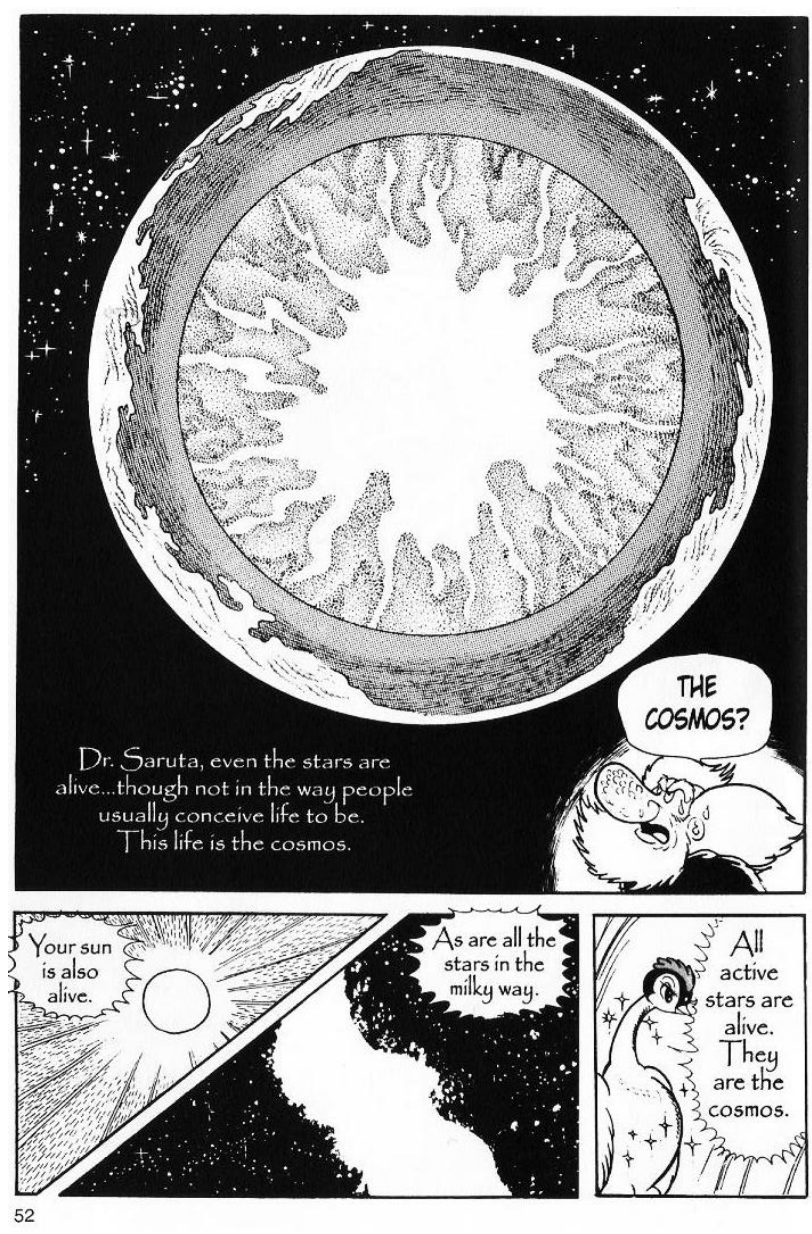

Figure 13. Tezuka Osamu, Saruta's vision of the cosmos, Future 52 
In the central image of page 51, we see the phoenix pressed against the glass of the dome, her form in contrast with the technology surrounding Saruta (see figure 12). She explains, "The Earth is alive. It is a living entity," to which Saruta responds “Don't be ridiculous” (51). The glass dome separates the phoenix and Saruta, implying a gendered division between nature and reason, life and science. I am reminded of Yevgeny Zamyatin's We (1921), the poetic dystopia upon which Orwell based 1984. In Zamyatin's authoritarian nightmare, life has been rationalised into perfect sterility: all of nature, the irrational and the wild are excluded behind a great glass wall, literalising the modernist project to overcome 'nature'. Tezuka's glass dome performs a similar role of separating the rational human enterprise from an alienated 'nature'. Tezuka frames the encounter as a traditionally gendered instance of animism versus mechanised reason, but his opposition does not fit traditional western dualisms.

In “The Cage of Nature: Modernity's History in Japan,” Julia Adeney Thomas compares Japanese political philosopher Maruyama Masao (1914-1996) with his contemporaries Max Horkheimer (1895-1973) and Theodor Adorno (1903-1969). She finds that "both sets of authors define modernity as the moment when humanity overcomes nature," but adds that they respectively celebrated and deplored this (16). Thomas argues that Japan was trapped by the discursive practice that "simultaneously traces the trajectory of modernity from servile Nature to freedom of Spirit and at the same time bases the identity of the nonwestern world on its closeness to nature" (16). In Future, however, instead of a feminised nature divided from and conquered by a transcendent, masculinised reason, the phoenix appears as both transcendent spirit and material "flesh and blood of the Earth" (51). Saruta asks "Are you a messenger of God?” revealing how he would be able to understand the phoenix more easily if she aligned with a transcendent "freedom of Spirit" rather than undermining the division (50). This aspect of Tezuka's vision parallels Blake's insistence in the Marriage that "the notion that man has a body distinct from his soul, is to be expunged" (plate 14). Blake's erasure of the body-soul dualism is equally an insistence on the 
inseparability of the material and the divine, but unlike Blake's critics, who saw his representation of divinity in "the fullness and rotundity of mortal flesh" as a sign of madness, Saruta's encounter with such an erasure causes him rather to question himself (qtd. in Bentley 270).

Although Tezuka's dome (and Zamyatin's wall) appear within narratives that challenge the validity of such dualisms, I wonder whether the depiction of the (feminised) phoenix as a figure of life opposite and separate to Saruta as a (masculinised) figure of science is a useful one. Perhaps the attempt to identify the problem perpetuates the sense of division, as with C.P. Snow's 1959 Rede Lecture lamenting the split between the 'two cultures' of science and literature, and the subsequent use of his phrase as a byline to reinforce belief in the incommensurability of science and the arts (3). Saruta's encounter with the phoenix dissolves some boundaries, but solidifies others.

In Visions, Bromion represents reductionist science and emerging capitalist doctrines when he anticipates "trees beasts and birds unknown: | Unknown, not unpercievd, spread in the infinite microscope" (4.15-16). His attitude towards knowledge is appropriative, as was his attitude towards Oothoon: his urge for new discoveries is driven by the rhetorical questions "are there other sorrows, beside the sorrows of poverty? | And are there other joys, beside the joys of riches and ease" (4.20-21). Bromion's instrumental view of the world places him as a follower of Blake's 'unholy trinity' of Newton, Bacon and Locke. Rather than suggesting a scientific method that involves responsive observation, his call for "one law for both the lion and the ox" implies the imposition of an abstract system from the outside, an authoritarian politics (4.22). Just as in the Marriage, the dualistic vision of the Angel is responsible for the vision of Hell (plate 20), so does Bromion's vision create "eternal fire, and eternal chains...| To bind the phantoms of existence"-everything divided from and conquered by his mechanical materialism (4.23-24). 
Considering Bromion and Saruta together suggests that Visions is not affirming transcendence at the expense of materiality, or mysticism at the expense of science: instead it can be read as a critique of such dualisms, and their expression in the specific forms of reductive empiricism, that seeks mastery over a conquered 'nature'.

Tezuka's union of the material and immaterial continues, as the phoenix tells Saruta that the Earth "is dying now... like a sick man" (51). This parallels Blake's recurring vision of characters as both country and body. Albion is what Blake calls in the Laocoön "The Eternal Body of Man...that is God himself...we are his members" (E273), and in the Marriage we hear that "Albions coast is sick silent” (plate 25). Similarly, Oothoon in Visions of the Daughters of Albion is both continent and body. Both Blake and Tezuka align the world with the body to highlight how both are abused by human practices that divide and conquer the material. The Phoenix's description of the world as a maligned body undermines the body-soul dualism that Blake's Marriage similarly contests when "The Voice of the Devil" asserts that "Energy is the only life and is from the Body" (plate 4). Onoda Power cites Lu Xun's definition of manga in 1918: "Manga is that which pierces through the societal disease" (20). Tezuka's description of the world as a sick body, and concluding hope that "this time man will realise his mistakes," casts the text as a medicine to the diseased body of society (285). Blake's 'Memorable Fancy' of the printing house in Hell and description of the diabolic Bible "which the world shall have if they behave well" evokes a similar role for the text as medicine for societal disease (Marriage plate 24). 

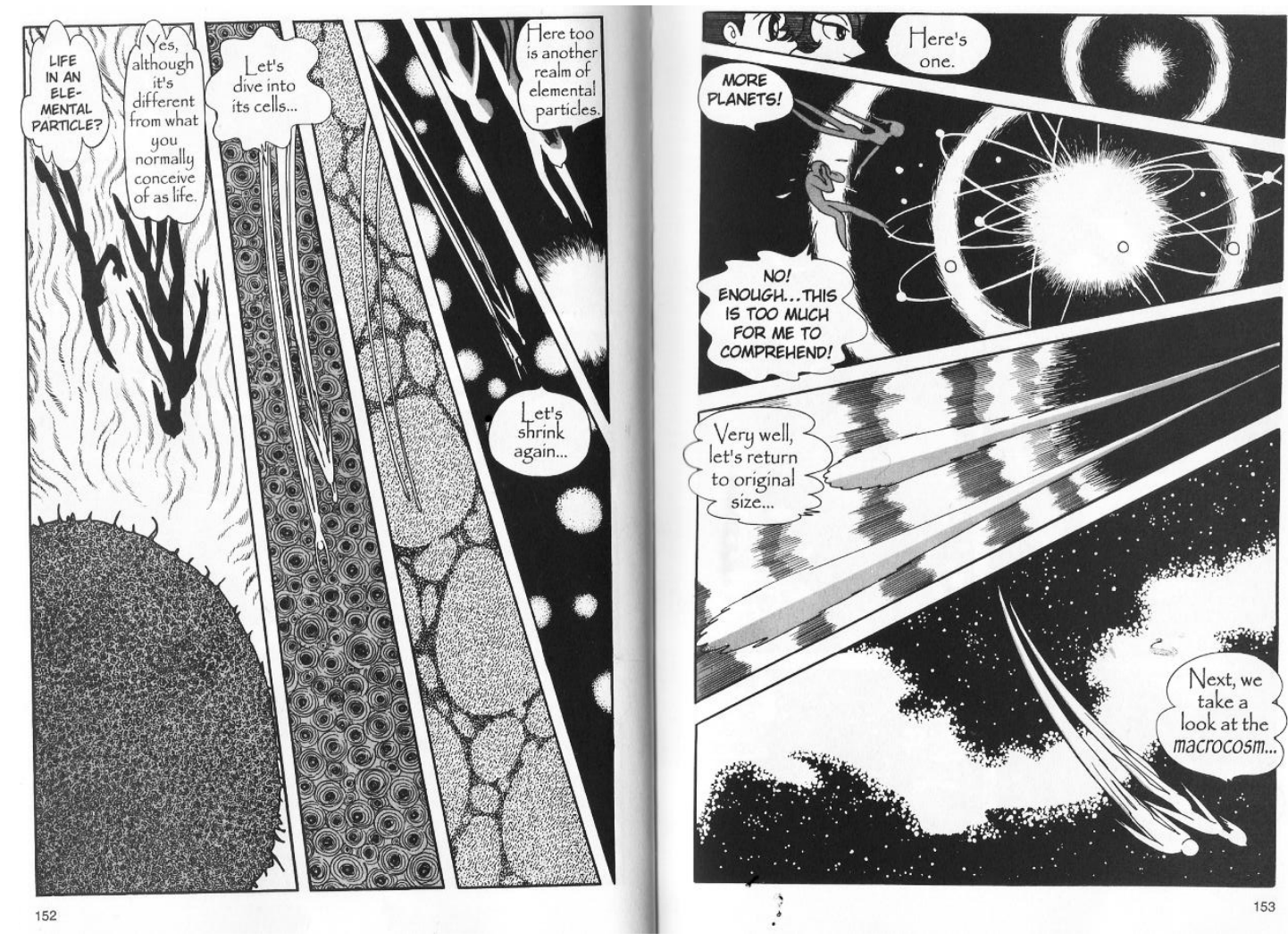

Figure 14. Tezuka Osamu, Microcosm, Future 152-153.

In Tezuka's myth, the phoenix takes Masato on a journey into elemental particles, showing him how each one is alive, and mirrors the structures of a solar system (150-153, figure 14). She then zooms out, revealing similar structures at an interstellar level, explaining that if she was to zoom out again, "this whole universe would be no more than one particle," and that "from the microcosm to the macrocosm they're all alive" (154-155). Tezuka represents the whole as the part and the part the whole, just as the phoenix's body earlier stood in for both the "flesh and blood of the Earth...[and] ... a living cell" (51). The reference to the microcosm and macrocosm conjures up the ideas of Paracelcus and Jakob Böhme, and the tradition of philosophical alchemy that led Victor Frankenstein astray. Shelley sets up Frankenstein's interest in "the wild fancies" of "Cornelius Agrippa, Albertus Magnus, and Paracelsus, the lords of my imagination” in order to reveal his lust for the "elixir of life" as the unstable beginnings of his urge towards "the raising of ghosts or devils" (22). Tezuka, however, depicts immanent life as 
something that is already there, rather than requiring human creation. Rather than just the reserve of what Northrop Frye called the "band of superstitious dilettantes [pursuing Blake] into the refuge of a specialised cult” (7), Edward Larrissy argues in William Blake that Paracelsus and Böhme's ideas were highly influential to radical Protestantism during the Civil War, regaining currency in the volatile 1790s, and that Blake's allegiance to this antinomian tradition marks where his version of liberty diverges from "the individualistic, bourgeois conception of his... contemporaries" (35). Larrissy maintains that although Blake's relationship with arcane traditions has been "anathema" to critics seeking to confirm his radicalism, Blake names Paracelsus and “Behmen” [Böhme] as major influences (E707), even though his "relationship with their tradition was critical and cavalier" $(31,33)$. Part of Blake's relationship with these ideas is a refusal to allow them to become part of a disembodied search for transcendence of reality: the Marriage warns against taking up the mental content exclusively without a body or form when the narrator states his "plain fact" that "any man of mechanical talents may from the writings of Paracelsus or Jacob Behmen" be able to repeat or analyse their ideas without necessarily producing "one new truth" (plate 22). Reading Blake alongside Tezuka is a reminder that these traditions were only useful to Blake if they didn't abandon what the phoenix calls "the flesh and blood of the earth" (51).

In Future, the rest of humankind has retreated underground into five "Eternal Capitals". We could read this as a literalisation of Blake's "cavern'd man" (E60), who has “closed himself up, till he sees all things thro' narrow chinks of his cavern" (Marriage plate 14). Each of Tezuka's skyscraper-filled cities are controlled by an all-powerful super-computer, who calculates non-negotiable directives. In these frames, Tezuka presents a parody of narrow rationality resonant with Blake's false god Urizen. Both artists house conceptions of destructive ideology in mechanistic yet humanoid idols. 


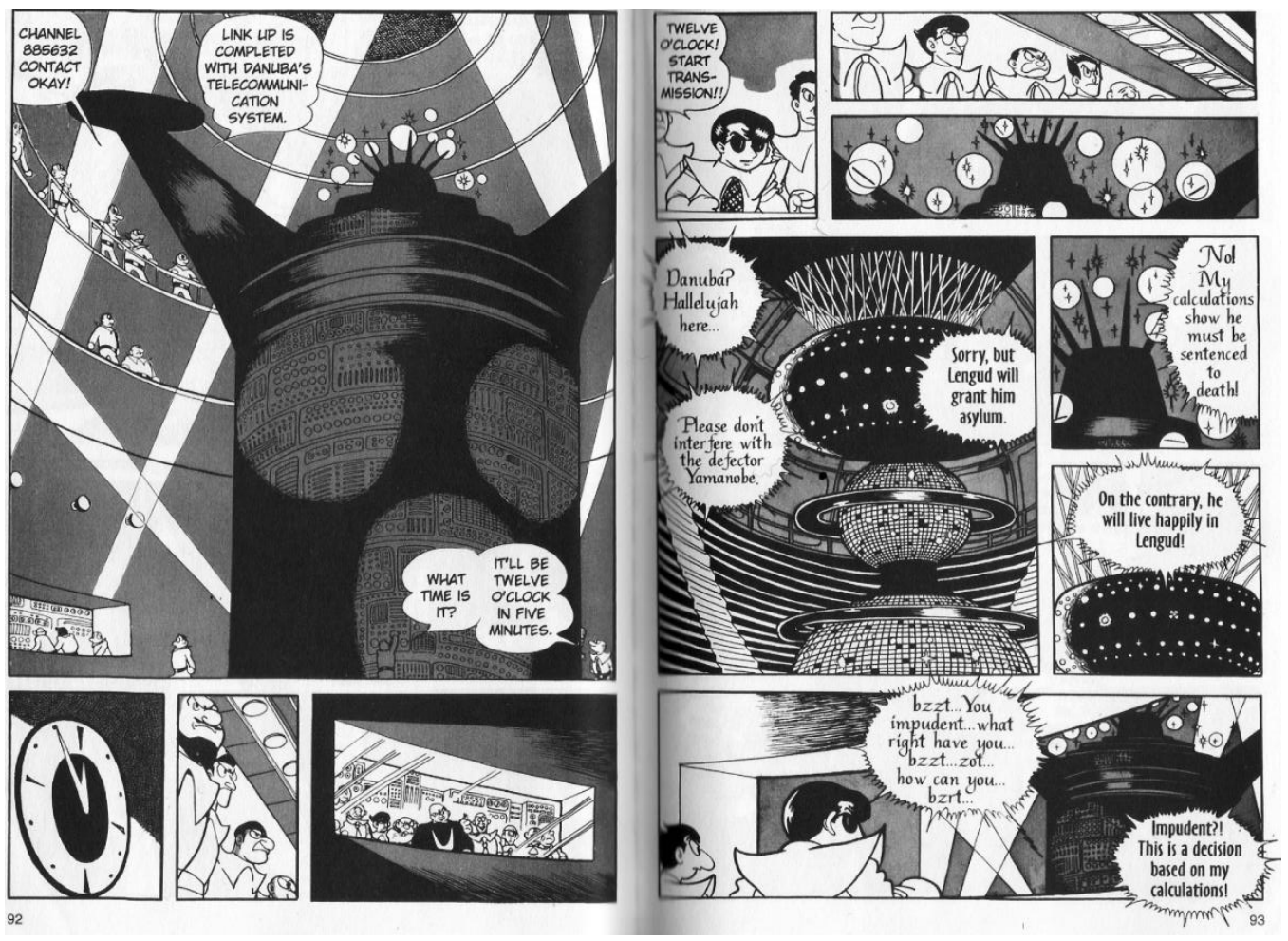

Figure 15. Tezuka Osamu, Hallelujah, Future 92-93.

Tezuka embodies instrumental rationality in the god-like machine who rules the city of Yamato, Hallelujah. Her name evokes and parodies her deified status; MacWilliams suggests an allusion to HAL 900o, the computer mind of Arthur C. Clarke's 2001, A Space Odyssey (191). As a structure, Hallelujah is both menacing and ludicrous, covered with buttons and swarmed over by technicians. Both she and her rival Danuba are towering figures in the centre of a spherical space, redolent of a panopticon. Hallelujah in turn is observed by stony-faced men who serve her from behind a glass panel. Her arms are outstretched in a perversion of Saruta's earlier open-armed gesture, and she 'sparkles' as the phoenix did, in a visual parody of the earlier evocation of the scared. Tezuka attacks what MacWilliams calls the "salvatory myth of scientific progress" by revealing its "essentially religious nature" (190).

The transmission between Hallelujah and Danuba flicks between the 'heads' of the machines in a travesty of conversation, until the dialogue melts 
down into static as the machines reach an impasse, able to agree only to mutual destruction (94). Tezuka presents irrational rationality, through the inability of the super-computers to acknowledge material vulnerability, even as they initiate a path calculated to have a $99.8 \%$ certainty of destroying everyone and everything in nuclear war-which is what ultimately occurs.

In Visions, Oothoon condemns Urizen as "Creator of men! Mistaken Demon of Heaven!” (8.3). This address suggests that Urizen is worshipped as "Creator," but also denounces a conventional idea of God as a "Mistaken Demon." Blake's depictions of him often resemble a Christian patriarch, with a long white beard (for example, on the title page of Visions). He is simultaneously hailed as all powerful, able to create "form men in [his] image" (8.4), and undermined by being revealed as a mistaken demon. Blake portrays a human construction as simultaneously powerful, oppressive, and imaginary, like the "spells of law" that bind the unwilling wife in marriage to "one she loathes" (8.22). Oothoon may be bound to Bromion, but she is still able to tell Urizen that "[his] labour vain" will never succeed (8.4). Oothoon's words displace condemnation of violence from the perpetrators to the ideology to which they are in thrall, redeeming the individual. She emphasises the different attitudes of those possessed by Urizen, comparing the "giver of gifts" and the "industrious citizen" with the "fat fed hireling," and exclaiming "[h]ow different their eye and ear! How different the world to them!" (8.12-16). When "she who burns with youth" must in the bondage of a loveless, violent marriage "bear the wintry rage | Of a harsh terror driv'n to madness, bound to hold a rod | Over her shrinking shoulders all the day," Oothoon recognizes suffering in both parties $(8.21,8.24-26)$. Terrorising violence is inseperable from fear, "driv'n to madness," which also is "bound"-no-one escapes the bonds inherent in the system which Oothoon indicts. Bromion's figure in the frontispiece to Visions shows him bound also.

In this way, both Blake and Tezuka situate faith in a "mistaken demon" within its effects. As David Aers argues, Visions shows that every "reasoner 
reasons" within a context (28), and the disembodied rationalities of Urizen and Hallelujah abuse the material realm even as they deny its relevance. In Future, the collective body - millions of human beings, as well as all other creatures-is destroyed when the machine of mechanised reason ignores its limits.

\section{VI}

An apocalyptic vision pervades the work of both Blake and Tezuka, differing in parallel to the changing meanings of the word. Once meaning "revelation or disclosure," general use of the word 'apocalypse' now signifies "a disaster resulting in drastic, irreversible damage to human society or the environment, esp. on a global scale; a cataclysm" (OED 2b). What can the shifting meanings suggest?

Against the conservative position that liberation would have to wait until the Second Coming, radicals in late eighteenth-century London interpreted the American and French Revolutions as preludes to a new era: "The times are auspicious,” Rational Dissenting Minister Richard Price declared in November 1789, four months after the storming of the Bastille (qtd. in Taylor 145). Popular prophets, disaffected workers, artisan radicals, and respectable Dissenters like Price alike anticipated "the earthly Millennium," framing their own actions as fulfilment of the book of Revelation (Mee 38). Within this potent brew, the antinomian 'revelation' urged by religiously-inspired enthusiasts like Blake was seen as a major threat to the status quo-"the contagion of insanity has actually caught the friends of anarchy," as one conservative critic wrote (qtd. in Mee 4849). Terrified authorities responded with brutal crackdowns, maintained by "a culture of surveillance and the prosecution of sedition" (Clark and Worrall 11).

Some radicals distanced themselves from popular enthusiasm's “convivial... mélange of blasphemy, millenarianism and sedition” (McCalman 1). Thelwall, for example, whilst committed to radical change, rejects "the rant of inconsiderate enthusiasm" because "so wild a scheme, must plunge the world into yet unheard-of-horrors" (qtd. in Makdisi 301-2). Such fears that the revelatory 
apocalypse of popular enthusiasm would cause literal cataclysm were fuelled by "the bloody transition in France from Girondin to Jacobin control in 1792-93" and the massacres of the Terror (Makdisi 48). We could speculate that older, positive meanings of the word were corroded by ongoing associations with violence. By the time we turn to Tezuka, the fantasy of our modern meaning-apocalypse as cataclysm-perhaps betrays the loss of faith in the possibility of the older meaning-apocalypse as revelation.

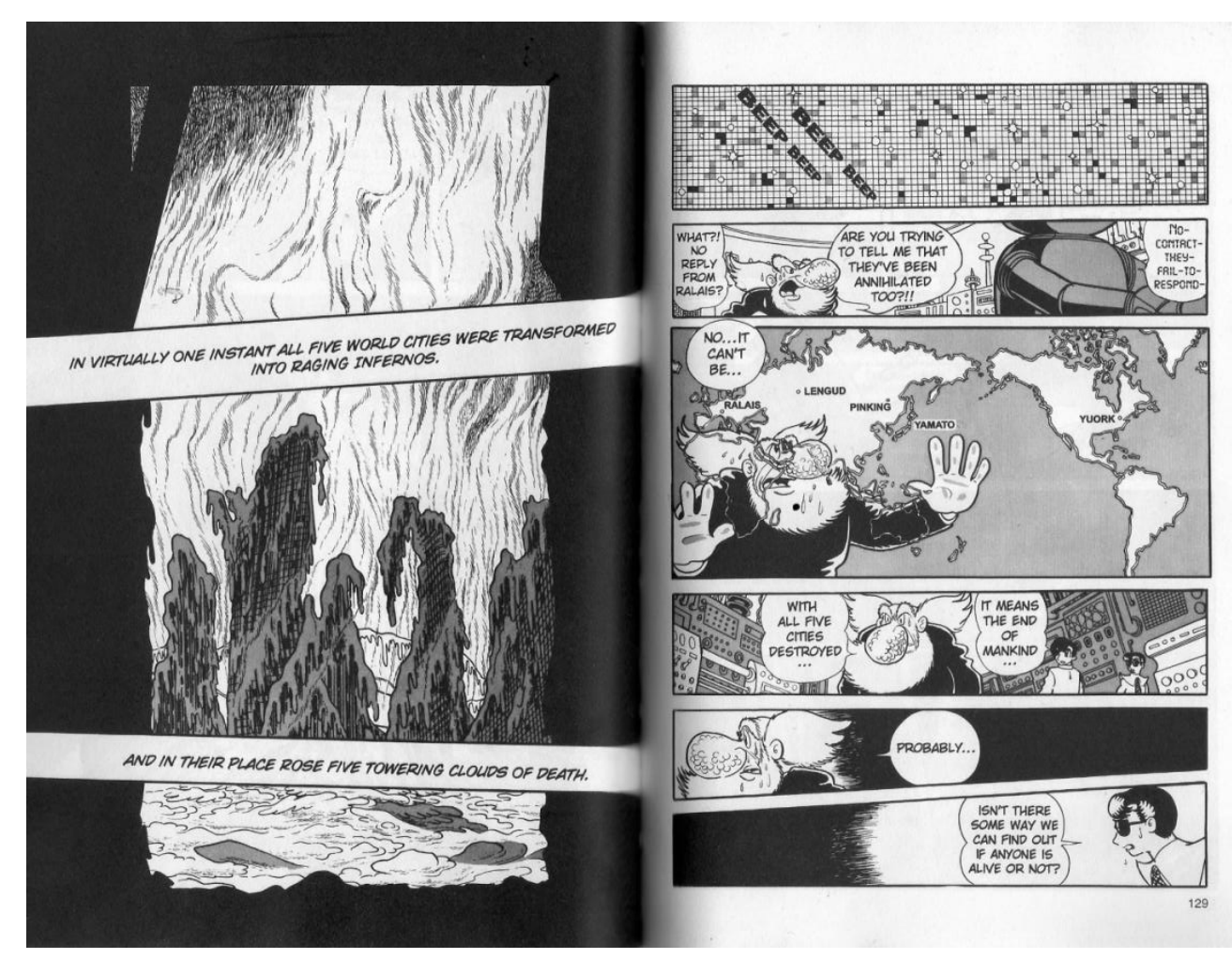

Figure 16. Tezuka Osamu, Apocalypse, Future 128-29.

In Future, Saruta and Masato watch in horror as all five eternal cities destroy one another with nuclear bombs, the computer gods' pyrrhic victory (figure 16). The black frame of the page evokes the blank horror of allencompassing destruction, beyond the full comprehension of the characters or the reader. Slashes of text close off the scene, unable to be integrated, and similarly the page numbers are eclipsed. The following page fills the silence with the impersonal beeping of control panel squares, a reminder of the inhuman politics 
that created the devastation. The abruptness of the scene belies its horror, for as Paul Brians writes, "the notion that civilization might be ended or life on Earth be destroyed through a technical malfunction or an error in judgment presents an absurdity of such enormous dimensions that it can scarcely be grasped" (2). Tezuka's presentation of total annihilation obliterates the narrative, grinding it to a halt.

During the 1945 U.S. firebombings of Osaka Tezuka witnessed scenes which, he said, "writing for forty years did not heal" (qtd. in Godart 36). Tezuka references both the nightmare of Hiroshima, and the insane logic of Cold War politics that influenced the 'New Wave' nihilism of many sci-fi writers in the 1960s. The conflict between Hallelujah and Danuba has become a scene of total annihilation with very specific historical echoes.

However there is no external evil to blame in Tezuka's vision, no band of 'chosen ones'-although Masato is told he must regenerate humankind, the reality is eons of lonely futility. A better fit for the modern image of apocalypse is the vision of Hell which the Angel shows the narrator of the Marriage: "By degrees we beheld the infinite Abyss, fiery as the smoke of a burning city; beneath us at an immense distance was the sun, black but shining," filled with the binary polarities of "black and white spiders" (plate 18). The 'Argument' evokes the destruction of Tezuka's underground cities and the "burdend air" of radiation, as the "hungry clouds swag in the deep" (plate 2). But when the Angel leaves the vision disappears, prompting the narrator's realization that "All that we saw was owing to your metaphysics” (plate 14). Like Hallelujah, the deified 'Angel of reason’ creates apocalyptic destruction through its dualised vision that thinks in polarities of 'good' versus 'evil'.

The revelation in Blake's Marriage is not the triumph of good over evil, but the erosion of the dualism between them, an apocalypse evoking the earlier meanings. Just as nothing appeared to Ezekiel "in any finite organical perception, the Marriage's claim that "The ancient tradition that the world will be consumed 
in fire at the end of six thousand years is true" does not herald physical destruction and literal fire (plate 12,14). The fire he envisages is one whereby "the whole creation will be consumed, and appear infinite. and holy" (Marriage plate 14 E39). This is not to suggest that Blake privileges private visions over public revolution: Mee's work shows the extent to which antinomian enthusiasm constituted a political act.

Tezuka's weapons of mass destruction are nuclear bombs: Blake's are his poems, but Tezuka's destruction is literal, whereas Blake's is the destruction of what motivates such insanity. Seen thus, the chasm between meanings of apocalypse becomes obvious, as for Blake, the "Last Judgement" was when "all those are Cast away who trouble Religion with Questions concerning Good \& Evil...which hinder the vision of God, turning all into a consuming fire" (E554). Thus we could say that in Blake's works, apocalypse is presented as the only way to avert apocalypse.

Kenzaburo Ōe's Rouse Up O Young Men of the New Age! relates his first encounter with words that profoundly influenced his fiction, and that he later learned were Blake's: “That Man should Labour \& sorrow \& learn \& forget, \& return | To the dark valley from when he came and begin his labours anew" (The Four Zoas, E385). After the Fukushima earthquake, tsunami, and nuclear disaster, Ōe's wrote, in words that recall these lines, that “[t]he lesson we learn from the current disaster will depend on whether those who survive it resolve not to repeat their mistakes" ("History Repeats" par. 1). The close of Future implies that Tezuka shares this cyclical vision, with the repeated rise and fall of destructive, greedy human beings (and subsequently, the slug-people) suggesting that the pattern will always repeat. However the Phoenix series does offer a redeeming perspective, in that no matter what the degree of destruction, the force of life appears impossible to extinguish. Blake's works may at times evoke a similar circularity, as in the Oothoon's cyclical lament and enslavement. Yet Visions simultaneously represents her resilience and emancipation, suggesting apocalypse as an ever-present possibility. 
VII

Filmmaker Akira Kurosawa describes being taken by his brother to walk around the wreckage of Tokyo as a child after the 1923 earthquake and fire. His brother would not let him look away from the horror of piles of burned bodies, saying: "If you look at everything straight on, there is nothing to be afraid of" (54). Both Blake and Tezuka present readers with unflinching depictions of suffering, in the faith that another way is possible. Throughout the Phoenix series, characters chase mastery and immortality, attempting to escape the body and the material because the body dies. Yet their attempts only hasten death. The traumatic split Future dramatizes aligns the phoenix's statement that "The Earth is alive," the "alterform" of God (51), with the Marriage's diagnosis of the "Error" that "Energy, calld Evil, is alone from the Body” (plate 4). Like Blake's Nebuchadnezzar, the tyrannical, ill-fated attempt to transcend the material has the opposite effect to that intended. Looking at Blake's works alongside Future suggests that rather than an irredeemable fallen world, they represent a material reality that must be fully and honestly examined and embraced, rather than transcended, in order to transform the logic of domination.

Tezuka's manga respond to a modern awareness of ecological limits, nuclear destruction, and mechanised warfare. Blake may have been working nearly two hundred years earlier, but his resonance with Tezuka shows that his work can speak to these concerns: in challenging dualised conceptions of the material their works undertake a comparable conversation with certain narratives of Western, capitalist modernity. Cross-cultural correspondances between Blake and Tezuka can develop our understanding of how each artist negotiates embodied vision, both through their combinations of word and image, and through undermining oppositions of reason and nature that divides mind from body. The Japanese Blake, and his resulting harmony with Tezuka, give fresh perspectives on Blake, perhaps helping to skirt some of dualistic pitfalls that Blake's illuminated poems rail against. 


\title{
Modesty and Sexual Embodiment in Wollstonecraft and Blake
}

\author{
THESEUS. To you your father should be as a god; \\ One that composed your beauties; yea, and one \\ To whom you are but as a form in wax \\ By him imprinted...
}

HERMIA. My soul consents not to give sovereignty.

William Shakespeare A Midsummer Night's Dream 1.1.47-50, 82.

O Shame O strong \& mighty Shame I break thy brazen fetters

William Blake, Jerusalem 10.34

The influence of Mary Wollstonecraft upon William Blake has been thoroughly discussed, reflecting ongoing interest in how Blake's Visions of the Daughters of Albion (1793) echoes and adapts Wollstonecraft's A Vindication of the Rights of Woman (1792). Changing assessments of both Wollstonecraft's work and Blake's Visions, however, call for continued inquiry in this area, in this case using the framework of 'embodied vision.' Blake's exploration of sexuality in Visions has often been taken as a paean to male entitlement to 'free love,' presenting all sexual experience as eternally redemptive, outside the bounds of history-with those unwilling to participate framed as spiritually defective. Reading Visions in the context of sexual double standards in the late eighteenthcentury, as an admiring, combative response to Wollstonecraft's slating of such standards, grounds Blake's poem in the context it rails against and seeks to transform. Both authors revised notions of female propriety and the culture of male dominance these norms served to maintain. In order to do so, both texts use concepts of universal experience, and I will argue that this is the point at which their challenges diverge most significantly. These strategies, too, need to be 
understood in the contexts of late eighteenth-century Rational Dissent and radical enthusiasm. Both authors' conceptions of the freedom of such standpoints enable rejection of ideals of femininity, sexuality, and social morality. This rejection exposes these ideals as culturally contingent, made-up stories. We need to trace what these constructions were, in order to understand how and why Wollstonecraft and Blake chart a course for liberation of women through such conventions.

What emerges from reading Vindication and Visions together, is that coercive gender norms can be related to a broader culture of domination and control: both Blake and Wollstonecraft expose sexual double standards in order to indict society more generally. With the unfolding French Revolution still fuelling radical hopes in England, questions of gender were exceptionally loaded. Challenging the construction of femininity raised questions about tyranny, power and control, subordination and socialisation. The 'modest' woman became not only an exposé of hypocritical societal ideals, but also, in Barbara Taylor's formulation, "the paradigmatic modern subject," formed to please others (“Gallants" 40). Rousseau declared "Do you want to know men? Study women," and whilst Vindication and Visions are both concerned primarily and directly with British women, they question the wider structures of oppression and alienation the era was grappling with (qtd. in Taylor 84). In this chapter, I will chart some of these constructions, before turning to Wollstonecraft and then Blake's attack on them.

In a key chapter in Vindication, "Animadversions on Some of the Writers who have Rendered Women Objects of Pity, Bordering on Contempt," Wollstonecraft dismantles "some modern publications on the female character and education" (147). Such books, she writes "cannot be too often or too severely exposed" (161). Her argument centres on the "pernicious tendency of those books, 
in which the writers insidiously degrade the sex," which "melts every human quality into female meekness and artificial grace" (161-62). Wollstonecraft argues that authors such as Rousseau, Presbyterian Minister James Fordyce (17201796), moralist John Gregory (1724-1773) promote behaviour which undermines the morality they claim to defend. In Mary Wollstonecraft and the Feminist Imagination, Taylor notes how "the vice that attracts Wollstonecraft's harshest censure is erotic guile, which she condemns with a fierceness that has led many critics to describe her as a sexual puritan" (13). Taylor gives us a Wollstonecraft who is closer to Blake's vision of a redeemed sexuality than might at first be apparent. Crucially, both Wollstonecraft and Blake object to the behavioural standards for women peddled by writers of the age.

What were these behavioural expectations, that were apparently both so natural and in need of such insistent policing? In her conclusion to Women, Gender and Enlightenment, Kate Soper writes how "the interest of the period in sexual difference is also an interest in the instability of sexual identity, its dissembling and masquerades" (710). It is this instability, Taylor argues, fuelled by "an unprecedented cultural convergence between the sexes," that necessitated "a rearguard effort to stave off the equalising pressures of commercial society, to shore up a 'sexual distinction' that, natural or not, was clearly in need of some vigorous reinforcing” ("Gallants" 41-42). 'Nature'-"this indefinite term," as Wollstonecraft calls it-comes to signify whatever a prescriptive author wishes to naturalise (97). The popularity of both essentialist presentations of femininity such as Sophie in Rousseau's Emile, and advice manuals such as Fordyce's Sermons to Young Women and Gregory's A Father's Legacy to His Daughters, are testament to anxious interest in female 'nature'. Taylor charts how such prescriptions came at a time when "[o]pen displays of misogyny... were no longer fashionable" (14). Instead, coercive behavioural norms came in the form of ostensibly pro-woman sentiments - "unfeigned regard for the Female Sex," as Fordyce claims (1). Whether in the work of Rousseau or the manuals of the moralists, strictures constructing feminine submissiveness came from "leading 
representatives of the male avant-garde" rather than conservative misogynists (Taylor 15).

Vindication's first target was Rousseau, whose writing Wollstonecraft largely admired. Like Wollstonecraft, Rousseau condemned what he saw as the artifice and corruption of social mores, famously opening The Social Contract in 1762 with the declaration that "Man was born free, and everywhere he is in chains" (156). Chains of "taste, manners, politeness [and] decorum," Rousseau had argued in A Discourse on the Moral Effects of the Arts and Sciences (1750), cause a "perpetual restraint," a "uniform and deceitful veil of politeness" which warps and perverts humanity (7). Socially constructed selves and private property among the bourgeoisie alienate humanity from natural goodness, he suggests. Yet in A Discourse on the Origins of Inequality (1755), Rousseau depicts this primordial 'goodness' as a state of instinctive animality, where everyone "awaits the impulsions of Nature, yields to it without choice" (152). The development of the imagination, he speculates, created a gap between instinctive needs and fantasised objects, "the space in which insatiable desire arises," rendering society a necessary evil "if individuals are not to annihilate each other" (Taylor 78). This paradoxical pessimism causes Rousseau's opening challenge to society to devolve into the question of "[w]hat can render [the chains] legitimate?" (156).

Wollstonecraft challenges Rousseau as a perceived legitimiser of women's chains, placing him alongside the likes of Fordyce and Gregory, the effect of which is "to make him appear less the great philosopher than common-or-garden male supremacist” (Taylor 86).

Such attention was not unwarranted: as “the century's foremost male theorist of gender," Rousseau, although now visible as a "notorious exponent of female subordination," at the time was seen as a "friend to womankind" (Taylor 74, 91). Wollstonecraft's critique in Vindication focusses upon Emile, and particularly Sophie, Emile's ideal woman. Here Rousseau's corrupted man, socialised into pleasing others, reappears in the form of woman, "expressly formed to please the man" (qtd. in Wollstonecraft 117). Yet what was in men a 
tragic artificiality, regrettably foisted upon them, is now "one of the laws of nature, prior to love itself." Women should be "passive and weak" and "make little resistance" to men. "If women be formed to please and be subjected to man," states Rousseau, "it is her place, doubtless, to render herself agreeable to him, instead of challenging his passion" (qtd. in Wollstonecraft 117). Yet women should display "that bashfulness and modesty with which nature hath armed the weak, in order to subdue the strong," he continues, in order to excite male desire and give men a sense of victory in conquest (qtd. in 117). Sophie embodies such a woman, "made to please and to be subjugated" (Emile 358). She is meant to stand in innocent contrast to the posturing of elite Parisian women, but Wollstonecraft points out that Sophie's submissive coquetry is just as "grossly unnatural" as the women she is meant to improve upon (Vindication 93). "Is this modesty?" she asks, citing Rousseau's description:

Her dress is extremely modest in appearance, and yet very coquettish in fact: she does not make a display of her charms, she conceals them; but in concealing them, she knows how to affect your imagination. Everyone who sees her will say, There is a modest and discreet girl; but while you are near her, your eyes and affections wander all over her person, so that you cannot withdraw them; and you could conclude, that every part of her dress, simple as it seems, was only put in its proper order to be taken to pieces by the imagination. (qtd. in Wollstonecraft 157)

"Nature never dictated such insincerity," Wollstonecraft declares, but rather "this partial moralist recommends cunning systematically and plausibly" (153-154). Plausible, because Vindication has plenty of similar characterisations. Amidst his evocations of what is 'natural,' Rousseau betrays how constructed this femininity is when he writes how women "must be subject, all their lives, to the most constant and severe restraint, which is that of decorum: it is, therefore, necessary to accustom them early to such refinement" (qtd. in 151). Behind presentations of natural feminine submissiveness lurk fears of an ungovernable female sexuality, and the instability of gender roles designed to control such disorder. "[A]ll perish 
from the disorder of women," Rousseau wrote in Politics and the Arts (109). The coy artificiality advocated by Rousseau is defined by Wollstonecraft as "the philosophy of lasciviousness" and "certainly only an education of the body" (117, 150). Rousseau's ideal female is a bodily object in the gaze of another, rather than a bodily subject. Because this version of femininity is reflexive to male desires and societal expectations, women are condemned to an existence as an object rather than as a desiring subject, a paradoxically disembodied existence.

Taylor summarises how in Rousseau's work modesty and modern citizenship coalesce into corrupt inevitability:

The realm of appearances to which women are confined is modernity as Rousseau understands and deplores it. The processes through which females become Sophies are those by which all men and women, born free and equal, are shackled into the bear-dance of modern society. Becoming a modern citizen... is for both sexes becoming Woman: a being deprived of all inner authority, whose life is one of duplicity and dependence. (84)

The bestselling conduct manuals of Fordyce and Gregory betray similar anxieties, sharing the sense that the issue at question was larger than the day-to-day activities of young women. Mary Catherine Moran discusses Gregory's best-seller A Father's Legacy to His Daughters, showing how "[t]he question of nature versus artifice, then, was by no means peculiar to the attempt to define and prescribe a female nature, but was also an important area of debate and discussion over the nature of man in general” (12). In Gregory's works we find that "the question of women's proper position is also a matter of the right relationship between the artificial and the natural” (Moran 15).

The preface to Gregory's Legacy states it was written for his daughters, and "not intended for the public" (i). This "domestic" marketing ploy substantiated the claim that "no sacrifices are made to prejudices, to customs, to fashionable opinions" (i-ii), the advice being rather "the genuine sentiments of a man who has no interest in flattering or deceiving you" (5). Gregory conceals his 
own constructions of femininity beneath the legitimising category of the private and 'naturally' uncorrupted. "I do not want to make you any thing," he writes, "I want to know what Nature has made you, and to perfect you on her plan" (62-63). Yet 'Nature' has apparently made women "designed to soften our [men's] hearts and polish our manners," (6) with "superior delicacy [and] modesty" evident in "the natural softness and sensibility of your dispositions" (12). In matters of love, "Nature, whose authority is superior to philosophy, has annexed a sense of shame" to women's "attachment," therefore "love is not to begin on your part, but is entirely to be the consequence of our attachment to you" $(77,90)$. If a woman marries a man she loves, she ought not express "the full extent of [her] love," as "[v]iolent love cannot subsist... for any time together, on both sides; otherwise the certain consequence... is satiety and disgust” (98). As Betty Rizzo has noted, Gregory “endorses a view of women's 'naturally' submissive and retiring nature that he himself belies in the strength of his caveats against all behaviour that was unsubmissive or unretiring" (qtd. in Moran 11).

Fordyce's Sermons is equally concerned with demarcating female submissiveness. Women have "from Nature a peculiar aptitude to please, with a wonderful facility in adapting themselves to the tempers of others," he writes (91). Elsewhere in his writings he presents a terrifying picture of deranged femininity: "Paint to yourselves... a woman who talks loud, contradicts bluntly, looks sullen, contests pertinaciously, and instead of yielding challenges submission... How forbidding an object! Feminality is gone: Nature is transformed” (The Character and Conduct of the Female Sex, 1776). Fordyce's vision in his Sermons of "modesty, sobriety, and simplicity" (7), was part of a selfcongratulatory Enlightenment ideal of "chaste conviviality," contrasted with the "levity" of the depraved French aristocracy (Taylor, "Gallants” 37). Fordyce’s brother David Fordyce similarly championed gallantry, arguing that "[w]e can hardly shew [women] too much respect, or pay them too much Deference, that we may conceal, and in some degree, compensate to them the Superiority which Nature has given us over them" (qtd. in "Gallants” 39). Taylor notes how 
Wollstonecraft's damning response- "away with the lullaby strains of condescending endearment!" (164)-marks her divergence from "mainstream enlightened opinion" ("Gallants" 30). It is within this divergence that Wollstonecraft's radicalism overlaps with Blake's indictment of hypocrisy.

Gregory's tone is less condescending than Fordyce's: in the Legacy he addresses his daughters as "companions and equals" (6), and even to a modern reader occasionally sounds insightful and humane, rendering Wollstonecraft's "affectionate respect" understandable (166). However as Moran notes, Wollstonecraft distinguishes between his "easy familiar style" as a father, and a "degree of concise elegance" (166) as an author, aligning the society-pleasing dissimulation he recommends as the latter, with a correspondingly artificial style (10-11). Wollstonecraft denounces such "rank affectation" in heightened rhetoric as "the root of the evil that has shed a corroding mildew on all thy [woman's] virtues; and blighting in the bud thy opening faculties, has rendered thee the weak thing thou art!" (166-167). It is not the behavioural advice itself that offends Wollstonecraft, but the way it comes "at the wrong end," that is, following moral laws constructed by others instead of the inner conscience (167). Better to strengthen the understanding so it can make decisions for itself, she argues, than make an interminable list of "starched rules of decorum" (167).

Wollstonecraft redefines what is natural by recourse to the inner light of Reason, the work of "the supreme Being" in a person as understood by her version of Rational Dissenting Christianity (90). As Taylor has argued, Wollstonecraft's 'Reason' is a more religiously motivated concept than some critics have acknowledged. Understanding this calls for caution, for as Moran observes, the Vindication argues that the wrong things are being essentialised, whereas "[f]or modern critics... it is... a given that any account of femininity is an artificial construct, while the invocation of nature is itself a measure of the work's artifice" (11). Soper notes how from some postmodern feminist perspectives, "[t]he unified self of Enlightenment is a fiction as well as a masculine fetish...a distorted and disguised will-to-power," with figures such as Wollstonecraft 
complicit in the distortion (707). But such analysis, she argues, homogenizes Enlightenment thought into "a single, unified value-system" that as we can see from Wollstonecraft's disputes, did not exist (707).

Wollstonecraft's version of modesty resists behavioural dictates, which aligns her thought with Blake. "Modesty!" she exclaims, "Sacred offspring of sensibility and reason!" (191). She redefines modesty as a clear view of the self, where "purity of mind" and inner virtue will lead effortlessly to right behaviour (192). This reliance on personal revelation must be situated, as Taylor stresses, within Wollstonecraft's "religiously inspired utopian radicalism" rather than assumed to be a precursor of a secular, "heroic-individualist brand of politics" from our own time (12). Wollstonecraft's conception of the autonomous self relied upon an understanding of autonomy as, in Taylor's formulation, the "freedom... to act rightly," not the "licence" of libertarian individualism (12). Her radicalism was influenced by the nonconformist Rational Dissent of figures such as Richard Price, but as Taylor charts, an "appeal to the inner authority of the individual believer was at the heart of all varieties of Enlightened theism" (104). The tradition of Dissent, and belief that God's will could be determined from reference to one's own intuitions, rather than established authorities, held obvious radical potential. "I do not draw... rules from the principles of a high philosophy, but find them written by nature with ineffaceable characters in the depth of my heart. I have only to consult myself..." Rousseau's Vicar of Savoyard explains in Emile (286), and Wollstonecraft similarly argues that "the heart should be made clean, and not trivial ceremonies observed" (97). "Jesus Christ was modest" (192), she asserts in a radical redefinition of the concept. This redefined modesty finds a parallel in Blake's The Marriage of Heaven and Hell, where the Devil lists rules broken by Jesus, concluding: "I tell you no virtue can exist without breaking these ten commandments: Jesus was all virtue, and acted from impulse, not from rules" (E42), which E. P. Thompson calls "one of [Blake's] most explicit statements of antinomianism" (172). But women cannot access their inner moral laws, Wollstonecraft argues, when they "hug their chains" (152). 
Women, in Wollstonecraft's scathing indictments, have deferred to pleasing men rather than accessing God through their own consciences. Denying women autonomy is denying them a relationship with God, and "[i]t is to this goal, the replacement of artificial Woman with the human creature of God's creation, that the Rights of Woman principally devotes itself" (Taylor 57).

Wollstonecraft's distinction between authentic impulses from God, and religiously ideological impulses of the individual-what Blake often refers to as "Opinion"- relies upon her concept of improvable reason. Femininity, as she finds it, leaves little room to trust women's consciences, amidst their current "serpentine wrigglings of cunning” (245). Wollstonecraft's version of 'nature' depends upon the idea of perfectability-"Rousseau exerts himself to prove that all was right originally: a crowd of authors that all is now right: and I, that all will be right," she states (84). This, argues Kirstin Wilcox, is the difference between 'women' (as condemned throughout the Vindication), and 'Woman,' the nonexistent, deserving entity whose rights are being vindicated (448). The space between, that "dark abyss of uncertainty" (Rights of Men 20) is where Wollstonecraft's utopian radicalism operates, making it clear that 'women' are a work in progress. The hypothetical nature of 'Woman' provides "an enigma at the centre of Wollstonecraft's argument, a dimly conceived but compelling field of possibility" (Wilcox 448). This allows Wollstonecraft to evade the normative practices she condemns in others, the "inbred sentiments" of Burkean moralism (Rights of Men 32). Like many Enlightenment writers, she uses 'nature' to imply not only a pre-socialised state-Rousseau's "state of nature"-but also that kind of education that "unfold[s] our reason" and thus brings women into relationship with God's plan for “civilisation, in all its possible perfection” (83). This is close to Gregory's claim in the Legacy that "I want to know what Nature has made you, and to perfect you on her plan," but in Wollstonecraft's “open-ended conception” (Wilcox 454), this is reversed: perfecting the plan reveals "what Nature has made you." Wollstonecraft aims to "trace what we should endeavour to make [women] in order to co-operate... with the supreme Being” (90), and her conclusion is that 
women require education to liberate their reason, for "the perfection of our nature and capability of happiness, must be estimated by the degree of reason, virtue and knowledge." Woman "must grow more perfect when emancipated," she argues, for submission to worldly hierarchies perverts the individual's reason and virtue (90). This argument builds upon the broader radical narrative that hierarchy itself is unreasonable, which Wollstonecraft deploys in the Rights of Men when she mocks how Edmund Burke's 'intuitive' sensibility leads him to empathise 'naturally' with Marie Antoinette: "Misery, to reach your heart, I perceive, must have its cap and bells; your tears are reserved, very naturally concerning your character ... for the downfall of queens, whose rank alters the nature of folly" (15). Reasonable women, living in equality, will be able to "rise above the state in which sensation produced brutal ease" (83) and "purify their heart[s]; but," she asks, "can they do so when their uncultivated understandings make them entirely dependent on their senses[?]” (97).

Wollstonecraft's scathing depictions of women in Vindication suggest not, but Wilcox notes how Wollstonecraft's authorial style provides "an implicit answer" - the voice of reasonable, redeemed "Woman" (460). This would not be read as a 'male' voice, she argues: it combines impassioned feeling with rhetorical persuasion, giving a "vivid authorial presence," a "disembodied yet robust display of self" $(460,459)$. The result is an abstract female subject, who, escaping the denounced realm of "brutal ease," has left little evidence of "a sexed body in the world" (Wilcox 462). This abstract voice is then free to denigrate the realms of the body and the sensory. Thus the universal, reasonable "Woman" is apparently free from social conditioning, but at the expense of embodiment.

Taylor notes how in any of the many references to the sexual in Vindication, Wollstonecraft's tone becomes "charged with fruity disgust" (116). Women are aligned with depraved sensuality, and are advised to avoid " $[\mathrm{t}] \mathrm{he}$ depravity of the appetite which brings the sexes together," and to seek marriages of friendship rather than "passion" in order "not to indulge those emotions which disturb the order of society" $(113,208,99)$. It is easy to see how Wollstonecraft 
could be read as endorsing the transcendent, masculine-gendered side of a mindbody dualism. But before categorizing Wollstonecraft's thought, some other factors should be considered. Firstly, at a practical level Wollstonecraft was a professional woman supporting herself through writing in a context where women's sexual agency was "absolutely prohibited in all but the lowest and highest levels of society" (Taylor 119). Her life and later fiction show her commitment to both sexual agency and exposing sexual violence, and the backlash after Godwin's memoirs and the publication of her unfinished novel The Wrongs of Woman, or Maria (1798), reinforces just how exposed she was. Throughout the Vindication Wollstonecraft expresses concern about how to make her polemic "minimally acceptable to popular prejudices" (Kaplan 29). A comparison with Blake must take into account the different generic projects he and Wollstonecraft were attempting, as well as the different experiences they had considering the double standards they faced. As Wollstonecraft phrased it, "there are some loop-holes out of which a man may creep, and dare to think and act for himself; but for a woman it is an herculean task" (215).

Secondly, Wollstonecraft is obviously not anti-corporeal: she advocates robust health, through exercise and dancing. But having sex was a dangerous business for women: social ruin, sexual violence and disease were real threats, as illustrated in Wollstonecraft's later unfinished novel The Wrongs of Woman, or Maria (1798). All were underpinned by sexual double standards, meaning the body was a strategic liability for a pro-woman polemic. Soper notes how Enlightenment thought was simultaneously obsessed with physical difference and the contradictory impulse to think in abstract universalisations (708). This created an opportunity for those challenging gendered oppression to utilise the dualism to emphasise equality, as "the idea...that the spirit is not sex-specific invoked a Platonist-Christian tradition of thinking of the soul as sexless, and this finds further resources in Descartes' mind-body dualism” (708). Wollstonecraft performs this manoeuvre when she writes, "it be not philosophical to think of sex when the soul is mentioned," echoing Augustine (103). The abstract citizen of 
natural-rights arguments had similar legitimising potential, as when Wollstonecraft reminds Talleyrand-Périgord of his admission that according to "abstract principles," women's exclusion from government was "impossible to explain" (67). Deploying the mind-body dualism in such ways "was, of course, a double-edged legacy," writes Soper, since "the neutral spirit [or abstract citizen] has its earthly existence only within a sexually differentiated body, with all the consequences for disparagement of women that have followed from that" (70910). Yet as Taylor observes, the concept of the sexless soul created feminist possibilities for the likes of Wollstonecraft, Marie de Gournay, and early Quaker women. This can be obscured by modern feminism's tendency to define agency as autonomy, rather than the "self-transcendence" and surrender to God these women understood it as ("Religious Discourses" 412). Wollstonecraft's conception of chaste modesty finds a place of pious authority, reinforced by natural-rights theory, but it comes at the expense of embodied female sexuality.

But even these practical and strategic considerations cannot wholly explain Wollstonecraft's disgust with sexuality. It may be worthwhile to enquire whose sexual body is in fact being rejected. The lascivious women's bodies that fill the Vindication are partly there to expose ideal femininity as an artificial travesty. Wollstonecraft sees women around her as uniform reflections of social compulsions, "levelled, by meekness and docility, into one character of yielding softness and gentle compliance" (165). These women have already been disembodied by being "made to assume an artificial character before their faculties have acquired any strength"-and this character is then called woman (113). Rather than their own sexuality being negated, it is "that passive sensualism in which desire is only the desire to be desired" (Taylor 89). Wollstonecraft rejects a sexuality that she frames as already having been appropriated, possessed by "the pride and sensuality of man" (113). It is impossible to deny the Vindication's rejection of female sexuality, but sensuality based on pleasing male ideals disgusts Wollstonecraft at least as much for its artificiality as for its evocation of the bodily. Pleasing others means that such a 
sexuality will be godless, as it won't have the autonomous reason and desire that in Wollstonecraft's conception enable a relationship with the "supreme Being" (114). As Sylvana Tomaselli argues, "what Wollstonecraft sought was a society in which all men as well as women could be freed from all that the need to be admired entails" (129).

Wollstonecraft's call for modesty can be seen as an attempt to reclaim autonomy of desire outside of gendered oppression, finding it instead in an erotic relation to God. Taylor's work shows that although the Vindication rejects embodied female sexuality, "[f]ar from turning away from erotic desire, Wollstonecraft persistently celebrates it as the dynamic core of human subjectivity... This eroticism, however, has its true source in the fantasising mind, not in the body," and at this point in Wollstonecraft's thought, "true love is found only in amorous communion with God" (112). Characterisations of Wollstonecraft as an exponent of cold Reason elide the way in which her rationality relied upon eros through love of God, described by Wollstonecraft's friend and disciple Mary Hays as "panting after good unalloyed" (qtd. in Taylor 108). Not all sexuality is condemned: Wollstonecraft makes a surprising, Blakean assessment of the problem of Rousseau's overactive erotic imagination: "Had he given way to [his] desires, the fire would have extinguished itself in a natural manner" (160). Both Wollstonecraft's life and later writings attempt to find an identity outside of socialised femininity, and reclaim a sense of embodied agency.

The Vindication's radical agenda met with success in the heady and hopeful intellectual climate of the early 1790s. But by the time Wollstonecraft died in childbirth in 1797, Britain was at war with France, and the current of utopian radicalism within which Vindication came to be was largely crushed by the repression of the Pitt Government. In this challenging context, the publication of Godwin's candid Memoirs of the Author of a Vindication of the Rights of 
Woman in 1798, which charted Wollstonecraft's unconventionality, caused her to become untouchable, "bespattered with mire," in Blake’s phrase. ${ }^{1}$

III

Although my interest in reading Visions alongside Vindication is more analogical than genealogical, numerous connections between Wollstonecraft and Blake surround how Visions "responded to the powerful arguments for the liberation of women put forth by Mary Wollstonecraft" (Mellor, "Sex" 345). These connections also illustrate the political context within which both were working. Did Blake and Wollstonecraft meet? Almost certainly, although scholars debate the nature and significance of their connection.

David Erdman's Prophet against Empire is careful not to overstate the relationship between Blake and Wollstonecraft. "That Blake was among politically sympathetic friends when he wrote his revolutionary prophecies of 1790-1795 seems fairly evident," he writes, but "we do not know whether any of the English Jacobins were aware of Blake except as a minor engraver occasionally employed by Johnson. We have no indication that... Mary Wollstonecraft... ever saw a line of his poetry" (153-54). What is known is that in the early 1790 B Blake attended Johnson's dinner gatherings, along with Wollstonecraft, Tom Paine, Joseph Priestly, John Thelwell, Anna Barbauld, William Godwin, Henry Fuseli and others. "We may suppose," Erdman concludes, "that author and artist met" (156). Blake's The French Revolution (1791) was typeset by Joseph Johnson, yet for unknown reasons never published (Erdman 152). This may have been Johnson's choice, as with his decision not to publish Paine's The Rights of Man in February 1791, or it may have been Blake himself who withdrew it (Erdman 152n10). John Mee notes the extent to which the Johnson group was concerned to appear

${ }^{1}$ From the Pickering Manuscript poem "Mary"-see below for speculation this poem refers to Wollstonecraft. 
reasonable to counteract accusations of fanaticism by Edmund Burke and others, and how Blake's 'enthusiasm' would have made him “an ambiguous ally” (223). As a result The French Revolution may have been left unpublished due to "a difference over the social politics of a style" (Mee 223). These tensions between rational radicalism and antinomian enthusiasm frame the complex and productive jostling between Visions and Wollstonecraft. 'Modesty' provides a place from which to chart the variance between the utopian polemic of a rational philosophe, and the embodied visions of an antinomian craftsman.

In 1791 Blake was employed by Johnson to design and engrave plates to accompany Wollstonecraft's Original Stories from Real Life (first published by Johnson in 1788), images that "offer a pervasive criticism of Wollstonecraft's

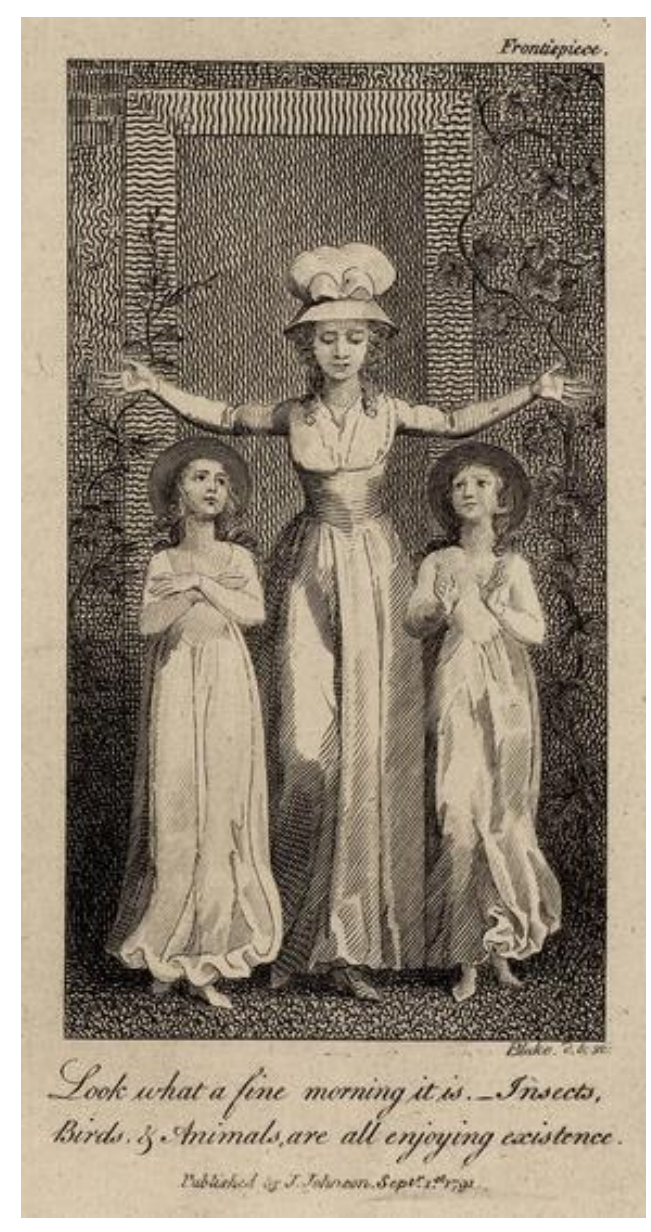

Figure 17. William Blake, engraving to Wollstonecraft's Original Stories from Real Life, copy 1 , object 1, 1791, Henry E. Huntington Library and Art Gallery

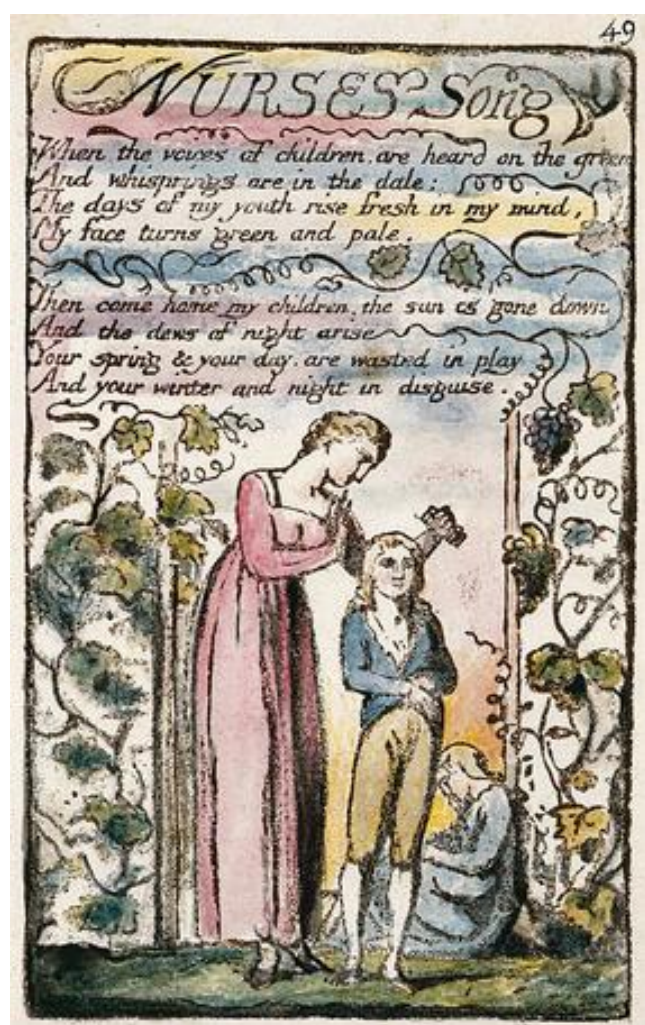

Figure 18. William Blake, "Nurse's Song" from Songs of Innocence and of Experience, copy L, 1795, Yale Centre for British Art. 
feminist doctrines" (Mellor, "Sex" 369). The illustrations betray Blake's antifeminism, Mellor argues, as the looming stance of Mrs. Mason, Wollstonecraft's benevolent governess, mirrors the overbearing nurse in Blake's "Nurses Song" from Songs of Experience (see figures 17 and 18). However, Mellor's defence of Wollstonecraft condemns Blake completely, setting up a polarised opposition that effaces the possibility that his subversion is part of an in-house dispute with as much common ground as divergence.

Beyond this, the scanty evidence about Blake's life at this time has given rise to several speculative connections between him and Wollstonecraft. Some have argued that the Pickering Manuscript poem "Mary" is a portrait of Wollstonecraft (S. Foster Damon, Mark Schorer); some that Visions has biographical roots in, variously, Wollstonecraft's relationship with Fuseli (Robert N. Essick, Alicia Ostriker, Nelson Hilton, Henry H. Wasser), with Blake (Kathleen Raine), or with Gilbert Imlay (Morton D. Paley). Yet speculation over Wollstonecraft's relationships often attempts to 'solve' Blake's text, rather than to enrich it. To regain a fruitful conversation between these two authors, I turn to these two parallel visions of liberation for women: Vindication and Visions.

IV

Changing assessments of the Enlightenment, of the Romantic period, and of the work of both Blake and Wollstonecraft within the 1790s have affected the way in which the relationship between the two is seen. As with criticism of Blake's work in general, gendered divides have haunted scholarly discussion of Blake's debt to Wollstonecraft. Erdman noted the critical tendency to read Visions as "a debate on free love," and that as a result "the poem has been widely explored in the light of... Mary Wollstonecraft's Vindication of the Rights of Woman," but negligibly so in the context of slavery and the abolition movement, a historicisation which Prophet Against Empire provides in brilliant detail (228). 
However Erdman's formulation divides the personal (represented by the alignment of Wollstonecraft with "free love") and the political (represented by the contextual history of slavery) along familiar gender-based lines. Such compartmentalisation was reinforced by critics such as Michael Ackland, who argued in 1982 that Wollstonecraft's “continued influence on Blake's work" in the area of "[Blake's] protracted exploration of embattled sexuality" is "obscured" by the "primarily sociopolitical" emphasis in works of 1793-1795, in which "personae often seem more suited to illuminating the larger historical forces at work in the poet's time than the intricate relationship of the sexes" (172). Visions, he argued, is where "the influence of Wollstonecraft is most apparent" because it "focuses on perverted relationships" (173). Such gendered dualisms between the individual and the social obscure the extent to which Vindication and Visions connect the two. Jason Whittaker, by contrast, notes the "profound effect" of Wollstonecraft's work upon Visions and how Blake (and by implication Wollstonecraft) "move from the specifics of sexual oppression, for example within marriage, to an understanding of the wider extension of patriarchy and power" (par. 4, 6).

For a long time comparisons of Blake and Wollstonecraft have highlighted the divergence between a Blakean liberated sexual energy, and what Kaplan describes as Wollstonecraft's "violent antagonism to the sexual" which "betrays the most profound anxiety about the rupturing force of female sexuality" (22). Taylor argues that in Wollstonecraft's case this is both "clearly right" and "must nonetheless give pause" (117). Wollstonecraft's distancing of the sexual body, she suggests, occurs "[a]t a time when the line between vicious and virtuous sexual behaviour in women, particularly middle-class women, was becoming drawn so rigidly that even to admit to sexual feelings was to risk disgrace” (118). This danger, in addition to the "prosaic experience of too frequent pregnancies, hazardous births... and venereal disease," and the general shallow narcissism that characterises the 'Woman' of Vindication in her conditioned ignorance, led Wollstonecraft to advocate for her renewed, authentic modesty, which functions 
as much as Jacobin anti-elitist attack as it does as a utopian plan for both women and men (118-121).

Taylor's even-handed exploration stands in nuanced contrast to the characterizations of Wollstonecraft as a sexual puritan, overshadowed by Blake's superior commitment to free love. Ackland, for example, asserts that "while Visions and Vindication are remarkably similar in their critique of debilitating sexual roles... . [Wollstonecraft's] conservative views, which tend to separate and repress basic human needs, are ruthlessly exposed in Visions of the Daughters of Albion" (172). Michael Ferber speculates that "[w]hat one would bring away from a close comparison, I would guess, is the feeling that Wollstonecraft was the braver soul... while Blake was the more profound and revolutionary thinker whatever his unsound tendencies" (112), while Nelson Hilton, arguing that Visions allegorises Wollstonecraft's relationship with Fuseli, concludes that "Oothoon finally cannot connect or develop because cut off by the impenetrability (or cunning) of history manifest in the psycho-cultural contradictions within Mary Wollstonecraft” (102). More recently, John C. Hampsey insists that "Blake's 'correction' upon Wollstonecraft is certainly not a sexist one... he is not so much attacking Wollstonecraft as taking aim at any theology that restrains sexual expression" (100). I examine these divergent understandings of Blake's sexual freedom in detail in the following chapter. Robert N. Essick regrets that Wollstonecraft's “passion for Fuseli and later, her unhappy affair with Gilbert Imlay hardly seem consistent with the rationalist views she propounds" (46). Biographical readings of Wollstonecraft have persisted long after Blake ceased to be read in this way, an indication of the potential of gendered assumptions to distort critical comparisons. Such readings of Wollstonecraft as "a would-be rational formalist who denied that conditions of embodiment are constitutive to reason, and as a woman who struggled unsuccessfully to reconcile her commitment to reason with a torrid emotional life," are, as Simon Swift observes, "deeply patronizing," and have been challenged both by feminist scholars and other recent scholarship (5). 
From a feminist perspective, Mellor emphasised the pragmatism of Wollstonecraft's position, but reversed and sharpened the value judgements, condemning "free love of the kind here envisioned" as "a male fantasy that serves the interests only of the male libertine" ("Sex" 367). Mellor insists on Blake's misogyny and intellectual inferiority to Wollstonecraft, but the characterization of Wollstonecraft as a disembodied rationalist remains in place, and the ahistorical perspective on Blake's depiction of sexuality is left unchallenged.

Recent scholarship has offered alternatives: studies such as Taylor's have "re-placed [Wollstonecraft] in an historical context which is no longer understood to be grounded in an implacable conflict between reason and sensation" (Swift 6); and studies of Visions have reframed the poem as "primarily a protest against the sexual customs of the times," and "a revolutionary critique of sexual and social exploitation" rather than a 'free love' fantasy (Bruder 55, Aers 33). The rediscovery of how "[s]ex pervades the Rights of Woman" (Taylor 116) and the refusal to read Visions as a paean to universal 'love,' together suggest that inquiry into a socially embodied 'modesty' is far from exhausted. Taylor records Wollstonecraft's errant lover Imlay writing "self-exculpatory remarks...about the moral superiority of an unconstrained sexuality," to which Wollstonecraft replies, if this "theory of morals is the most 'exalted'," it is also "certainly the most easy...to please ourselves for the moment, let others suffer what they will!" (234).

Williams argues that both Blake and Wollstonecraft's exposure of the social conditioning that produces "hypocrite modesty," can be seen as a form of incipient ideology critique (Visions 6.16). However in the process Williams accepts how Vindication "castigates its female readers in the harshest terms for classic feminine follies... [including] cunning” (Taylor 12). As discussed above, Wollstonecraft's indictment of women is a "scathing attack[...]," Williams concedes, "often indistinguishable from the attacks of the leading misogynists of the day" (78). However rather than illustrate, in Taylor's formulation, "that women are coerced into this debilitated condition by a male-dominated society" (13), Williams uses Blake's concept of the manipulative "Female Will" to defend 
Wollstonecraft's indictment of female cunning, as "like Wollstonecraft, Blake sees the actual power hidden behind a mask of feminine weakness" (78). Williams' Rousseauian description of "the cunning power which women possessed in a culture which established them as the gatekeepers of sexuality" uses the potentially misogynist troping of one author to validate the similarly questioned images of another (93). ${ }^{2}$ Statements such as these substitute an awareness of broader structures of power with a vague sense of personal grievance, which undermines the argument for Blake's utopian pre-eminence over Wollstonecraft. Clearly our current structures of gendered behaviour and sexual double standards warrant careful investigations. With Wollstonecraft's negotiations with modesty and sexual difference in mind, and a sense of the comparisons made by others, let us turn to Blake's Visions.

In most copies of Visions, the first page is the confrontational frontispiece, where we immediately encounter the bodies of Blake's characters. The physicality of Theotormon's self-bound huddle, and Bromion's overmuscled form, “[b]ound back to back" with Oothoon's wilting paleness, take us directly to sexual difference (2.5). In contrast to the strategic deployment of disembodiment discussed above, Blake's image relies upon the viewer to use their "infinite brain" to celebrate physical difference (2.32). Whether Oothoon's bowed posture and eyes downcast eyes are indicative of an essentialist vision of feminine submissiveness remains to be seen.

Across on the title page, a female figure advances over a stormy seascape, arms outstretched in an ambiguous gesture of joy or terror, perhaps fleeing the fireclad Urizen-like figure above. The key 'V' word and syntax of the title suggests

\footnotetext{
${ }^{2}$ For discussion of the 'Female Will,' see Susan Fox, “The Female as Metaphor in the Poetry of William Blake."
} 
a familial relationship with Vindication, an impression which sharpens as the poem develops (Essick 34).

The text of Visions opens with "The Argument," eight lines of verse where a clear voice-we can assume it is Oothoon's-expresses herself strongly. Her declaration that "I loved Theotormon | And I was not ashamed," is a courageous statement of initiative-a realm banned to women, as we have seen-combined with a defiant refusal of shame. Yet this awareness of transgression is also a sign that proprieties have been incorporated, and in the next line she ambiguously names them as her own: "I trembled in my virgin fears" (3, my emphasis). Trembling evokes both desire and anticipation-"she who burns with youth" (5.21) - and fear, arising both from internalized female standards of modesty, which Wollstonecraft calls "innocence, as ignorance is courteously termed" (113), and an external sense of sexual threat that proves well-founded. This sense of both diffidence and desire is reflected in the figure's stooped pose, where she either covers or holds her breasts, leaning into the small figure in the flower. She actively "pluck[s] Leutha's flower," choosing to embrace sexual experience and "rose up from the vale" (7-8) echoing the rays radiating from the flower, part of an ongoing pattern of rising sun imagery.

However in what seems like direct retribution for claiming sexual autonomy, she is raped by "the terrible thunders" (Argument 7). The semicolon pivot between the halves of the stanza implies a disturbing cause and effect relationship between her escape from arrested development and the ensuing experience of brutality. This force "tore" her "virgin mantle" "in twain," suggesting binary division and violence.

The sexual violence appears as both elemental and naturalised, perhaps referenced by the threatening clouds down the right of the title plate, yet at this point still faceless. This and the plural of "thunders" is worth keeping in mind, as Oothoon's later insight moves beyond criticism of her rapist as an individual to indict the wider sexual ideology he represents. As David Aers argues, "the sexual 
situation [in Visions] is an integral aspect and product of a society structured on principles of division and domination" (29). Yet the narrator's description of the violence suggests it was perpetrated on an isolated part of her, significant given later suggestions of dissociation from her body. This could be why her sexual vision and first person narrative ceases at this point. Blake's reversal of the generic convention of a disembodied prose summary Argument (as in Paradise Lost, for example), in favour of a short, subjective verse, whose narration is nonetheless crucial to our understanding of what ensues, reinforces both female agency and the embodied individual. This revaluation is also implied by the ambiguous syntax of the title: it suggests not only 'visions' featuring Daughters, but also that the 'visions' are those reported by a traditionally unauthoritative source, the daughters of Albion.

The large "Visions" heading the poem's body is entwined with the emphasised first word, "Enslav'd," connecting questions of perception with those of subjugation, and introducing the multiple axes of oppression the poem indicts. "Enslav'd" invokes slavery and abolition, to the fore of the popular British imagination at the time. Yet as with the characterisation of women as "convenient slaves" that pervades the Vindication (68), here it is the "Daughters of Albion," the local women of England, who are enslaved, echoing the "mind-forg'd manacles" of "London" in the Songs of Innocence and of Experience (E27). Taylor argues that this polemical alignment is a "commonplace of pro-woman writings since at least the mid seventeenth century," based on the classical trope of citizen/slave (226). Wollstonecraft clarifies that "[w]hen, therefore, I call women slaves, I mean in a political and civil sense" (167). However she does reference the British slave trade, asking "Is sugar always to be produced by vital blood? Is one half of the human species, like the poor African slaves, to be subject to prejudices that brutalise them, when principles would be a surer guard, only to sweeten the cup of man?” (215). Throughout Visions, Blake similarly entwines colonial, sexual, and ideological violence, depicting a "vicious colonization of the body," in Stephen Vine's words (42). 
Throughout Visions there is an interplay between the literal shackles that restrain the illuminated figures, and the figurative enslavement that leads to the stasis of the frontispiece tableau. As the poem progresses, religious institutions, capitalism, patriarchy, child labour, colonialism, the slave trade itself, conventional education, politeness, dependent relationships, monarchy, material greed, marriage, and scientific materialism are all depicted as forms of bondage or slavery. The overarching enquiry into the logic of domination common to these practices is carried out by Oothoon in her response to the retribution she faces as a sexually aware woman.

The narrative confirms Oothoon, the "soft soul of America," as the voice of the Argument. Oothoon's name is a Blakean creation of Ossianic mythology, personification of America as continent and country, with long vowels evocative of the African names which Blake would have encountered whilst illustrating John Gabriel Stedman's first-hand account of slavery and colonisation, The Narrative of a Five Years Expedition against the Revolted Negroes of Surinam (1796). ${ }^{3}$ Oothoon is all of these and none: she is individual psyche responding to patriarchal violence, female slave, rejected lover, prophet in the wilderness. Yet despite these multiple identity markers, Oothoon has a human solidity that marks Blake's lyrical, generic divergence from Wollstonecraft's prose polemic. Whereas Vindication seeks to "speak collectively of the whole sex" (95), Blake embodies the totality in one subjectivity, evoking the later passage in Jerusalem where Los cries in a vision of divine immanence that "he who wishes to see a Vision; a perfect Whole | Must see it in its Minute Particulars" (91.20-21, E251). Oothoon is a "Minute Particular" who, in Blake's presentation, reveals the totality through her embodied experience. As discussed above regarding Wollstonecraft's conception of autonomy, Blake's Oothoon is only able to be this paradigmatic figure to the extent that she gradually embodies Blake's conception of divinity, rather than a liberal individualism. Her opposition to homogenisation is 
expressed when she asks "How can one joy absorb another? are not different joys | Holy, eternal, infinite!” (5.5-6).

Initially, Blake does not depict an Edenic virginity in Oothoon: instead, as in Songs of Innocence, he creates a character in a potentially dangerous state of ignorance rewritten as innocence by institutional power. The Daughters are already "enslav'd," Oothoon is in "woe," searching for "comfort": we know from her 'Argument' that she loves Theotormon, but does not know what to do about it within her sheltered "Vale" that denies her sexual agency or knowledge (1.1, 1.35). This is one way of looking at Wollstonecraft's insistence on Reason, as a way out of the enforced ignorance that left young women vulnerable.

In the narrative expansion of the Argument, Oothoon converses with the flower-nymph Marygold, who encourages her to recognise and act upon her desire, "because the soul of sweet delight | Can never pass away." (1.9-10). In other words, and in contrast to the commodifying sexual mores of the time, women's sexuality belongs to the realm of experience. Catherine Macaulay, a profound influence on Wollstonecraft, had attributed sexual double standards to "women having been considered... mere property of the men...[with] no right to dispose of their own persons" arguing that contrary to those who saw sexual experience as ruining a woman's morals for ever, "no such frail beings come out of the hands of Nature. The human mind is built of nobler materials than to be easily corrupted" (qtd. in Taylor 120). But she and Wollstonecraft, who endorses this position in the Vindication, were lone voices in daring to argue anything even vaguely similar. Blake emphasises the physical, intentional nature of Oothoon's transgression- "thus I turn my face": away from prevailing codes of conduct, and towards "where my whole soul seeks" (1.13). Like Wollstonecraft leaving England for revolutionary France, Oothoon sets off "over the waves... in wing'd exulting swift delight," her "impetuous course" implying the confident spontaneity of Blake's valorisation of impulse over rules (1.14-15). Wollstonecraft's position in the Vindication is more ambiguous: she places a high value on self-control, describing the "vulgar" as "creatures of ... impulse" (16). 
The figure running freely across the waves on Blake's title page looks up towards menacing elements: it is "Theotormon's reign" that she travels over. Taylor writes " $[\mathrm{t}] \mathrm{o}$ live as a free woman in an unfree world was impossible, Wollstonecraft discovered” (202). Almost instantly Oothoon faces aggression: "Bromion rent her with his thunders," an image which evokes rape and division. The troublesome equation of rape with the naturalised image of the thunderstorm, suggesting that rape is as impossible to prevent as a storm, is now qualified by the named figure wielding this force. Yet he is still an elemental force, his name usually glossed as 'Thunderer,' or 'roarer' (Essick, 42). This ambiguity could reflect the paradox that even though standards of propriety have been socially constructed, they also possess an almost elemental force.

Bromion's violence reveals the ambiguity of the physical body. In Vine's terms, "[t]he body as a site of desire and possibility becomes, in a terrible inversion, the body as a site of domination and subjection" (43). This is the first moment at which Oothoon's description- as "faint maid"-evokes the bowed figure of the frontispiece. Daring to transgress sexual proprieties, she has been punished into a more conventional submissive femininity. Bromion invites Theotormon, the reader, and the world at large to "behold this harlot," and blame his victim (1.18). His justification reveals how this appropriative ideology spans diverse forms of violence:

Thy soft American plains are mine, and mine thy north and south:

Stampt with my signet are the swarthy children of the sun:

They are obedient, they resist not, they obey the scourge:

Their daughters worship terrors and obey the violent:

Now thou maist marry Bromions harlot, and protect the child

Of Bromion's rage, that Oothoon shall put forth in nine moons time. $(1.20-2.2)$

The repetition of "mine" and "my" illustrates that Oothoon has been recast as property, echoing Stedman in his Narrative, who upon marrying Joanna, an 
enslaved Surinamese woman, crowed: "She was all mine!" (Erdman 27). “Thy" initially seems to refer to Oothoon, but the speech is addressed to Theotormon, with Oothoon handed down as an assertion of one male's precedence over another. In Luce Irigaray's formulation: “women exist only as an occasion for mediation, transaction, transition, transference, between man and his fellow man, indeed between man and himself" (192-3). Oothoon's loss of 'purity' is a crime whereby Bromion steals Theotormon's property, rather than an assault upon Oothoon as a subject. Bromion gives permission for Theotormon to marry Oothoon, knowing full well that without her virginity, she is worthless for the marriage transaction. Colonial lands, the enslaved, women- all appropriated as an extension of Bromion's ego, "fungible commodities... for establishing power relationships among competing males" (Essick 44). This objectifying process occurs both through discursive branding as a "harlot," and physical branding: slaves are "Stampt with my signet." The reference to signet ring seals, used to frank letters, evokes the passage in A Midsummer Night's Dream (a text which haunts the Vindication), where Hermia's father and Theseus, the Duke of Athens, discuss Hermia's future:

EGEUS. As she is mine, I may dispose of her;

THESEUS. What say you, Hermia? Be advised, fair maid,

To you your father should be as a god:

One that composed your beauties, yea, and one

To whom you are but as a form in wax

By him imprinted and within his power

To leave the figure or disfigure it. (1.1.47-51)

Like Wollstonecraft's reflexive, self-alienated women, Hermia should be infinitely shapeable by her 'maker' and owner, until she can be transferred to the ownership of a husband.

This reduction of a woman to sexual value-"the rich worth of your virginity" (MND 2.1.19) - drives both Blake and Wollstonecraft's attacks on 
sexual morality. Both are radical by insisting upon worth beyond virginity and by locating the "ruined" woman within a far wider culture of objectification and appropriation. Any such critique goes against the language of appropriation, formed over centuries: the word 'rape,' despite originally meaning "forced sexual intercourse," came to signify the literal theft or abduction of a woman (OED n3.3) and "The act of taking something by force; esp the seizure of property by violent means; robbery” (n3.1 ). Similarly, 'ravish,' in extended use, meant “to spoil, corrupt (a thing)" (OED 1c). The root of the word is the Middle French ravir, signifying among other meanings "to plunder, rob, steal (something), to seize (something) as plunder" (OED). The recurrence of the word 'thing' in these etymologies is no coincidence.

Oothoon's challenge to this objectification places Blake's poem in significant divergence from generic literary portrayals of rape. Framing women as 'things' meant that portrayals of rape were in some ways more socially acceptable, compared to today. Shakespeare's The Rape of Lucrece frames rape as an unforgiveable crime, that cannot be blamed upon Lucrece:

For men have marble, women waxen minds,

And therefore are they form'd as marble will;

The weak oppress'd, the impression of strange kinds

Is form'd in them by force, by fraud, or skill:

Then call them not the authors of their ill,

No more than wax shall be accounted evil

Wherein is stamp'd the semblance of a devil. (1240-1246)

They cannot be "the authors of their ill" because they cannot be the authors of anything: absolution comes at the price of any kind of subjectivity or agency, and however tragic, the only honourable path for such a woman is death. This was the non-negotiable fate of Lucrece, and also of 'Oithona,' Macpherson's Ossianic heroine from whose story Blake took many of Visions' details. Bromion's 
objectification of Oothoon, contrasted with Oothoon's insistence on her own purity, show Blake's rejection of this tradition.

Wollstonecraft aligns the patriarchal "impression" of women's identities with the appropriation of their bodies. Vindication, but especially Maria, portray sexual violence as an expression of entitlement to women's bodies which is on a continuum with gendered objectification. The rhetorical weight falls on women, but the indictment is of the entire culture, not just isolated incidents or individuals. Prostitution, Wollstonecraft argues, arises from how "women are... taught to look up to man for a maintenance, and to consider their personas as the proper return for his exertions to support them" (140) This commodification "gives force to the prevailing opinion, that with chastity all is lost that is respectable in woman. Her character depends on the observance of one virtue, though [ie, even if] the only passion fostered in her heart - is love” (140). Wollstonecraft considers Lovelace's claim to Clarissa that he has robbed her of her honour, and concludes that it cannot be so, for "miserable beyond all names of misery is the condition of a being, who could be degraded without its own consent" (141). Her argument is not that Clarissa must have consented to sex, but that the label of degraded is unfairly applied. This position rejects dominant narratives such as Rousseau's, who wrote:

the most delightful circumstance a man finds in his victory is, to doubt whether it was the woman's weakness that yielded to his superior strength, or whether her inclinations spoke in his favour: the females are also generally artful enough to leave this matter in doubt. (qtd. in Wollstonecraft 148)

"I may be allowed to doubt whether woman were created for man," is Wollstonecraft's cautious response. Rousseau's words and Wollstonecraft's objections demonstrate the extent to which, in psychologist Nicola Gavey's words, "rape can be seen as simply an extreme act at one end of a continuum of heterosexual coercion (62). 
In Bromion, Blake creates a related challenge to norms of feminine submissiveness. In his muscled caricature of sexual difference, Bromion counteracts the rhetoric of those who connected a love of "riches and ease" (Visions 4.21) with effeminacy. Bromion justifies his actions by invoking the response in those he oppresses-"they resist not," therefore they must be naturally passive. Wollstonecraft condemns this kind of essentialism whereby "superficial reasoners... term that weakness the cause, which is only the consequence of short-sighted despotism" (Maria 167). Rather than happily "obedient," gentleness is "forbearing, because it must silently endure injuries; smiling under the lash at which it dare not snarl. Abject as this picture appears, it is the portrait of an accomplished woman, according to the received opinion of female excellence" (Vindication 102). This argument is central to Wollstonecraft's case: that women may be very bad, but are only made so by their conditioning, the very systems deemed necessary to manage their 'natural' badness.

Bromion's boast of a "child" of his "rage" evokes the modern recognition that rape is caused by a dynamic of control, enacted as sexual violence, rather than an overflow of lust (2.2). Wollstonecraft, by contrast, insists throughout the Vindication that men's (and women's) depraved appetites are to blame, leaving her conception of Reason as a controlling force over the untrustworthy body.

Bromion's view of Oothoon as Theotormon's property means that his crime is against Theotormon, not her. Theotormon's reaction, as "storms rent [his] limbs" (2.3), refigures the rape as Bromion's "storms" tear him apart with jealousy. He can no longer enhance his own worth through possession of Oothoon, and so "folded his black jealous waters around the adulterate pair | Bound back to back in Bromions cave terror and meekness dwell” (2.4-5). Theotormon's acquiescence to Bromion's violence causes him to bind Oothoon and Bromion together. He believes that Oothoon is permanently tainted by Bromion and so forever tied to him. "Bromions cave" indicates that this imprisonment stems from Bromion's bigoted perceptions, echoing Blake's belief that "man has closed himself up, till he sees all things thro' narrow chinks of his 
cavern" (Marriage E39). Bromion and Oothoon are bound back to back by Theotormon's resentment, but unable to communicate with each other, as the speeches which comprise the majority of the remainder of the poem reveal. Oothoon remains an object in their perceptions throughout.

Blake's description of Bromion and Oothoon in Visions as "Terror and meekness" evokes Wollstonecraft's nemesis Edmund Burke's concept of the 'sublime' masculine, dominating principle, in contrast to the 'beautiful' feminine, submissive principle (2.5). By embodying abstract masculinity in Bromion's specific form, Blake undermines conventional dualisms of male and female, exposing their socially constructed nature. The categories lose ahistorical stability as we see that in the frontispiece, Bromion appears terrified, rather than terrifying, and "meekness" becomes suspect in the wake of Bromion's speech essentialising "obedience" as a quality of those whom he forces to submit. Meanwhile, Theotormon guards at the cave's mouth, "wearing the threshold hard | With secret tears" (2.6-7). Immobilised by victimhood, he is cut off from the sensory in a "self-enclosed fetal ball" (Heffernan 9). His grieves, but only from self-pity, and his tears are "secret," like the "dark secret love" of "The Sick Rose," because he rejects bodily emotion in favour of ascetic evangelicalism. He embodies the idealism of sexual purity and its direct fallout of arrested development for everyone. This is the position Blake aligns with conventional religion, the "Priests in black gowns" whose doctrines are "binding with briars, my joys \& desires" (“Garden of Love” E26). “[B]eneath” Theotormon, ignored, can be heard ignored oppressed voices: slaves, and child labour. His repression is shown to be actively complicit, as the cause is traced back to "the burning fires $\mid .$. [at] the summits of the earth" (2.9-10).4

Bromion and Theotormon emerge as complementary aspects of Urizenic sexual conventions, inverted symptoms of the same cultural norm that commodifies both female sexuality and women themselves. Bromion would not

\footnotetext{
${ }^{4}$ I examine this portrayal of religious transcendence in detail in the following chapter.
} 
feel the same thrill of the chase if what he was chasing was not valued, and Theotormon would not value 'purity' so highly if there was no one preying upon it. Similarly, Helen Bruder argues that conduct books and pornography are flipsides of the commodification and control of women's sexuality by men, as “[m]any...writers seem to have felt that there was something unspeakably destabilising in women's erotic potential, and modesty was constantly invoked as a charm against this" (60). She believes that "the most significant aspect of Visions is that it seems to find Blake engaged in the difficult task of trying to unmask these fears, and challenge the validity and necessity of the repressive sexual defences which grew out of them" (60).

Oothoon's response to Bromion's attack partially explains the abrupt end to the Argument: her emotional embodiment is lost, for "she cannot weep! her tears are locked up" (2.11) Her self-alienation mirrors Theotormon's "secret, fearful” (6.17) self-enclosure, however this attempt to escape the body, like all attempts at abstraction thus far, only increases physical suffering, causing her body to "howl" and "writh[e]" (2.12).

Oothoon attempts to respond to her enforced powerlessness by regaining control over her body, but her alienation causes her to continue the violence against it. She calls upon "Theotormons Eagles," who by connection with him harm the body in their pious attempt to erase it, to "prey upon her flesh" (2.13). Conventional morality's dualistic violence is invoked through her "holy voice," with which she asks the eagles to "Rend away this defiled bosom" (2.14-15). The repetition of "rend" restages the rape, as she harms herself with the doctrine of mortification learned from Theotormon. Divided into dualistic body-denigration, she believes herself defiled, and by pursuing Theotormon's construct of 'purity'aiming to "reflect [his] image" (2.16)-she perpetuates the cycle of violence.

Fred Hoerner uses Marx's aphorism that "men make history, but not in conditions of their own choosing," to argue that "Oothoon can exploit the resources of the discourse that enslaves her" (120). Embodying a series of 
destructive ideologies she has been taught to live within, each one progressively falls away under the pressure of its own contradictions, once implemented and questioned. Despite their destructive nature, the obedience of the eagles to her call gives us a continued sense of her agency as she struggles to regain control over her body. The inescapable corporeality of theory, Aers suggests, means that every "reasoner reasons" in a context, and the pretence not to will have certain material results (28). This becomes evident as Oothoon's desire for a "pure transparent" breast becomes a further "ren[t]" and "bleeding" body (2.17). By attempting to live within Theotormon's logic, she reveals the doctrine of purity in all its hypocrisy, demonstrating how "structures only exist as they are instantiated or... voiced," an empowering act that places responsibility back onto bodies. This embodiment of his ideas provokes Theotormon sufficiently that he "severely smiles" (2.18) revealing his "purity" as sadism, yet Oothoon's "soul reflects the smile," hopeful, yet still reflecting him rather than accessing her own impulses.

In response to Oothoon, the first punctuating 'chorus' of Daughters "hear her woes," but only “eccho back her sighs" without offering solutions or reassurance (2.20). Their impersonal group identity and fearful echo suggest the broader function of Bromion's violence: to police Oothoon's transgression of passivity, but also, by making an example of her, to monitor behavioural standards for women in general. The daughters do not need to be similarly treated, as they will now police themselves. The huddled figures on plates 7 and 8 embody the broader gendered subordination that Oothoon's individual treatment enforces. Their failure throughout the poem to provide any meaningful support or emulation of Oothoon leaves her exposed in much the same way that Wollstonecraft eventually was. Offering sympathy rather than solidarity, the Daughters of Albion cannot help Oothoon escape.

Yet the daughters' support, however faint, somehow encourages Oothoon to question Theotormon's self-pity. She still addresses herself to him, but her imagery, echoing the Song of Songs, turns on figures of change, new dawn, and 
renewal. This culminates at line 28 where she declares: "Arise my Theotormon I am pure.” This is a definition of purity outside of the realm of commodified virginity. It is part of Oothoon's antinomian drive to find a renewed sense of selfworth outside of the social narratives that tell her that she is ruined. Similarly, Wollstonecraft's emphasis on inner conscience allowed her to brave sexual scandal: in response to being 'dropped' by friends shocked at her relationship with Imlay, Wollstonecraft would point out she was "conscious of [her] own purity and integrity" (qtd. in Taylor 196).

Oothoon is still tied to Theotormon's ideology by her reliance on his approval, pleading "Silent I hover all the night, and all day could be silent. | If Theotormon once would turn his loved eyes upon me" (3.14-15). But she then demands, "How can I be defild when I reflect thy image pure" (3.16). Conscious of her immanent purity, she exposes the hypocrisy of Theotormon whereby he values a "pure" soul, but relates to Oothoon only as a "defild" body.

Oothoon then gives a series of examples of temporary contamination and inner purity which have troubled some critics.5 Perhaps it is useful to briefly examine some of Blake's conceptions of cause and effect within suffering. He wrote "a blight never does good to a tree" (E737), condemning the church doctrine that suffering was spiritual growth. However he also wrote "Understanding ... is not natural to Man it is acquired by means of suffering \& Distress i.e. Experience” (Annotations to Swedenborg, E603). Together, these statements suggest that "Understanding" is something a person may acquire, through transforming their experiences into embodied knowledge. This is not to endorse a fortunate fall. Returning to Oothoon's words, it seems possible that in spite of violence and sexual double standards, she has been able, through her own efforts, to access a sense of self that cannot be "defild". 
The next chapter will discuss with Theotormon and Bromion's 'replies,' as indictments of idealist and materialist practices. In the face of two kinds of disembodied misreadings of her words, Oothoon waits "silent all the day, and all the night" (4.25). With the dawn she begins again her "lamentation" (5.1), which spurs the Daughters to again "eccho back her sighs" (5.2). Encouraged, Oothoon leaps to her next insight, connecting Bromion's and Theotormon in the realisation that they are both "form[ed in the] image" of "Urizen" (echoing Genesis 1.26), a "mistaken Demon" representing the isolated, dualistically divided faculty of reason, worshipped as the only worthwhile capability (5·3-4). Oothoon recognises that Urizenic thought is unable to engage with particulars or subjective bodies, attempting instead to make "one joy absorb another" (5.5) through abstraction, characterised by either incorporation or exclusion of the Other. She attacks oppressive doctrines by questioning once again what they look like as embodied relations, questioning the perception of the "fat fed hireling with hollow drum; | Who buys whole corn fields into waste," and the unsensing "parson" whose puritanical "nets \& gins \& traps" create "cold floods of abstraction" (5.14-15, 5.17-18). Wollstonecraft has been charged with the latter, but she similarly criticised "metaphysical sophists and cold mathematicians" (Rights of Men 15). This ideology is revealed to pervert marriage, as "she who burns with youth" and desire is forced by the all-powerful, made-up "spells of law" to go through the marital motions "in weary lust," "bound" to mechanically "turn the wheel of false desire" (5.21-27). The breadth of Oothoon's accusation reveals that all institutions are corrupt when in service to Urizen-"whose code separates bodies from souls and reduces women and children, nations and lands, to possessions" (Erdman 228). Oothoon shows sympathy not only for the "shrinking shoulders" of the abused wife, but also for the "wintry rage | Of a harsh terror driv'n to madness, bound to hold a rod" of the husband. Blake's ambiguous syntax suggests violence driven by terror, as well as tyranny expressed in violence, where both suffer (5.24-26). The language of slavery-“chain,” "bound," the violent, phallic "rod," "shrinking shoulders" and the laborious work of "turning the wheel"-presents a grim picture of patriarchal marriage and the 
"abhorred births" of reproductive labour, shown as "a system of psychic and economic exploitation” (Essick 56). In Wollstonecraft's Maria, the eponymous heroine tells how a terrible marriage "had bastilled me for life" (146). Wollstonecraft's oft-criticised vision of platonic marriage must be read in relation to her argument that some men marry in order to then "seduce their own wives," who being naturally submissive and legally owned, are always available (141). This suggests marital rape, which was not recognised as a crime in many countries until the late $20^{\text {th }}$ century. Emma Goldman wrote in 1911 that "Mary Wollstonecraft came into the World at a time when her sex was in chattel slavery: owned by the husband while at home and passed on as a commodity to her husband when married" (115/10). Yet Blake's repetition of "bound" in reference to both husband and wife shows how, within this ideology, no-one wins. This is echoed on the facing plate, where the male figure raises a whip that resembles the Marygold of sexual experience, while the female hides her face in her hands. He is both beating himself and threatening her: the image suggests both.

Oothoon challenges this system that seeks to "inclose [her] up" (2.31) by returning to the animal world, describing the richness of diverse, unequivalent forms of being. Each of these animals has an intuitive identity, she says, undermining the idea that morality or rules can come from external impositions of authority, as this would be as unnatural as a whale panting at human feet like a $\operatorname{dog}(5 \cdot 33)$.

Oothoon then describes the "infant joys" of human sexuality free from impositions of authority as "fearless, lustful, happy... . honest, open," aligned with the "morning light" of dawn. This spontaneous innocence, Oothoon says, is compromised by the indoctrination of "subtil modesty" $(6.4-5,6.7)$. Like Wollstonecraft's authentic modesty, true innocence must be "honest" rather than the people-pleasing of "a modest virgin knowing to dissemble" (6.10). Such a one has been perverted by a culture which takes "virgin joy" and "brand[s] it with the name of whore," replacing the inner fires of "honest morn" with the artificial modesty of "smoky fires," second hand from "religious dreams and holy vespers" 
(6.11-15). "And does my Theotormon seek this hypocrite modesty!” she concludes, disbelieving, realising she would need to be "artful, secret, fearful, cautious and trembling" to meet the standard (6.16-17). She rejects this system of morality for women, arguing that if that is what modesty looks like, she would rather be a "whore" (6.18-20). Oothoon recognises the complicity of language in systems of power, and thus radically redefines "virgin" to mean "open to joy and delight" (6.21-22). She then also co-opts "copulation," redefining all vision as synaesthetic and erotic: "where ever beauty appears |... there my eyes are fix'd | in happy copulation" (6.22-4).

Oothoon's reclamation of language "frustrates all attempts to categorise her," writes James Heffernan, as it "will not fit the categories of possession and opposition that we customarily use to define ourselves and our relation to others" (18). By exposing hypocrisy, Oothoon mocks how religious "self-enjoyings of self denial" create the secretive mastubatory practices they condemn. Hell's proverb states "Brothels [are built] with bricks of Religion" (Marriage, E36) and the irony is the same.

Oothoon's attack on Urizen as the "Father of Jealousy" (7.12) condemns Theotormon, Bromion, the church, and others, whilst recognising that her oppressors themselves were indoctrinated, and that Urizen's system keeps them in chains as well. This is characteristic of how she "challenges all binary oppositions" (Heffernan 6), a characteristic that makes it very difficult and unrewarding to read the poem through a dualistic or binary lens. Yet as Oothoon finds, this way of thinking is bound up in our language, and very difficult to escape. Wollstonecraft, similarly an "Iconoclast of the false Gods" (Goldman 115/10), faced this as lived reality. Blake's heroine's inclusive approach finds her "wailing on the margin of non-entity," pre-empting the appearance of the word "marginalised" in 1970, (OED), a description as apt for Oothoon as it is for Wollstonecraft's final heroines, Jemima and Maria, who are described as "outlaws of the world" (x). This marks the most dissected and least understood part of the poem, where Oothoon cries "Love! Love! Love! happy happy Love!” (7.16). 
This rhetorical excess can be read as ecstatic enthusiasm, as Oothoon has passed through the dark night of that "non-entity" imposed by social conventions (7.15). She rejects the jealous, greedy love "that drinks another as a sponge drinks water" and the "self-love that envies all" of Theotormon (7.17-21). It is Theotormon's warped idea of love that "clouds with jealousy his nights," not her. However for many critics her radical alternative to jealousy compromises the liberated quality of her rhetoric thus far:

But silken nets and traps of adamant will Oothoon spread, And catch for thee girls of mild silver, or of furious gold;

I'll lie beside thee on a bank \& view their wanton play

In lovely copulation bliss on bliss with Theotormon:

Red as the rosy morn, lustful as the first born beam,

Oothoon shall view his dear delight, nor e'er with jealous cloud

Come in the heaven of generous love, nor selfish blightings bring. $(7: 23-29)$

Oothoon becomes a procuress and a voyeur, offering to catch "girls" for Theotormon and watch their "copulation" $(7.24,26)$. Some have argued that the placement of the passage as an alternative to the jealous "frozen marriage bed" (7.22) means that Blake intends Oothoon's offer to exemplify "happy Love," regardless of whether this impulse is delightful (Bloom, Erdman and other midcentury critics) or deluded (Aers, most feminist readings). The former can't explain the scene's distinctly negative vocabulary: "nets and gins and traps" to "catch... girls of mild silver, or furious gold," and "wanton" (7.23-25) together suggest entrapment, commodification, virginity, servitude, and prostitution. Oothoon has twice indicted "nets \& gins \& traps" (5.18) and "nets" (6.11) as tools of repressive ideology.

If Oothoon has been dragged under by the system she deconstructed, this would explain the juxtaposition of "nets and traps" with (previously positive ) “lovely copulation” (8.23-6, Bruder 82). Perhaps Oothoon's attempt to transcend 
jealousy is a perversion of a valid ideal, a frustrated attempt at emancipation in a Urizenic cultural climate, where repression is hopelessly internalised. But this compromises Oothoon's triumphant culminating insight that "everything that lives is holy," (7.10).

Earlier, Oothoon's described "the crafty slave of selfish holiness" she would have to become to please Theotormon and society (6.16-7-2). She rejected this and instead chooses to redefine virginity, to "Sit on a bank and draw the pleasures of this free born joy." Similarly in the "girls" passage, the opening "But" and the modal "will" indicate that her offer of procurement is a hypothetical scenario, that exposes how hypocritical and shut off from the world Theortormon is. Certainly after this point she no longer addresses him. I am tempted to conclude that her utter rejection of jealousy is meant to be assertive: the radical position of someone who has been objectified herself refusing to own anyone else, an opportunity to show how Theotormon's "selfish blightings," would not have occurred if their roles were reversed. It still does not explain the nets, however.

In the final section we revisit Oothoon's belief that embodied agency can transform experience, for like the "wild snake," she has taken "the pestilence" of brutality and injustice "to adorn [her] with gems \& gold" (8.7). In other words, her insight is not because of her suffering; instead her commitment to growth has allowed her to feel first-hand the contradictions of oppressive ideologies, a perspective which rises above them (in the airborne illustration, literally), with an inclusive vision that proclaims "every thing that lives is holy!" (8.10).

But the ears of the disembodied hear only "wails," and through the socialised filters of those who oppress her, she is a tainted object. These figures may be deluded but nevertheless possess real power. Theotormon cannot see her, only "shadows dire," and the chorus of daughters selectively hear only her "woes," and "eccho back her sighs," rather than responding to her radical critique (8.1113). Blake refuses an improbable narrative of heroic individualism, instead handing Oothoon's insights to the reader, that they may become a more effective 
community for Oothoon. Like Oothoon, Wollstonecraft was left extremely exposed, as “[u]rging emancipation from crippling social conventions, she practiced what she professed-and paid a predictable price for it" (Taylor 202).

VI

Reading Wollstonecraft and Blake together we can see the insufficiency of conventional dualisms to describe their differences. Emotional reason, divine sexuality, rational bodies, embodied logic, utopian particularities: both authors deliberately bring together disparate concepts- sometimes in ways that echo one another, sometimes in direct opposition. Placing their indictments of sexual double standards, and the self-alienation of modesty, against the repressive norms of the 1790 s serves to highlight just how radical both authors were, at this moment of millenarian and revolutionary hopes. The points at which they chafe at one another are conundrums still largely unresolved by contemporary feminisms, and still difficult to gain a clear perspective on from within our own familiarity with many of these historical, oppressive gender norms. These visions from the late eighteenth-century can appear as self-interested calls for individual autonomy. But what Kate Soper suggests is that the "republican quality" of appeals to address injustice beyond individual grievances, has potential to "open... up a less domestic and self-focussed understanding" of broader emancipation $(712,714)$. If modesty is self-interest dressed as pleasing others, then emancipation, both Wollstonecraft and Blake's texts suggest, is bringing together personal enjoyment and embodiment and the greater good-being a radical body rather than having one. 


\section{Embodied Perception and Visions Criticism}

Nay I see that God is in all Creatures, Man and Beast, Fish and Fowle, and every green thing, from the highest Cedar to the Ivey on the wall; and that God is the life and being of them all, and that God doth really dwell, and if you will personally... in them all, and hath his Being no where else out of the Creatures.

The Ranter Jacob Bauthumley, 1650

The Bishops never saw the Everlasting Gospel any more than Tom Paine.

Blake, Annotations to Watson, E619

\section{I}

William Blake's Visions of the Daughters of Albion is an extraordinarily rich poem. The work's challenge to slavery and patriarchy, its position at an approachable threshold to Blake's later prophecies, its inspiring heroine, and its genesis in a politically explosive England, have stimulated great critical attention. As noted already, this attention has spread an exceptionally wide net, resulting, as E. P. Thompson charts, in "a great many William Blakes on offer... most of [which] have some plausibility" (xv). This chapter charts how accounts of the poem have often either isolated or ignored certain passages of the poem, resulting, I will argue, in distortions of possible meaning overall. Robert $\mathrm{N}$. Essick's commentary on Visions, for instance, observes that the epistemological middle section of the poem "delves into some rather obscure eighteenth-century debates over the nature of the senses" and as a result, "does not speak directly to the issues of sex, slavery, and colonialism of central interest to modern commentators" (48). This chapter examines whether this claim can be upheld and considers the implications of ignoring or isolating these passages. Lastly, I propose an 'embodied' reading which aims to find some historically grounded relevance in these so-called "obscure...debates." 
The segregation of the perception-focused middle section (2.21 to 4.24, as bookended by the chorus of the Daughters) from the rest of Visions creates an unhelpful, 'disembodied' split between ways of perceiving and ways of acting. Essick, for example, notes that the shift from "the immediate tyrannies of [Oothoon's] situation" to "the tyranny of the limited senses" may imply "that Blake links them to the same fundamental errors in thought and deed," but does not further explore what this crucial connection might entail (49). Such dismemberment of the poem into 'action' and 'philosophy' parallels larger divisions between ways of reading Blake's work. Nicholas Williams writes of "the war between Blake's socially oriented critics and those who would interpret his poetry as an internally coherent, largely mental and necessarily ahistorical triumph," describing it as "a war between the mental and the corporeal themselves" (1). In the case of this debate, he argues, "Blake stands at one of the busiest intersections in English literature" (xii). Yet this "war" between idealistic and materialistic modes of reading is to some extent played out in Visions itself, where both modes are revealed as complementary aspects of a dualistic epistemology that surprisingly, as I will show, share a denigration of the material realm and the body. Placing the epistemologically-inclined sections in relation to the rest of the poem reveals the connections Blake draws between ways of seeing and their lived expressions. I will also indicate how Blake uses this relationship to criticize specific cultural practices found in his time, anatomizing epistemologies he opposed, thereby "Giving a body to Falshood that it may be cast off for ever" (Jerusalem 12:13). I use the framework of 'Embodied Visions' to reassert the necessary continuity of the poem, and explore, to borrow Peter Otto's phrase, "the fate of the body in a culture of transcendence" (8).

The critical relationship with the dissection of modes of perception in the sections of the poem has shifted over time. Older studies in the footsteps of Northrop Frye or Harold Bloom are more likely to engage with the apparently metaphysical bent of Oothoon, Bromion, and Theotormon, yet their common focus on transcendent 'free love' often depends on the very dualisms that, as I 
hope to demonstrate, the central sections criticize, meaning they were misinterpreted or isolated from the rest of the poem.

Therefore when Jane Peterson wrote in 1973 that "Visions of the Daughters of Albion has not yet been discussed as Blake's portrayal of the problem of perception," the observation was fair, yet her solution did not heal the divide (253). Instead, as in Mark Bracher's "The Metaphysical Grounds of Oppression in Blake's Visions of the Daughters of Albion," the epistemological sections are abstracted, made dominant, and used to insist upon autonomous individual responsibility for all outcomes, which are ultimately based on "the metaphysical decision which one makes" (Bracher 164). Vernon E. Lattin, for example, finds that "the condition of Oothoon's enslavement is her mental attitude" (14). These approaches ignore how Oothoon deconstructs the structures that inculcate such metaphysics to begin with. Relating the centre of the poem to the 'action' will show that 'Urizenic' perception is not merely an unfortunate individual choice made in a vacuum of non-ideological freedom.

Uncomfortable with the implications of Blake as champion of an illusive "sovereignty of the individual" (Bracher 164), more recent criticism began to move away from Visions' exploration of perception. Nancy Moore Goslee in 1990 registers unease with "the way Blake's representations of freedom from enlightenment metaphysics merge with symbols of a more conventional enslavement by gender" (102). Goslee argues that the epistemological sections compromise the more "revolutionary claims of race and gender," by "suggest[ing] that private, metaphysical vision brings about social change" (104). David Blake and Elliot Gruner criticize “[t]he metaphysical registers of Blake's polemic...[which] divert attention away from the suffering which initiates the poem" and are therefore a "retreat from these original social concerns" (26). As we will see, such suspicions can be read as a reaction to the imposition of models of transcendence and idealism onto the poem by earlier critics, founded in a separation from, and often denigration of, the material and the body. Ironically, by avoiding discussion of modes of perception in the poem we miss out on Blake's 
dissection of the forces which made those sections appear distasteful or reactive to begin with.

\section{II}

Before considering how dualistic epistemologies appear in both the critical tradition and in Visions itself, a brief outline of an alternative standpoint may be useful. What follows derives from my reading of Visions, rather than Blake's entire oeuvre (although I have drawn on other works, especially The Marriage of Heaven and Hell), and more investigation would be required to see if it would serve as a way of reading other poems. In some ways this is a conclusion before the argument, but the landscape is subtle and full of pitfalls, and an alternative, 'embodied' vision may help us to negotiate it.

The epigraph to this chapter is drawn from E. P. Thompson's study of Blake's antinomian tendencies, Witness Against the Beast: William Blake and the Moral Law. Working in the tradition of historians A.L. Morton and Christopher Hill, Thompson noted the striking similarities between radical cultures of antinomian Dissent-such as the Ranters-and Blake's idiosyncratic style, and traced the possible transmission of these cultures through to Blake. Subsequent scholarship has both challenged and focused this connection. Keri Davies and Marsha Keith Schuchard disproved Thompson's hypothesis of a maternal Muggletonian connection by discovering Blake's mother's connections with the evangelical Moravian church, yet as Thompson himself writes, his "argument does not stand or fall upon the Muggletonian hypothesis" (106). Hill and Thompson note the prevalence of antinomian currents in the late eighteenthcentury, with "innumerable reprints of seventeenth-century antinomian books and pamphlets" (Thompson 6 and passim, Hill 214-226). John Mee argues that the "conscious revival of ranting ideas" arose from a similar historical moment rather than any direct lived tradition ("Heresy" 43). It is not my endeavour to establish precisely where and how Blake encountered a cluster of immanent 
visions: either way provides a vocabulary and historical grounding to the enriched materialism which Blake's work presents.

Accounts connecting antinomianism in the revolutionary 1650 os to Blake are concerned with the 'enthusiastic' tradition of opposition to all forms of hierarchical authority or 'Moral Law,' especially church and state. In many writings by Ranters, Muggletonians, and others of antinomian persuasion, reliance on inner (embodied) revelation depends upon rejecting any soul/body creator/creation dualism (Thompson 83). The Ranter Laurence Clarkson wrote "till flesh be made Spirit and Spirit flesh, so not two but one, thou art in perfect bondage" (qtd. in Makdisi 97). Morton saw this "radical, quasi-pantheist redefinition of the notion of God" as the key Ranter belief (Thompson 26). Such dissent was taken as a political threat, not as a matter of private concern: Joseph Bauthumley (author of my epigraph) was imprisoned by the state together with other antinomian writers, their works burned, and Bauthumley's tongue bored through (Makdisi 95). Thompson traces how critics like Kathleen Raine, who seek to recruit Blake wholesale to 'The Tradition' (i.e. Behmenism, Neo-Platonism, hermeticism, alchemy), often connect him with religious groups such as the Philadelphians. However, he writes, "the fierce antinomian opposition between our faith and their reason becomes, with the Philadelphians, an opposition between mundane materialism and supercelestial visionary mystery," leading to "the loss of radical attack [and] failing social content" (46). As Edward Larrissy notes, "Blake inverts the values of the occult tradition. He believes that body and soul are one" (33). The "Argument" of the Marriage could be read as an expression of this gradual historical slide of embodied dissent into antimaterialist dualism: once, in the seventeenth-century, "The just man kept his course," creating a "perilous path" which gave an enriched vision of the world"Roses are planted where thorns grow." However "the villain left the paths of [conventional] ease" in order to appropriate the "perilous paths, and drive | The just man into barren climes," where he "rages in the wilds" outside polite acceptance. The "sneaking serpent" usurper of the path now "walks | In mild 
humility," masking conservative quietism with the trappings of spirituality (Pl. 2). Read thus the argument would be an appropriate, historically meaningful opening statement for Blake's attack on dualist epistemologies in the Marriage.

With this in mind, Visions can be read as pointing towards an enriched vision that includes and reanimates the material world and physical senses, rather than to the imposition of imaginary ideals, as critics from diverse dualistic traditions have sought to prove. Blake described this elision in a variety of ways, from the clear statements of "The Voice of the Devil in the Marriage," that "Man has no Body distinct from his Soul," and that "Energy is the only life and is from the Body" (plate 4, E34), to the narrator of Europe who asks his muse, a "fairy," "what is the material world, and is it dead?," to which the fairy promises to "shew you all alive | The world, when every particle of dust breathes forth its joy" (iii.13, 16-17, E60). Such expressions are unequivocally not anti-materialist, yet because Blake condemns the narrowness of a dualised or devitalised vision, and criticises the tendency to "In ignorance... view a small portion \& think that All," many have assumed that what he values is an alternative or 'better,' 'spiritual' perspective (E216). This is often framed as a conflict between 'Accident' (a tiresome material realm or body) and essence or "Substance" (an eternal, imaginative, superior, redemptive internal 'soul' or mind). The words are Blake's, and despite seeming exclusive and antagonistic, it is not helpful to take them this way. "The Little Black Boy" from The Songs of Innocence and of Experience is a case in point: misreadings result when the boy's chilling words "I am black, but O! my soul is white" and desire to "be like" the white boy "and he will then love me" are read straight rather than as a savage indictment of Christian dualism and the liberal desire for sameness (E9). ${ }^{1}$ As Larrissy argues, "Blake uses the complex and ramified symbolism of a tradition marked by dualism of mind and body to attack that dualism" (33).

\footnotetext{
${ }^{1}$ The misreading is the same whether the boy's words are taken as a positive call to "ignore colour differences" (Erdman "Slavery" 249) or criticized as "colonialist discourse" (Mellor "Sex" 358-359; Bindman 374).
} 
In context in Milton: A Poem, Blake uses these words to indicate how "Accident being formed | Into Substance \& Principle, by the cruelties of Demonstration | It became Opake \& Indefinite...” (29.35-37, E128). In other words, one could paraphrase, the physical, seen in a reductive way as the main and only event by the norms of rational empiricism, was stripped of agency and vitality. Victims of such a view, Blake suggests, can no longer see 'through' the literal-physical, perceiving only a reductive materialism, what philosopher Val Plumwood calls "a stripped-down, dualised machine nature" (6). The world becomes "Opake," a one-dimensional realm that is paradoxically "Indefinite" because any other qualities become unproveable or indeterminate. Plumwood writes how, in this modern paradigm, "Being is split into an uncreative, featureless material part and a hyperseparate, externalised and often dematerialised 'director' or 'driver', usually intelligence, mind or reason, on the other side... it is to this external driver that true agency and respect is attributed" ("Nature" 4). Against the harmful effects of such dualisms, she argues for a reanimated relation to the material world, an enriched materialism, and Visions can be read as Blake's dramatization of a similar critique and solution-an inclusive embodiment that enlivens perceiver and perceived. In Blake's Critique of Transcendence, Otto tracks how The Four Zoas "treats chaos as a human creation, a product of the sublime turn from the suffering body," whereby the sublime denotes "a wide variety of cultural practices designed to achieve transcendence," that in their failure reveal "the suffering body that is [their] ground"-the very place they are designed to escape, control and disguise $(8,18)$. I rely on Otto's framework in suggesting that Visions expresses an expanded, not transcendent, sensory engagement, that remains in the body and the world, as well as a scathing analysis of specific transcendent practices, fuelled by Blake's “ actively and overtly oppositional enthusiasm" (Mee, "Heresy" 53). I will now outline what happens when instead of this embodied understanding, divisive frameworks are applied to the poem. 
Mid-century critics established a tradition that set Blake against the material world, taking his denunciations of 'Nature' as transcendently anticorporeal and explicitly anti-natural. ${ }^{2}$ Northrop Frye's landmark work Fearful Symmetry: A Study of William Blake attributed the view to Blake that "nothing outside man [is] worthy of respect. Nature is miserably cruel, wasteful, purposeless, chaotic, and half dead. It has no intelligence, no kindness, no love and no innocence" (39). As Otto notes, this view "polarize[s] life between "the Creator and the Creation'” (28). Frye's formulation was influential to the point that Blake's 1995 biographer Peter Ackroyd could mention "the material world that [Blake] despised" without causing any reaction (272). 3 The formulation implies a transcendent force-Otto's sublime, above-as the animating power that manipulates and gives meaning to an inert material realm, the "unconscious floundering universe" (Frye 39). Depending on the permutation, this transcendent force can take the form, for example, of the Christian God, the divided Cartesian mind, or the Platonic soul (or some forms of the Romantic Imagination). ${ }^{4}$ This force is conceptualised in a dualised hierarchy with its 'other': Creator-creation, mind-matter, soul-body, imagination-mundane world-the permutations are many. The belief that Blake scorns the literal world around him, rather than criticising dualistic ways of being in that world, has influenced even those who are critical of this account. Michael Ferber, for instance, writes that Blake's nature is "a demonic force whose power must be broken and trampled underfoot. It gets in the way of everything he honours: forgiveness, brotherhood, imagination, art. It fosters war, tyranny and slavery, it perverts religion, it degrades art. It is a snare and a delusion. And it is female” (91).

\footnotetext{
${ }^{2}$ For a history of this consensus and early exceptions such as J.J. Garth Wilkinson in 1839 and Mark Schorer in 1946, see Hutchings, Imagining Nature 37-44.

3 Ackroyd's turn of phrase and its critical acceptance are noted by Hutchings, Imagining Nature 38. 4 For analysis of the latter, see Jerome J. McGann, Towards a Literature of Knowledge, Preface i-ix and Introduction 4-7.
} 
Ferber's dramatic turn of phrase draws our attention to the way in which constructions of the material world as chaotic other and inert background are paralleled in what Plumwood calls "the western mapping of a gender hierarchy onto the nature/culture distinction" (10). Criticism of Visions has often been characterised by what Helen Bruder calls "a relentless association of women with an ensnaring natural world" (42). The division between the "passive nature/ woman' and the 'active consciousness/man' underscores comments such as Frye's criticism of Orc's "helpless dependence on Mother Nature” and admiration for how he "gets more control of her" (227-228). These constructions have several implications in terms of the way Visions and its heroine have been understood.

Firstly, a tradition dominant for much of last century has presented Visions as a "hymn to free love" whereby sexual experience is eternally redemptive of fallen materiality (Bloom, E90o). Raine claims that Oothoon "knows the spiritual nature of love, and eloquently defends Platonic love, 'free' love, whose laws are based upon the nature of the soul as the Platonists conceived it" (1.166). This summarises the problem nicely: that 'free' love is seen to be timeless and "spiritual," thus the body is always "defiled" already, and must be tutored by fallen experience and transcended. As Otto explains, "If the fallen world can be redeemed by a simple turn to the imagination, there is no need to analyse its causes, mechanisms, or structures...one could [then] argue that the violence of the fallen world is redemptive" (8). This is what numerous readers have done. 5 Bloom refers to "the sexual awakening [Bromion] has brought about in his victim" (E901) and describes Oothoon as "having enjoyed the sexual act, though it was a rape" (anthologised in Romantic Poetry 45). He glosses Oothoon's call for the eagles to "Rend away this defiled bosom"- a self-harming reflection of Theotormon's body-negating asceticism - as a display of sexual enjoyment designed to manipulate Theotormon (E901). Michael G. Cooke describes the violent results as "an act of enlargement and love" (110). Robert P.

\footnotetext{
5 Including those, such as Blake and Gruner, who criticise what they see as Blake's causal connection between suffering and vision, but nevertheless accept the causality (27).
} 
Waxler writes how "entrance into sexual passion could lead the feminine consciousness to grace" (50). These perspectives, which as Goslee notes, assume that "sexual experience is so essentially good that it leads to a liberating imaginative experience" (114), rely upon a mutually exclusive distinction between mind/spirit and matter. " "Oothoon's degrading experience of sex asserts the holiness of her love," writes Stephen Cox in 1992 (113). Cox argues that in Visions "Blake hardens his dualism" in distinguishing between the "repellently sensuous" and "defiled body," and the "undefiled soul," which in his formulation benefits from sexual violence. In his version of Visions, "every form of sexual joy can be a legitimate form of 'Love'," because delight is “incorruptible" $(117,113)$. Cox supports this with Wollstonecraft's statement "I discern not a trace of the image of God in either sensation or matter," aligning this with Blake's view of the senses (119). The problem with Blake's depiction of rape, Cox writes, is that "no matter what Oothoon may say against common notions of reason and sense, she will retain the reader's sympathy" (123). Williams calls Oothoon's statement "I am pure," "seemingly nonfactual" (86). These critical arguments would collapse if the central section of the poem were fully considered in the context of Bromion and Theotormon's actions, as the poem's dissection of dualistic perception would undermine their own critical assumptions.

Secondly, and closely related, ignoring Blake's analysis of practices that divide and conquer the body prevents us from recognising Oothoon's agency. Blake's embodiment of certain epistemologies in violent characters is connected with his claim that "He who sees the Ratio only, sees himself only" (There is No Natural Religion b, E3). "The Ratio" is a deanimated vision that turns everything outside the self into a resource, requiring manipulation by an external driver, and a female sexuality thus perceived has no desire or agency of its own. Within

\footnotetext{
${ }^{6}$ Such accounts include: Arthur Symonds 95-96; Frye 239; Bernard Blackstone 291-3; H.M. Margoliouth 93-4; George Mills Harper 257; Bloom, Blake's Apocalypse 101-116, commentary in E900-901, and introduction to Romantic Poetry and Prose 44-45; D.G. Gillham 42; David Wagenknecht 206; Duerkson 186-194; Cooke 107-14; Howard H. Hinkel 285-289; Diana Hume George 127-44; Robert P. Waxler 48-52; Jean Hagstrum 114-15; Raine 1.166; W.H. Stevenson 18081; Cox 113-35; Essick 43; Welch 109. For objections similar to Goslee's, see Vogler 273.
} 
cultural practices that define female sexuality as inherently without agency, as psychologist and researcher into sexual violence Nicola Gavey charts, "sexual encounters can easily be narrated in ways where the absence of a woman's desire and pleasure is not only permissible, but almost unremarkable" (142). Readings based on the assumption that for Blake "salvation comes from the "improvement of sensual enjoyment," ignore the textual evidence that Oothoon does not 'enjoy' Bromion's violence (Hagstrum 115). Steve Clark, for example, writes that after picking the Marygold, Oothoon's “subsequent 'wing'd exalting swift delight' (1: 14, E45) can, however, be read as synonymous with rather than opposed to the subsequent rape," that "[t]he initial act can be read as a cruel dispelling of illusion, if read consecutively, or a longed-for consummation, if read as simultaneous," and that "no mention is made of [Oothoon] putting up resistance, and her emission of 'woes' might be seen as motivated by the desertion of her assailant rather than by condemnation of his assault” (164). Susan Matthews contests accounts of Visions that imply "not just a fortunate fall, but a fortunate rape," but only by quoting Martin Priestman's argument that “though 'Bromion rent her with his thunders' certainly sounds like rape, Oothoon never makes an issue of her unwillingness" (147-48). Rather than challenging the connection established by earlier critics between violence and vision, Matthews contests the coercive nature of Bromion's violence by offering a dubious redefinition of consent.

In a further removal of agency, many critics have used language that frames Oothoon in objectified terms reflexive to Theotormon- she is liberated because she can "offer herself" (Bloom Romantic Poetry 45). Butler complains that "whatever [Theotormon] might have had to say" about Oothoon's desire for him "does not seem to matter" (44). Several accounts describe Oothoon as "aggressive" or "wilful". 7 These gendered misreadings of agency can assume that Theotormon is the failed protagonist. Brenda S. Webster, for example, calls

7 See for example Butler 45; Lattin 12, 14; Haigwood 98, 102-3; Cox 119. 
Theotormon the "hero," the protagonist in an Oedipal psychodrama (91). When Bloom writes that "it only remains for Theotormon to truly fulfil [Oothoon], the implication is that the critic is better placed to understand Oothoon, blurring mastery of the (passive) text with transformation of a (passive) female body (E901). Williams similarly asserts that, when other critics misinterpret the poem, "[t]he gap that Bromion forcefully opened is thus effectively closed" (90).

Sympathetic critical identification with Theotormon has obscured the extent to which critical enterprises have enacted the same dualistic denigration of the material and the body (and its associated idea of the 'female'). Theotormon's response is "moving," writes Bloom, because "all men have suffered his jealousy," but "to seek to possess, to appropriate another, is to diminish a human subject into a natural object" (111-2, 116, my emphasis). A fallen world that is impure and inert implies a fallen body that needs domination and control, in Frye's words, "there for us to transform" (39). This calls to mind Bruder's survey of lateeighteenth-century constructions of female sexuality as both passive, needing transformation, and ravenous, needing domination and control (65). In similar fashion, the removal of agency is justified by critical revision of Bromion's rape of Oothoon as something she authored, because " $[\mathrm{t}]$ he feelings Bromion felt roused in him were against his consent” (Butler 46). "The trouble with Oothoon's Thellike prettiness," continues Butler, "is that...[it] functions as a lure not for any particular man but all men-including, in Oothoon's case, the reader" (45). "Oothoon has engaged in an extra-marital amour, apparently with Bromion," was Frye's phrase (239), but more recently too John C. Hampsey is able to write that "the poem is a prophetic cautionary fable about women who are unable to celebrate life and desire" (100). The constructed community of criticism-“all men," "us"-has led to a selective tradition that favours certain versions of the text.

Concern over the removal of agency has prompted Laura Haigwood to object to calling Bromion's actions rape as it “impl[ies] that Oothoon has no real 
will of her own toward it" (97). She argues that "Oothoon is not a rape victim but an active and aggressive participant in her experience," as "she does not effectively protest" $(98,101)$. For Haigwood, acknowledging that sexual violence is violent, perpetuates models of femininity without agency. This argument ignores the violence in the text, and effaces the way in which Oothoon highlights how cultural indoctrination circumscribes agency. Visions gives us an analysis in poetic bodies of cultural practices and distorted ideologies that denigrate and subjugate women, which is not to insist on the inevitability of such practices. Haigwood's liberal model of rational autonomy is unable to accommodate Bromion's violence except as a result of Oothoon's failed personal choices.

Thirdly, and again interrelatedly, the poem is often framed as a polemic against social restrictions, described as early as 1912 as an "outburst against restrictive law and reason" (Allardyce Nicoll 112). However, as with the sexual revolution of the 1960 s, blind spots relating to power and agency meant that it was sometimes not questioned whose restrictions were lifted. Often liberated access to the female body is celebrated, rather than "the liberating joys of sexuality" for women themselves (Ellis 26). Brian Wilkie, for example, claims that "Blake doubtless hates in women what Oothoon calls 'hypocrite modesty' (6.16) not only because it limits women's erotic potential but also because it limits men's sexual enjoyment of women" (83). Grounding Blake's work in antinomian tendencies is a reminder that his concept of freedom differs from modern libertarian formulations of licence. ${ }^{8}$ Cox registers confusion as to the difference, asking "if freedom isn't doing what one likes, then what is it?" (123). To illustrate the distinction, Hill describes an antinomian in 1746 said to have rejected all moral laws: "When asked the obvious succeeding question," Hill writes wryly, “'Have you a right to all the women in the world?' he replied, tactfully, 'Yes-if they consent"' (224). Perhaps the recruitment of Blake to an agenda of individualistic sexual entitlement has certain parallels with the way in which

\footnotetext{
8 This distinction is emphasised by Makdisi 95 and Hill 214-226, 329-332.
} 
"[m] uch of Ranter libertinism was taken over by restoration rakes" (Hill 22). As Thompson notes, the antinomian impulse might "lead to strange consequences in the unbalanced mind” (26-27). The 'freedom' celebrated in the poem will have serious limitations unless we pay attention to Oothoon's celebration of agency in all beings, and opposition to ideologies that frame other beings as resources.

Blake's annotations to Bishop Watson defend Tom Paine, whose deistic, revolutionary writings the Bishop had attacked. Blake felt they were both wrong, but as Thompson writes, "Paine (in Blake's view) has much the best of the argument, since his polemics are directed, not at the Everlasting Gospel (which he does not understand) but at the Moral Law of Antichrist" (6o). Both miss the fully embodied dimension, Blake suggests-“The Bishops never saw the Everlasting Gospel any more than Tom Paine"-but at least Paine does not reject the material world for a made-up transcendence, dismissed by Blake as "an allegorical abode where existence hath never come" (E62). Paine ignores what to Blake is the enriched view of the world: the Bishop denigrates the whole lot. Blake celebrates Paine's attack on the authorities of church and state, even as he criticizes Paine's rational Deism, referring to "the Holy Ghost who in Paine strives with Christendom as in Christ he strove with the Jews" (E614). Blake's annotations deplore the Bishop's hypocrisy in pretending to defend the Bible, whilst to Blake's mind going against its very spirit. I note this in order to explain how historically oriented criticism emerges more favourably than Platonic, Christian dualist or 'free love' readings, in terms of gender politics. Questionable defences of 'love' or 'the imagination' depart from the text for superimposed ideals, distorting Oothoon's words and actions, as shown above. By contrast, critics such as David Erdman have been able to read Visions on its own terms with less apparent difficulty. His prescient observation in "Blake's Vision of Slavery" in 1952 that "[i]nterpretation...is sometimes blurred by failure to distinguish Oothoon's offer of herself to Theotormon from her rape by Bromion” demonstrates why Erdman's work remains important. He states here in uncomplicated fashion that “Oothoon's argument is not that she likes Bromion or 
slavery but that she refuses to accept the status of a fallen woman," and that “Oothoon resists Bromion” (247). The latter phrase, however, was removed in revision of the article into a chapter in Prophet (236). Nevertheless, without the rejection of the material implicit in idealist readings, the body fares better. Yet Erdman, whilst avoiding some of the tendencies charted above, still describes Oothoon as a resource: "a continent longing for fruit in her fertile valleys" who "wants to be cultivated by free men" (Prophet 227).

More recent critics have noted the destructive nature of 'free love' interpretations of the poem, and redefined Visions in historical relation to the tangible issues of oppression the poem indicts. ${ }^{9}$ As mentioned above, Essick suggests that "modern interpreters" are more likely to focus on "the issues of sex, slavery and colonialism" than on the epistemological turn, leaving the question of perception, with all its taints of idealism, largely behind (48). ${ }^{10}$ However to divide Visions is to accept epistemology and action as separate, and valorize the opposite, maligned side of the division, without examining how the poem connects these problems. Makdisi notes how

often in Blake scholarship, issues and questions in Blake's work that seem, according to a modern political idiom, not to be readily identifiable as political in nature-his understanding of being, his views on art, his sense of love, his conception of the imagination-are assumed to mark a departure into some other realm: the mythic, the cosmic, the universal, the spiritual-all of which are assumed to be somehow opposed to or irreconcilable with the historical, the political, and the real. (2)

9 See Bruder 55; Haigwood 95-98; to some degree Linkin 194; Vogler 271-273; Lattin 17; Punter 475; Blake and Gruner 31; Butler 39-43.

${ }^{10}$ Although some recent discussion continues to promote forms of the beliefs charted above-for example Cooper in 2013 refers to "Blake's powerful abstractions from physical reality" and "the romance of Oothoon's... self-awakening" (2, 102-3). 
The assumptions Makdisi notes are understandable when we see, as detailed above, how universal knowledge claims have been invoked in service of biased and historically bound gender norms. But it must be remembered that despite his approval of Paine's politics, Blake still saw something missing in the greater scheme of anatomizing the logic of domination. Critics such as Bruder have shown that Visions relates to specific late-eighteenth-century forms of, in her word, "literal" enslavement and patriarchal oppression, and is not a disembodied psychological or spiritual allegory (77). Having done so, is there now space to extend the understanding of Blake as "deeply engaged with politics and history" (Otto 14), to include the disorienting politics of Blake's nondualist epistemology? In other words, is it possible to reintegrate the dynamic Blake builds between perception and action?

To avoid this question is to minimise Oothoon's insights. Haigwood has a certain point when she criticizes the tendency to "overemphasise the victimization" of Oothoon (95). Unspoken but specific expectations of victim behaviour in response to sexual violence have contributed to the belief that Oothoon's pursuit of the logic of domination into an analysis of perception is either irrelevant or unrealistic. Essick writes that "she is less a dramatized character, burdened with the trauma of rape and its aftermath, than a mouthpiece for Blake's ongoing attack" on Newton and Locke (49). This echoes Gillham 34 years earlier, who claimed it "diminishes the Visions as a work of art" how "Oothoon is acting obviously as the mouthpiece of Blake who is making an attack on the moral philosophies of the $18^{\text {th }}$ century" (49-50). Swearingen argues that her characterisation shows a lack of suffering and thus "insensitivity to the specifically sexual... event of the rape." He thinks this is unrealistic and therefore shows the mythic nature of the poem: "Oothoon is not an actual woman, nor the rape an actual rape" (206). David Aers' claim that "it is misleadingly undialectic to imagine a female consciousness like Oothoon's" that has "so clear a revolutionary critique of sexual and societal exploitation” arguably comes from similar assumptions ("Sex" 32). The expectation is that she should follow a 
homologous pattern of disintegration. "It's as if we see moving beyond... trauma as denying its impact," writes Vanessa Veselka in an analysis of cultural responses to sexual violence, emphasising that her argument is against the imposition of a single model of response onto all experiences, and not a reactive or minimising further set of demands (56-61). She argues that the expectation of collapse stems from the same narratives that construct rape as theft and connect a woman's value with sexual purity, yet also notes the impact of these narratives on women's experiences (58). There is no convincing reason as to why Blake would suddenly devolve into using Oothoon as "a mouthpiece" for abstract philosophical debates, as Essick suggests (49). Rather, the invitation to us as readers is to make sense of the connections between what Oothoon, Bromion and Theotormon say, do, think, and see. The same cultural norms exposed in Theotormon and Bromion's treatment of Oothoon underwrite a reluctance to engage with her unfolding exposure of the interrelatedness of violent actions and thought structures.

Some of the phenomenological approaches increasingly prevalent within the growing area of literary 'ecocriticism' have engaged with issues of epistemology in Visions. Such accounts differ from the founding 'Green Romanticism' of Jonathan Bate, for example, by emphasising Timothy Morton's view that "Nature [is] a transcendental term in a material mask" (qtd. in Hutchings "Ecocriticism” 196). Because Blake does not fit an approach solely celebrating texts about wilderness or 'nature'-with the attendant dualism of such a generic code-ecocritical readers of his work necessarily participate in the same debates as the rest of Blake criticism.

Kevin Hutchings' Imagining Nature is the only book-length study which explicitly aims to revise the characterisation of Blake as nature's adversary, in part by reframing Blake's damning comments against 'nature' as attacks on specific "discursive practices" (Nature 206). Hutchings argues that Blake's work exposes how "nature embodies, on a conceptual level, the inescapable politics of human practice," and elsewhere discusses Oothoon's “attempts to refute the socially and ecologically destructive dualisms underpinning...the tendency... to 
align human biology with a hostile natural world that must be transcended in the name of an ostensibly liberatory spirituality" (Nature 9, "Pastoral" 1). Yet Imagining Nature concludes only that Blake's works demonstrate an "ambivalent...stance," as their "contrary sets of assertions are exceedingly difficult to reconcile" (113). Similarly, Mark Lussier argues that Blake's accepted hostility to nature "needs to be re-examined," but only because "Blake's stance... did not crystallize into such a single vision" ("Ecology" 398). Rather than using the label of 'ambivalence' as what Matthews calls "the intellectual means to quiet conflict" in Blake's work, these accounts need to be taken as an invitation to continue to consider the critical consensus as to Blake's hostility to the material world (3).

The willingness of those using a consciously ecocritical framework to reengage with perception in the poem stems in part from the idealist approach to history prevalent in such frameworks. This approach argues that current ecological crises are, in ecofeminist Freya Mathews' words, "a symptom of a deeper, metaphysical crisis in human consciousness" (qtd. in Rigby par. 2). Hutchings, for example, argues that "human conceptions of nature are largely the cause of nature's devaluation and downfall" (Nature 207). Both Hutchings and Lussier implicitly continue what they see as Blake's attempt to replace "the enlightenment episteme... with an episteme of wholeness" (Lussier "Ecology" 407). This one-directional causality stands in curious contrast to the focus on the material world found throughout the works of both authors, a contradiction at the heart of many ecocritical accounts. A perspective of "wholeness" is conceived as a stable 'thing' that Blake 'had,' and that the reader is implicitly encouraged to also 'have,' rather than as specific activity. Perhaps we need to remember that Blake's insistence on the politics of being comes from a different tradition to the sovereign autonomy of "the Painite/Lockean individual" (Makdisi 39). Ecocritical accounts that rely on an ahistoric version of this concept of the individual struggle to recognise Blake's engagement with specifics of human reality-in Otto's words, "Blake's patient delineation of the traumatic real and the relations on which it depends" (34). An embodied criticism needs to further value the material reality 
by attending to Blake's dissection of how it shapes individuals. In the context of Visions, this means reading the epistemological inquiry in relation to the physical and social action of the poem, which it does not exist without.

IV

The motto which opens Visions-“The Eye sees more than the Heart knows"-has been subjected to every possible divergent interpretation. Bloom claims it suggests "the primacy of perception over the limited wisdom of the natural heart" (101), and Debbie Lee that it instructs "viewers to... disentangl[e] themselves from the self-centred heart” (99). Both seem to reference Blake's tirade against "the Selfish Virtues of the Natural Heart" in Jerusalem (E201), but this is no reason to take all references to the "Heart" as critical. Wilkie dismisses the motto in exasperation-"whatever that enigmatic statement means, exactly" (68). Essick calls it "cryptic" and is "tempted to claim that Blake simply made a mistake" but admits this is "suspect," before making a crucial comparison to Isiah 6:9: "Hear ye indeed, but understand not; and see ye indeed, but perceive not" (35). This comparison to the "firm perswasion" of the Biblical prophetic mode shows the importance of defining Blake's conception of prophecy to a reading of the motto and the narrative of Visions (E38).

Blake's prophetic mode is diagnostic, rather than prognostic. His works claim company with the Biblical prophets: when Isaiah dines with the narrator in the Marriage, he explains that he

saw no God. nor heard any, in a finite organical perception; but my senses discover'd the infinite in every thing, and as I was then perswaded. \& remain confirm'd; that the voice of honest indignation is the voice of God, I cared not for consequences but wrote. (E38)

Blake explains the prophetic role in his annotations to Watson: "Prophets in the modern sense of the word [as foretellers] have never existed... Every honest man 
is a Prophet he utters his opinion both of private \& public matters | Thus | If you go on So | the result is So" (E617). By this account Blake's prophetic function involves anatomising a culture, enquiring into the logic of the oppressions he sees around him, and uttering his indignant opinions as to what the problems are.

In Isaiah 6:9 the prophet is acting as cultural critic to identify a problem whereby information is taken in but not digested or absorbed. Similarly the motto may be read as a diagnosis of what is wrong with the Urizenic ideology the poem exposes: much is available at a sensory "Eye" level, but less is processed or understood at an integrated "Heart" level. This would parallel the Ranter Thomas Tany's words: "Christ in the head is a lye, without being in the heart" (qtd. in Thompson 29). Blake's use of the word "more" raises the question of quality versus quantity-the sense-based way of knowing evidently involves a great deal of information, but these sense data are of limited worth if the understanding is impoverished. The enrichment of the knowledge of the Eye constitutes both Oothoon's perceptive progression and the narrative movement of the poem.

Thus I agree with Peterson's remark that we must take the motto to indicate that the poem deals with "the problem of perception" (253). I disagree, however, that this means we must turn away from physicality and history as "the wrong kind of perception" to pursue a self-referential "true perception" of the “inward Eye” (Peterson 253). The survey above indicates that such idealism, in Blake's words,

...make[s] an Abstract, which is a Negation

Not only of the Substance from which it is derived

A murderer of its own Body: but also a murderer

Of every Divine Member: it is the Reasoning Power

An Abstract objecting power, that Negatives every thing

This is the Spectre of Man: the Holy Reasoning Power

And in its Holiness is closed the Abomination of Desolation.

(Jerusalem 10.9-15, E153) 
To conclude that "Heart" knowledge is superior to "Eye" knowledge, and that the senses are "the wrong kind of perception" is understandable, but it distorts Blake's argument, which insists on enriching rather than transcending "the Vegetated Mortal Eye's perverted \& single vision” (E202). As my discussion of modes of seeing within the poem will suggest, Oothoon asserts an enlivened vision that includes and reanimates the physical senses, not the imposition of imaginary ideals.

The images and principal words from the motto recur at the point where Oothoon begins to question ways of seeing. Looking outside the culture that perceives and constructs her as degraded, she turns to figures of renewal and dawn from the natural world, echoing the Song of Songs, culminating in her statement "Arise my Theotormon I am pure" (2.23-28). The contrast between how she is viewed and how she now sees herself impels a critique of Lockean education:

"They told me that the night \& day were all that I could see:

They told me I had five senses to inclose me up.

And they inclos'd my infinite brain into a narrow circle.

And sunk my heart into the Abyss. a red round globe hot burning

Till all from life I was obliterated and erased. (2.30-34)

Oothoon rejects the reductive binaries she has been made to see and taught to see, describing an engagement with only the empirical "five senses" in claustrophobic terms of imprisonment. This circumscription, by the repeated forces of "They," has injured the eye's ability to integrate knowledge beyond the intake of sense-data, meaning that the Heart is "sunk...into the Abyss," like an apocalyptic sunset. Oothoon frames this constrained vision as a kind of death in life, a loss not only of the perception of life outside the self, but of the experience of being alive itself, with only "single vision" left as a substitute. Within this passage, she does not reject the senses, only the way they have been used to "inclose [her] up" into an uncreative, dead materialism, which is sensory engagement without embodied participation. The violence of being "obliterated 
and erased" reveals Blake's insistent connection between coercive ways of seeing and their expression. Like Bourdieu's account of education as "the process through which a cultural arbitrary is historically reproduced," Oothoon realises the extent to which her education has served to perpetuate an ideology rather than develop her uderstanding (32). ${ }^{11}$ As Larrissy notes, for Blake "[t]he world is not only described mechanistically for the purposes of science. It is experienced thus" (81). Yet the question arises, what is there to see beyond "the night \& day"? Where else is her "infinite brain" to go? Her engagement with the interrelated perspectives of Theotormon and Bromion helps answer this, as she searches for a position beyond binaries, rejecting both Lockean empiricism and mystic idealism.

\section{$\mathrm{V}$}

Oothoon's insight invites an examination of the specific forms of "they" in Visions. It is by understanding these embodiments of what Blake calls "Falshood" that we can unravel the contradictions in human reality they create. Visions engages with specific contested ideologies, not an abstract and eternal psychological pitfall-“The Infinite alone resides in Definite \& Determinate Identity," the "voices of the Living Creatures" tell the abstract "Reasoner" in Jerusalem (E205). "By mapping the various relations and voices that produce the fallen world," Otto writes in relation to The Four Zoas, "Blake hopes his readers will recover the threads of the conversation of which they are part and, in so doing, gain the power to change it" (33). This is equally true of Visions, and the first and oft-noted connection is to John Locke's Essay Concerning Human Understanding (1689). It is beyond my scope in this thesis to summarise Locke's thought or track the full extent of Blake's productive skirmishes with the philosopher, but I will trace several key ideas that relate to Visions.

${ }^{11}$ Nicholas Williams compares Blake's Songs of Innocence and of Experience to Bourdieu's study of education, but does not discuss in relation to Visions (32-70). 
Firstly, the Essay rejects innate ideas and describes the human mind as a tabula rasa wherein "simple ideas" are supplied by the senses and are made into knowledge by the mind. The mind stands apart and superior to the material world, meaning that in the Essay, paradoxically, "Locke directs attention to an internal reality" (Otto 41). Despite appearing to valorise the material at the expense of the ideal, Locke's thought is rather a permutation of the familiar dynamic that posits "an autonomous power" above and in charge of the chaotic raw material of reality (Otto 41). Blake's work challenges such a conception, not least because it negates the antinomian intuitions of the enthusiast. Locke attacked the "firmness of Perswasion" in those of "enthusiasm," who "feel the hand of GOD moving within, and the impulses of the spirit, and cannot be mistaken in what they feel" $(4.19 .8,12)$. Blake's Isaiah responds in the Marriage to this attack on "firm perswasion" (E38), and Blake elsewhere objects to Locke's tabula rasa because it conflicts with his belief that all knowledge worth having is available to "the Child \& to the Poor \& Unlearned" regardless of formal education: "The Man who says we have No Innate Ideas must be a Fool \& Knave. Having No Con-Science or Innate Science" (E664, 648).

Secondly, Locke uses the metaphor of a "dark room" or cavern with apertures where light comes through to describe the operation of the mind and senses (2.11.17). Blake's works suggest agreement: the fairy narrator of Europe opens the poem with the diagnosis that "Five windows light the cavern'd Man" (E6o), and Blake repeats a similar figure in the Marriage, and in Visions where Oothoon is "inclos'd" (2.32). The difference is in whether this state of affairs is inevitable or conditional. Locke's Essay reads as a theory of the true foundations of reality, rather than as a diagnosis of current delusions. Blake's works reject "[t]he universe of rational thought built on this foundation" as it "provides the dogma used to circumscribe existence" (Otto 43). In other words, Blake's poetry can be seen as an "attempt to historicize" Locke's thought (Otto 43). Visions does not imply Locke's claim are wrong, but places them as specific conditioned relations between human bodies at a specific point in time. This is why we must 
view Bromion and Theotormon's speeches as indivisible from their actions, and the centre of the poem as inextricably continuous with the beginning and end.

Thirdly, Locke suggests that anything beyond direct sensory data is unknowable. He refers to the "supposed, but unknown" substance or essence of a thing and compares this to "those Qualities, we find existing" in observable phenomena (2.32.2). Locke does posit an abstract underlying essence, but famously calls it "something we know not what," emphasising the unknowability of anything beyond "qualities" or sense-data (2.23.2).

Welch argues that Locke's emphasis on the tangibility of observable qualities "valoris[es] the external," "rendering essence... incomprehensible," in an "attack on immaterial essence" (Welch 112). However this assumed opposition between "external" and "essence" indicates how "the notion that man has a body distinct from his soul" distorts Welch's elucidation of Locke and Blake (Marriage E39). A discussion of Visions, Welch argues, "boils down to the contrast between essence (i.e., Oothoon's identity or that which is most irreducible, unchanging, and constitutive of her) and the constructed male world she occupies" (106). Using "essence" as an argument for the soul, he claims that the focus on "accidental properties" in Locke and others enabled racism and sexism, as concepts of the soul were universals, allowing people to rise above physical difference. This recalls the argument that Wollstonecraft deployed in favour of the sexless soul. We might call this approach 'strategic dualism.' In this analysis, Blake joins ranks with Berkeley and Isaac Watts to contest Locke's epistemological challenge. Yet Blake is not the idealist that Welch wants him to be. Welch describes "Blake's understanding of individual human identity" as "the union of spirit and body in the imaginative body," but this is an ideal rather than an imaginative body, the latter of which would have included the physical as well (108). Instead, the body disappears.

The distortion caused by Welch's idealism can be seen when he cites Blake's verdict that “Accident being formed | Into Substance \& Principle, by the 
cruelties of Demonstration | It became Opake \& Indefinite...” (Jerusalem 29.3537, E128). Welch explicates, quoting Locke: "it became only 'the supposed, but unknown'," aligning Locke's unknowable essence with Blake's “It” (Accident), which is the opposite (112). Blake is asserting that perception is constrained by a devitalised mechanistic ideology: Welch's Locke is implying that knowledge beyond this reduced perception is incomprehensible.

Welch cannot admit that Visions suggests agreement with Locke's abandonment of the unknowable "essence" side of the dualism, on the basis that it was made up anyway - an "imaginary heaven into which [a person] projects the divided state of [their] own soul" (Larrissy 128). Blake's poetry challenges the parameters of Locke's divided and conquered empirical world, rather than abandoning that world for a waffly and insubstantial "essence". This will not do for Visions: I am with Otto when he argues that "Blake... directs us to a human rather than transcendent reality" (33). If we are going to criticise Locke, we must do so without fleeing to the opposite side of the division he manufactures.

Welch invokes late-twentieth-century arguments to justify the "resistive potential" of essentialism (108). However "essentialism" means something very different in 1970 than it does in an eighteenth-century epistemological debate. Welch cites Stephen Heath, Alice Jardine and Gayatri Spivak as endorsing "a reconsideration of essentialism" (107). Yet reading these critics' 'endorsements' undermines Welch's project: Jardine and Heath discuss the case for strategic essentialism in group collectivity, and Spivak mentions "strategic use of a positivist essentialism in a scrupulously visible political interest," followed by the observation that "the strategic use of essentialism can turn into an alibi for proselytizing academic essentialisms," which is what Welch seems to invoke her for (Spivak 3-4).

Thus Welch uses Blake in order to express his own dissatisfaction with "those aspects of British empiricism that valorize the external and accidental over the internal and essential," arguing that "the deepest and most pervasive systems 
of tyranny Oothoon resists are philosophical” (108). We need to question what "deepest" refers to or is compared with. Oothoon encounters philosophical positions only as they are embodied in the practices of Theotormon and Bromion, therefore it is pointless to say that a philosophy is 'more' tyrannical than the way in which it finds expression. As Plumwood writes: "we do have to understand philosophy in social terms, not as a collection of individual philosophical ideas" (4). Welch's ideological distinction between spirit and matter causes him to argue that Blake "remained a dualist," who separated "essence (spiritual substances) [and] accident (diverse embodiments...)" (119n32).

Bracher argues that "each character [in Visions] represents a metaphysical perspective"-Bromion empiricism, Theotormon "the metaphysics which valorizes the pure essence or ideal of a being in separation from the being's actual existence...the type of Platonic and also Christian idealism which demands that actual existence conform to a pure, abstract ideal” (165-66). Welch disagrees, arguing that Theotormon's questions reveal "an empiricist perspective” (118). This disagreement arises because Theotormon functions as an extreme version of the kind of idealism that Welch practices. In order to refute Welch's essential argument, we must turn attention to Visions itself.

Discussion of Bromion depends considerably upon one's view of transcendental dualism. For example, Kathleen Raine relates Bromion's speech to Locke, condemning Bromion's and Locke’s “materialist... philosophies” (2.124), but does not explore how, in Otto's words, "Locke directs attention to an internal reality" that scorns the body much as her own Platonist approach does (41). Clark, by contrast, finds Bromion's "sensible" words to have "specificity," and "a certain elegance" that Oothoon lacks (167). Bromion has been described as "a Puritan" (Larrissy 122); a "lustful tyrant" (John Beer, Life 45); "reasoning, restraining, dogmatic” (Duerkson 187); “a sensationalist” (Gillham 52); "not a 
Puritan but a Deist" (Frye 241); "a thunder Titan" (Bloom 103); the "moral law" (Hinkel 286); an “arch-rapist” (Cooke 107); "a Blakean experiment in reductive monism" (Cox 115); "patriarchal law" (George 127); a "materialist” (Raine 2.124); a capitalist (Punter 484); "on the verge of enlightenment" (Wagenknecht 208); and a "slave-driver" analogous to pro-slavery Parliamentarians (Erdman 228, 237). These characterisations are often presented as if they are self-evident, but the contradictions in this array merits further investigation.

Although he speaks after Theotormon, it is useful to examine Bromion's "lamentation" first (4.12):

Thou knowest that the ancient trees seen by thine eyes have fruit;

But knowest thou that trees and fruits flourish upon the earth To gratify senses unknown? trees beasts and birds unknown: Unknown, not unpercievd, spread in the infinite microscope, In places yet unvisited by the voyager. and in worlds

Over another kind of seas. and in atmospheres unknown:

$\mathrm{Ah}$ ! are there other wars. beside the wars of sword and fire! And are there other sorrows, beside the sorrows of poverty? And are there other joys, beside the joys of riches and ease? And is there not one law for both the lion and the ox? And is there not eternal fire, and eternal chains? To bind the phantoms of existence from eternal life? (4.13-25)

This speech parodies Locke's Essay through the motto's opposition of quantity and quality. As Anne Mellor notes, this speech has been read as a "sincere if futile attempt to understand Oothoon's world through rational categories. But these are rhetorical questions" (Form 59). Bromion's interest in the "infinite" and the "unknown" has led critics to suggest he "would appear to be questioning Lockean limits" (Essick 51). Matthews refers to "the ability of Bromion to sense the infinite 
nature of the world" (148). But on closer inspection, his speech aligns very closely with Locke's position, and in doing so reveals contradictions in Locke's thought.

Bromion's enquiry is driven by a spirit of progressive discovery. He refers to Theotormon's vague longings for the past as "ancient trees" which once had "fruit," but directs attention to new potential forms of gratification-"trees beasts and birds unknown." Bromion assumes that "trees and fruits flourish upon the earth" in order to "gratify senses"-resources to be appropriated for his exclusive use. We saw this earlier in his repetition of "mine" to justify the appropriation of Oothoon, the American land, and other humans as slaves (1:20). Like Bromion's earlier speech (1.18-2.2), his words here are addressed to Theotormon, repeating Theotormon's concern with "ancient," "joys," and "sorrow." Bromion does not address Oothoon, as she is not recognised as an agential subject, only as a resource. He tells Theotormon to forget his "ancient loves" (3.4) for Oothoon, and seek out new forms of gratifying "fruit." Plumwood describes such a relation to the world, ascendant in Blake's time, as inventing "a mindless meaningless materialist universe open to endless unrestricted manipulation and appropriation: nature is the suppressed slave collaborator-a mere resource, or transparent enabler of projects" (par. 27). Bromion describes other beings as "unknown, not unpercievd," recalling the dichotomy in the motto: his "Eye sees" them, but because of his appropriative gaze, the "Heart knows" very little. He can only conceive of both known and unknown beings instrumentally, in terms of how they might give him "the joys of riches and ease." Bromion "sees the Ratio only," and thus "sees himself only," by relating to everything outside the self as mindless resources (E3). As Locke writes: “whilst I know, by seeing or hearing, etc. that there is some Corporeal Being without me, the Object of that sensation, I do more certainly know, that there is some Spiritual Being within me, that sees and hears[,]... an immaterial thinking Being” (2.23.5). By embodying Locke's theory in Bromion's practice, Blake dramatises the effects of dualising mind and matter into active self and objectified world. This further suggests that the hostile 
references to "Corporeal” elsewhere in Blake's works attack this Lockean relation to matter, rather than material reality itself.

Blake's repetition of “unknown” in Bromion's speech mocks Locke’s theory of unknowable essence and knowable properties. By positing essence "within me," the properties which Locke observes are stripped of life, enabling things to be treated exploitatively as "bare insensible matter" (Locke 2.23.5). The appearance of enquiry that has impressed some critics seeks quantity of stimulation, not quality of mutual engagement. The concern with new "places...worlds...seas. and...atmospheres" privileges an empirical accumulation of resources, not a qualitative expansion of relationship with the world. Locke writes: "For how much would that Man exceed all others in Knowledge, who had but the Faculty so to alter the Structure of Eyes... as to make it capable of all the several degrees of Vision, which the assistance of Glasses... has taught us to conceive? (2.23.13). For Locke "Vision" and "Knowledge" are achieved through an increase in sensory information. Bromion's "infinite microscope" is a Blakean mockery of Locke's faith in increased knowledge from accumulated data about "visible tangible Qualities" (2.2.3). Blake creates a generic travesty of his own prophetic mode in Bromion's infinite yet misguided desire. In a passage that Visions seems to directly reference, Locke posits the possibility of "a Sixth, Seventh, or Eighth Sense"-Bromion's "senses unknown"-and speculates that "there may be other and different intelligent beings, of whose faculties [one] has as little knowledge or apprehension as a worm shut up in one drawer of a cabinet hath of the senses or understanding of a man" (2.2.3). At first glance this may seem to reinforce Oothoon's subsequent argument that the world appears differently to different subjectivities. However, Locke's interest, like Bromion's, is in an expansion of the amount of sensory data one might catalogue, with a simultaneous insistence upon its unknowability, because "the Understanding is not much unlike a Closet wholly shut from light, with only some little openings left, to let in... Ideas of things without" (2.12.17). The similarity of this figure to 
Blake's “cavern'd Man” emphasises once again that Blake's conversation with Locke is more complex than simple opposition (Europe iii.1, E6o).

W.H. Stevenson notes that "[d]iscovery, by travel or by microscope, was part of the texture of the age," and Blake's portrayal of Bromion is a portrait of an empire bent on acquisitive discovery (187). In all his multiple personae-slave owner, rapist, colonial appropriator of land-Bromion relates to things outside himself in a way that justifies active violence. There is No Natural Religion [b] claims that "More! More! is the cry of a mistaken soul, less than All cannot satisfy Man” (E2). We can read this as an indication that Bromion's desire for more of "the joys of riches and ease" is misguided, as it still reduces everything outside the self to a resource, rather than the "All" which recognises the world as rich and mindful in its own right. Bromion's impoverished knowledge leads him to seek 'quantitative easing,' yet his approach is a "lamentation" and doomed to failure, as it is founded upon the sense of lack it seeks to assuage (4.12).

Bromion's concluding questions confirm this impoverished vision: he can conceive only of literal wars "of sword and fire," suffering through lack of material wealth, and happiness in terms of "riches and ease". Yet it would be a mistake to assume that Blake denies that war and poverty create suffering, which further shows that we need to pursue an expansion of Bromion's categories and not reject the literal for Raine's “immaterialist” realm (2.214). Bromion's speech reveals the contradiction in Locke's thought whereby the focus appears to be on the physical, whilst making the physical subservient to the organising activities of the mind, which "hath no other immediate object but its own ideas" (4.1.1). Hence why critics have labelled Bromion both lustful and Puritan, rationalist and sensationalist. His confident rhetorical question "is there not one law for both the lion and the ox?" demonstrates this contradiction, as one might think that a focus on the physical would result in an emphasis, like Oothoon's, on the unique quality of every creature. Instead, Bromion states a position already characterised by Blake as "Oppression” in The Marriage of Heaven and Hell. 
Locke's focus on the understanding as a predictable "internal reality" (Otto 41) and characterization of things outside the self as data, result in a theory of stable essence that functions in a similar way to theories of the soul. As Otto writes, "Locke's understanding is paradoxically turned towards a transcendental realm while being bound to a physical body" (191). Locke and Bromion can be seen to state a position of liberal 'sameness' that argues for "one law" regardless of the characteristics of each embodied being. Blake's critique of this universal self confronts not only the dominant culture of the Enlightenment, but also the ascendant 'natural rights' radicalism of revolutionaries such as Paine. "[S]ince the French Revolution Englishmen are all Intermeasurable One by Another,” wrote Blake in an 1827 letter, "Certainly a happy state of Agreement to which I for One do not Agree" (E783). Welch argued that it was Locke's emphasis on externals that enabled a sexist or racist position, but Bromion's words suggest that it is the inability to cope with physical difference, and the need to efface it in favour of an eternal and stable realm, which enables and justifies violence.

Finally, Bromion turns to those aspects of existence that the understanding struggles to control-desire, the emotions-calling them the "phantoms of existence." Otto argues that Lockean understanding is "threatened by the active powers of the body" which have, however, "for the most part been disciplined" (42-43). Bromion's ordered universe is revealed to rely upon the same pious dualism Blake deconstructs in the Marriage, between angelic order and control, and demonised energy. He invokes "eternal fire, and eternal chains" to suppress the bodily energies from the "eternal life" promised by Locke's "universal and certain" knowledge (4.12.13). The purpose of Bromion's "infinite microscope" is to confine the chaos of reality to an orderly series of empirical data. In a similar scenario in The Four Zoas, Urizen uses "vast instruments... to measure out the immense \& fix | The whole into another world better suited to obey | His will" (73.17-19, E350). Yet his efforts will turn out to be fruitless-"Nor could he calm the Elements because himself was Subject” (71.3, E348). 


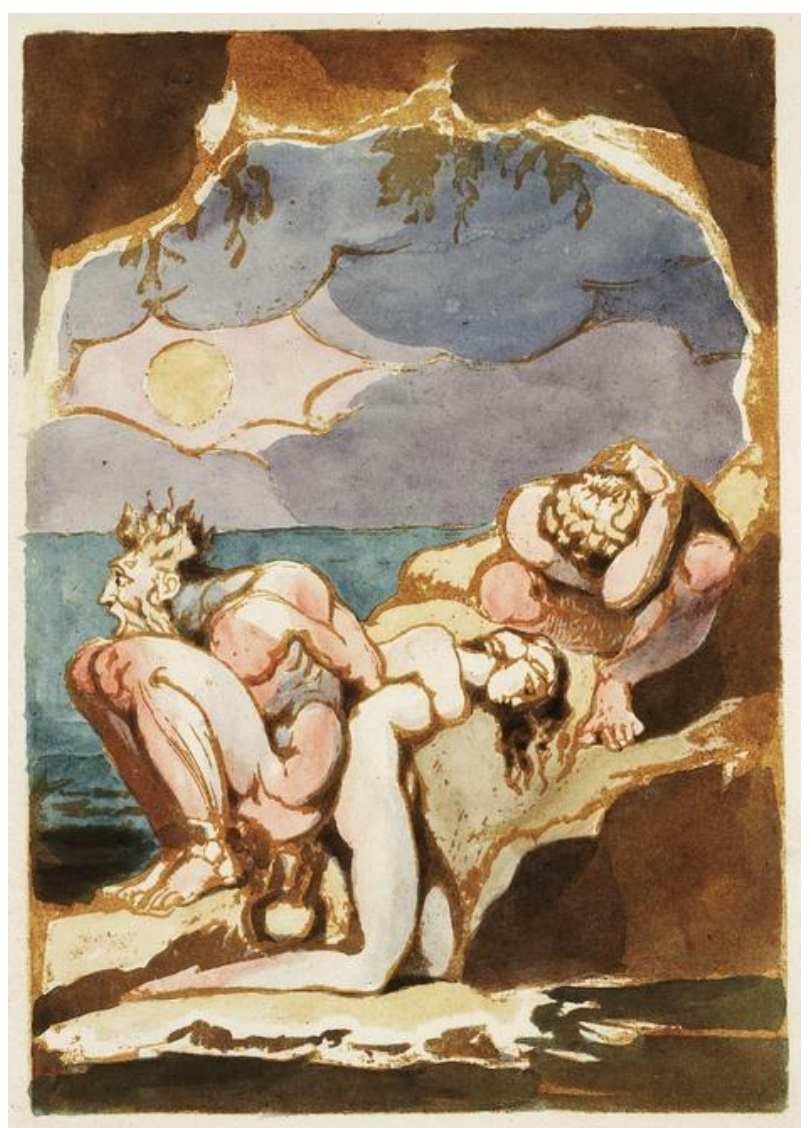

Figure 19. William Blake, frontispiece to Visions, copy E. 1793. Henry E. Huntington Library and Art Gallery, San Marino; rpt. Blake Archive.

Turning from the text to the illuminations, Bromion's form in the frontispiece can be seen to be almost as tightly self-bound as Theotormon's, revealing his rule of bodily discipline (figure 19). The over-muscled caricature of masculinity is combined with an expression of terror, focused outside of the visual field. This demonstrates Bromion's failure to engage with Oothoon or Theotormon, and perhaps also his turn from the material reality of the image towards an abstract realm outside of the frame. Blake's placement of the frontispiece at the end of the poem in one copy causes Bromion's shock to appear to be in response to Oothoon's freed form on the final plate. The effect is to connect the poem's beginning and end into a cyclical repetition, emphasising both the repetition of Oothoon's cry "every morning," and suggesting the continual possibility of transformation, incomprehensible to Bromion's Lockean 
understanding. Bromion's manacles are, after all, more visible than Oothoon's in this image.

VII

Because Blake's presentation of Theotormon indicts the kind of idealism that has often been imposed upon the poem, and because Bromion appears more obviously and actively pernicious, Theotormon has been glossed even more variously than his counterpart. There are some knotty contradictions within Theotormon, hence the decision to discuss Bromion first. Just as Bromion seems to be a materialist who upon closer inspection depends upon the manipulation of the material by the mind, so conversely Theotormon's apparent idealism can be seen to rely upon the material reality he disdains.

His name is often glossed as tortured by god (theo), or the law (torah) (Essick 36). If so, it is the God of his own conception, the God of the Moral Law that Blake refers to in a wide variety of hostile terminology, such as "Antichrist" in his annotations to Watson (E612). This system of morality assumes an opposition between ideal spirit and chaotic body. Watson, for example, thinks Paine's writings have "corrupted morals" by "giv[ing] the reins to the domination of every passion" (qtd. E612). Like the Angel of the Marriage, who in speaking with the energetic Devil "became almost blue but mastering himself he grew yellow, \& at last white pink \& smiling," Theotormon restrains and controls the body (E43). His response to Bromion's goads reveals how "the self enjoyings of self denial” (7.9) leave him with either elemental outbursts-"storms rent Theotormon's limbs"-or hypercontrolled "secret tears" $(2.3,7)$. Blake frames Theotormon's moral stance in opposition and antagonistic relation to the impulses of the body, demonstrating the effects of the imposition of the moral law as opposed to the antinomian belief in the availability of inspiration to the enthusiastic body. This moralistic self-control is then imposed upon Oothoon, whose “tears are locked up" also (2.11). Theotormon's asceticism leaves him as 
dry and lifeless as a "desart shore," enacting self-harm at a bodily level. His replacement of reality with moral ideals creates specifically "religious caves," where the injustices that his narcissistic search for transcendence avoids "shiver" (2.9-10). These "slaves beneath the sun," and "children bought with money" are shown to be the material ground that such idealistic stances avoid. The repetition of "beneath" presents Theotormon himself as comprised of "the burning fires | Of lust, that belch incessant from the summits of the earth" (2.8-10). The words evoke Hell, yet this is inverted from the depths to the summits, revealed as a result of Theotormon's repression. Heaven is his perfectly controlled body, whereas Hell is the bodily energies Heaven is invoked to suppress. Blake suggests that both are "alienated and projected portions of our earthly psyches" (Otto 40). In this short passage, Blake intertwines economic, political, psychological and religious forms of alienation. The society from which Theotormon takes his moral laws is based upon slavery and child labour: the polite "white pink \& smiling" angel of the Marriage similarly denies the energetic bodily basis of his existence. Theotormon's lust is his search for transcendence of the despised body, a search that denies and controls the disorderly material, which ironically further fuels "the burning fires." The alienated aspects are not discarded but become "a furnace of dire flames | Quenchless unceasing," as phrased in The Four Zoas (74.14-15, E351). Otto argues that Blake indicts religious practices designed to achieve transcendence, and rationalising practices such as Locke's philosophy, as different forms of the same impulse (35). In both cases Blake wants to bring our attention back to "the repressed and mutilated physical body that is the hidden referent of the disciplined body and of... heavenly bodies" (Otto 40).

In contrast to this denial of the body, Oothoon celebrates the unique embodiment of various creatures. This has been understood as an appeal to a supersensuous essence, once again an abstract ideal beyond the material world, but perhaps we can better understand this passage with reference to Roland Barthes' concept of J'aime, je n'aime pas. Here he lists his idiosyncratic likes and dislikes in great detail, before observing: 
this is of no importance to anyone; this, apparently, has no meaning. And yet all this means: my body is not the same as yours. Hence, in this anarchic foam of tastes and distates, a kind of listless blur, gradually appears the figure of a bodily enigma, requiring complicity or irritation. Here begins the intimidation of the body, which obliges others to endure me liberally, to remain silent and polite confronted by pleasure or rejections which they do not share. (117)

Barthes' understanding of the body as a collection of idiosyncratic impulses helps explain how Oothoon's argument is for particularity, not liberalism or what Thompson called "supercelestial visionary mystery" (46)

This gives a context to Theotormon's contribution to the poem's discussion of the senses. At the end of Oothoon's enquiry into these different "forms and...joys" (3.6), she says "And then tell me the thoughts of man, that have been hid of old" (3.13). The suggestion is that the indoctrination of the "infinite brain" obscures human intuitions, which are potentially available, just as the diverse intuitions she details are part of the other creatures' embodiments (2:32). Yet Theotormon takes this question both literally and personally:

Tell me what is the night or day to one o'erflowd with woe?

Tell me what is a thought? \& of what substance is it made?

Tell me what is a joy? \& in what gardens do joys grow?

And in what rivers swim the sorrows? and upon what mountains

Wave shadows of discontent? and in what houses dwell the wretched

Drunken with woe forgotten. and shut up from cold despair,

Tell me where dwell the thoughts forgotten till thou call them forth

Tell me where dwell the joys of old? \& where the ancient loves?

And when will they renew again \& the night of oblivion past?

That I might traverse times \& spaces far remote and bring

Comforts into a present sorrow and a night of pain

Where goest thou $\mathrm{O}$ thought! to what remote land is thy flight? 
If thou returnest to the present moment of affliction

Wilt thou bring comforts on thy wings. and dews and honey and balm;

Or poison from the desart wilds, from the eyes of the envier. (3:22 - 4:11)

Firstly we could note the inadequacy of this speech to deal in any way with either Bromion's violence or Oothoon's challenge to the dogma that holds her to be eternally ruined. This indicates that his "woe" is not sympathetic, but, as Oothoon soon realises, an expression of self-pity caused by "self-love that envies all!" (7:21). In The Four Zoas Urizen's "Wisdom" is to "let Moral Duty tune your tongue | But be your hearts harder than the nether millstone" (E80). Moralistic Theotormon "sees more" than his "Heart knows," as his heart is similarly hard. His demanding monologue registers some key words from Oothoon's entreaties, but only as abstractions that mock the relevance of her original enquiry. He is unable to bear the bodily experience of jealousy, as the loss of Oothoon as commodity signifies a loss of self. If Bromion is obsessed with a future of exploration and progress, Theotormon takes the same approach to the mental realms of the past.

He asks "what is the night or day to one o'erflowd with woe," indicating how concern for his own sense of loss silences Oothoon's crucial insight into her dualistic education. Blurring night and day together, his subsequent questions refer to meaningless abstractions, demanding to know locations for "thought," or "joy," which reveals his distance from the body in which these are experienced. Yet his questions also evoke Locke's negation of the insubstantial, leaving him without either side of the division. This shows the split between what he appeared to value (a religious essence which he has now misplaced), and what he actually values (a conventionally 'pure' female possession to enhance his status, also misplaced). To demonstrate this, we can consider Cox's claim that Theotormon "has difficulty distinguishing [Oothoon's] defiled body from her undefiled soul" (115). This has a certain logic to it. But it is insufficiently self-critical, as it is Theotormon's belief in a separate body and soul that causes his difficulty to begin with. Where is this soul? Theotormon is looking for it and unable to find it. All he 
can find is what he wants to find: the confirmation of his assumption that her body is defiled already. The whole point of Blake's elision of the dualism is that the body is not defiled. What about it is 'defiled'? And yet Oothoon experiences it as "defiled," he shows (2.15). Why? Because she was taught to reflect Theotormon's code, the code that Cox now serves to further disseminate.

Theotormon's hypocrisy is his reliance on the material possession of Oothoon for his emotional wellbeing. His supposed idealism is revealed to be a made-up abstraction, his apparent religiosity an avoidance strategy. Oothoon exposed this doctrine of purity, revealing its contradictions in lived experience. As Welch argues, Theotormon's questions do apparently take an empirical bent, as he demands to know information about insubstantial feelings, demanding material proof for their existence. Yet this does not negate his idealism: rather, his irrelevant inquiries, himself "shut up from cold despair," demonstrate his allegiance to "cold floods of abstraction" over lived reality $(4.2,5.19)$. The series of narcissistic questions appeal to memories of the past as a way of avoiding engagement with the present. Living in mental constructs, he looks to the "remote land" his thought flies to, hoping for non-existent comforts, frightened of more poisonous thoughts. The more he rejects the body and instead attempts to mentally "traverse times \& spaces far remote," the more he creates his "night of pain" which prompted the departure in the first place.

Blake's visual depiction of Theotormon supports this analysis. On the frontispiece, his body is barely human in its condensed negation of the sensory (see figure 19). He is "closd up in Moral Pride," clenching the body against reality (E211). This stance is echoed in the Urizenic, bearded figure of the title page, who is also "self-closd," in contrast to Oothoon's gestures of openness (E70, figure 20). Similarly, on Plate 4, where Oothoon "hovers by his side, perswading him in vain" (2.22), Theotormon's head is buried in his knees, encircled by his arms wrapped over the knees, and only one foot is visible: his body is again contracted into the smallest possible shape. His inability to engage with Oothoon confirms his rejection of the material world for an attempted transcendence. 


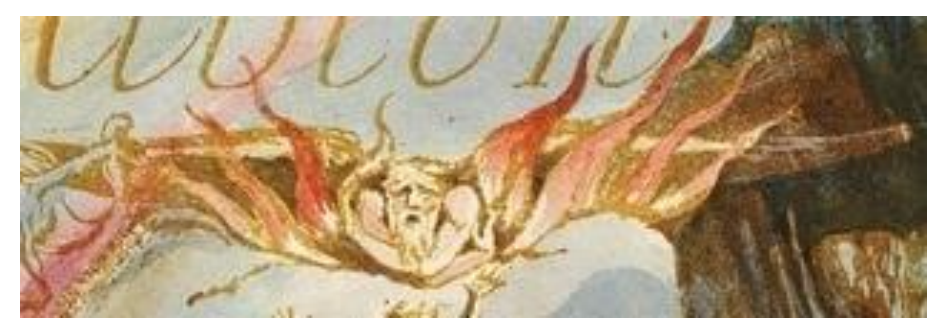

Figure 20. William Blake, detail from title page of Visions, Copy E, 1793;

Henry E. Huntington Library and Art Gallery, San Marino; rpt. Blake Archive.

\section{VIII}

A close examination of Bromion and Theotormon illuminates how reductive materialism and idealist religiosity rely on the same perceived split between matter and spirit. It is a trap to perceive Blake's "Contempt and Abhorrence" (E660) for Locke's work as evidence of allegiance to Welch's conventional Christian dualism between soul and body. Against accounts that suggest that the theories of Locke and other thinkers of the Enlightenment erased and replaced older religious beliefs, the similarity of Visions' two male characters suggests their basis in similar assumptions. "Reductionism," writes Plumwood, "actually relies on a reified separation that took place a lot earlier, through a process of splitting and a hegemonic construction of agency and identity" (par. 23). The reductive materialism of modernity is revealed as only a truncated version of the older mind-body dualism, one that preserves the distinction between inert matter and the creative, animating spirit, intelligence or reason, whilst abandoning the latter as incoherent or irrational. This separation is Descartes' "empire of man over mere things," as everything outside the self is stripped of agency and autonomy, available to be possessed or exploited (Plumwood par. 22). Thus Bromion and Theotormon are flipsides of the same exploitative coin. Theotormon believes in moralistic ideals, yet he is constrained by his physical inability to achieve full disciplinary control over the material body or world. Bromion believes in empirical facts, yet privileges the mind as reality, and treats the world as the data with which it can be filled. Theotormon looks for 
the tangible in the abstract, whereas Bromion looks for the abstract in the tangible. Both are unable to accept reality as it is, subsuming it to a controlling and transcendent power. Thus Oothoon identifies "Urizen! Creator of men! mistaken Demon of heaven" as the ideological father of both Theotormon and Bromion. Urizen reveals that rather than opposites, Reason and Faith are equally suitable vehicles for his project of creating an eternal world. He is both the moralistic force mistaken for God, and the rationalising force mistaken for truth. Either way "the head governs and controuls the Body under it," as Swedenborg wrote in The Wisdom of Angels Concerning Divine Love and Divine Wisdom, for "the body is nothing but obedience" (14). Yet Oothoon reveals the violence that such a project inflicts, in its attempt to shape human bodies into the ideal bodies of "thine image" (5.4). Why do they need to be all the same, she asks-"How can one joy absorb another" (5.5). Blake's immanent stance finds the "Holy, eternal, [and] infinite!" nowhere but in diverse, tangible, finite bodies (5.6). Oothoon's insight is to see that, despite seeming to embody opposite epistemologies, Bromion and Theotormon both depend on the same dualism, which reduces everything outside the self to a lifeless commodity. In addition, it also fuels the impulse to use everything so, because a "heart [sunk] into the Abyss" will continue, like Theotormon's "burning fires | Of lust," to seek more and more at this level of the commodity, in an attempt to satisfy its impoverished relation with the world $(2.33,9-10)$.

Oothoon's alternative to this kind of Urizenic relation to the world is an erotic vision: "where ever beauty appears | If in the morning sun I find it: there my eyes are fix'd | In happy copulation" (6.22-7.1). Instead of a possessive hoarding of sense-data, or rejection of the senses outright, Oothoon envisions a procreative relationship with what she sees, thus returning agency and animation to the world beyond herself. This is how Blake imagines expansion from "Single vision \& Newtons sleep" (E722). Fourfold Vision is not so much an argument for pluralism calling for further debate between the extremes of a hypocritical 
idealism and a denuded materialism, as it is Blake's solution to his motto's diagnosis: the reintroduction of the heart's knowledge into what the eye sees.

IX

The narrative movement of the poem indicates both how epistemologies cause certain actions, and how actions shape and use epistemologies. It "is no coincidence of course," Plumwood writes, that "[b]y consolidating the narratives of the empire of man over mere things, reductionist rationality removes key constraints at the dawn of commoditisation and capitalism" (par. 25). Neither empiricism, idealism nor Urizenic perception exist, except as they are enacted in human practices. Just as Blake comments that "God only Acts \& Is, in existing beings or Men" (Marriage, E40), the philosophies of Bromion and Theotormon cannot be considered apart from their actions. Oothoon's turn to indict Urizen is, like her identification of "they" as the instillers of some of her ideas, a recognition that "human beings are constrained by ideologies and projections which, as individuals, they are not responsible for" (Larrissy 4). The distortion of Blake's version of freedom into an autonomy of the sovereign individual can be seen in the poem "London," from Songs of Innocence and of Experience (E26-27). The "mind-forg'd manacles" of this poem are often cited, but it is useful to remember that these occur within the shaping forces of "London" itself-the poem and the city. At no point does Blake's work suggest that the manacles are a result of an unfortunate and isolated individual choice. In his notebook Blake frames freedom from these manacles in terms of the removal of hierarchal, coercive structures:

Remove away that blackning church

Remove away that marriage hearse

Remove away that --- of blood

You'll quite remove the ancient curse (E475) 
It is not a coincidence that Visions simultaneously analyses multiple forms of domination, both within and without the human body, as the politics and structures are made by humans in what Blake sees as a fallen, fragmented state, which meanwhile craft more humans into that state.

Visions could be described as prophetic in that it can be seen to anticipate the conditions of its own critical reception. Blake engages in productive battle with those of his contemporaries he sees as shaping the dominant culture, giving bodies to their doctrines to reveal their lived effects. Visions dramatises the patterns of the logic of domination, revealing the violence caused by the impulse towards transcendence. As inheritors of the liberal legacy of Locke's Enlightenment, we have, generally speaking, "go[ne] on So," and played out the very tensions dramatised within the poem itself. It is in this sense that the poem can be seen to predict its own reception. Thus the strategic omissions and distortions of some approaches within the critical tradition have the effect of elucidating the poem with their actions, even as they obscure it with their words. In giving bodies to doctrines that dualise mind/soul and body, Blake himself gives us an 'anatomy of criticism'. You could say that the best analysis of Visions' reception history comes from the poem itself.

Oothoon is made to live within these divisive contradictions and by giving them form, she moves towards an enriched, not transcended, human relationship with the material world. By reading the epistemological sections of Visions as part of the continuous whole of the poem, we regain Blake's poetic, political representation of the relationship between perception and action. This has the potential to reconcile the 'mental' and 'corporeal' strains of Blake criticism, and suggests that Visions, at least, both analyses the specifics of historical reality, and works towards a millenarian expansion of the body's perception through desire. As Theodor Adorno wrote of Marx, Blake is the "enem[y] of utopia for the sake of 
its realization" (322). Rereading Blake's works as non-didactic exhortations to perceive a more agential, lively, mindful world, and to remember we are part of it, could enrich our relationships with both his poetry and the world.

XI

"The wisest of the Ancients consider'd what is not too explicit as the fittest for Instruction because it rouzes the faculties to act," Blake wrote (E702). The provocations of Blake's poetry, including Visions, have inevitably led to divergent interpretations. Our desire for mastery over a text is thwarted by Blake's open-ended conceptions. Binary reductions cannot harness the body of the poem, but nor is it indescribable. An affirmation of the body of the poem can enrich our reading of Visions. Oothoon's position outside of night and day, and Blake's project, allows for engagement with a reality that is neither transcended nor mechanically reduced-“not Abstracted nor Compounded from Nature" (E648). What does it mean, to be governed by creative desire rather than reason? Blake seems to invite the reader not just to "Reason and Compare," as I am doing even now (E153). A thesis about embodied vision in Blake's work still entails an abstraction from the world it describes. Yet freeing Visions from binary impositions facilitates richly incomplete, embodied encounters with this poem and others, acknowledging Blake's conviction that "the true faculty of knowing must be the faculty which experiences" (E1). 


\section{Works Cited}

Ackland, Michael. “The Embattled Sexes: Blake's Debt to Wollstonecraft in The

Four Zoas.” Blake: An Illustrated Quarterly 16 (1982-3): 172-83. Print.

Ackroyd, Peter. Blake. New York: Knopf, 1995. Print.

Adeney Thomas, Julia. 'The Cage of Nature: Modernity's History in Japan.'

History and Theory 40.1 (2001): 16-36. Web. JSTOR. 11 July 2014.

Adorno, Theodor. Negative Dialectics. Trans. E.B. Ashton. New York:

Continuum, 1992. Print.

Aers, David. "Blake: Sex, Society and Ideology.” Romanticism and Ideology. Ed.

David Aers, Jonathan Cook, and David Punter. London: Routledge \& Kegan Paul, 1981. Print.

Askew, Rie. “The Critical Reception of Lafcadio Hearn Outside Japan.” New

Zealand Journal of Asian Studies 11.2 (2009): 44-71. Print.

Beer, John. William Blake: A Literary Life. Basingstoke: Palgrave Macmillan, 2005. Print.

Bentley, G.E. Blake Records. Yale: Yale UP, 2004. $2^{\text {nd }}$ Ed. Print.

---. "William Blake and the Empire of the Imagination." Wiriamu Bureiku:

Yanagi: Blake no deai | William Blake: Great Encounter, Yanagi and

Blake. Tokyo: Japan Folk Crafts Museum, 1990. Print.

Bindman, David. “Blake’s Vision of Slavery Revisited.” Huntington Library

Quarterly 58.3/4 (1995): 373-382. JSTOR. Web. 3 Nov. 2014.

Blackstone, Bernard. English Blake. Cambridge: Cambridge UP, 1949. Print.

Blake, David and Elliot Gruner. "Redeeming Captivity: The Negative Revolution of Blake's Visions of the Daughters of Albion." Symbiosis: A Journal of Anglo-American Relations 1.1 (1997): 21-34. Print.

Blake, William. The Complete Poetry and Prose of William Blake. Ed. David Erdman. Commentary by Harold Bloom. Rev. ed. Garden City: Anchor, 1982. Print. 
---. Visions of the Daughters of Albion. Ed. Robert N. Essick. San Marino: Huntingdon Library, 2002. Print.

Blake, William, Muneyoshi Yanagi, Kenkichi Kamijima, Teiko Utsumi, G E. Bentley, and Kimiyoshi Yura. Wiriamu Bureiku: Yanagi: Blake no deai | William Blake: Great Encounter, Yanagi and Blake. Tokyo: Japan Folk Crafts Museum, 1990. Print.

Bloom, Harold. Blake's Apocalypse: A Study in Poetic Argument. London: Victor Gollancz, 1963. Print.

---. Commentary. The Complete Poetry and Prose of William Blake. By William Blake. Ed. David Erdman. Rev. ed. Garden City: Anchor Books, 1982. 894970. Print.

Bloom, Harold, and Lionel Trilling, eds. The Oxford Anthology of English

Literature: Romantic Poetry and Prose. New York: Oxford UP, 1973. Print.

Bourdieu, Pierre, and Jean Claude Passeron. Reproduction in Education, Society and Culture. Trans. Richard Nice. London: Sage, 1977. Print.

Bracher, Mark. “The Metaphysical Grounds of Oppression in Blake’s Visions of the Daughters of Albion." Colby Library Quarterly 20 (1984): 164-76. Print.

Brians, Paul. Nuclear Holocausts: Atomic War in Fiction, 1895-1984. Kent: Kent State UP, 1987. Print.

Bruder, Helen. William Blake and the Daughters of Albion. Basingstoke: Macmillan, 1997. Print.

Butler, Gerald J. "Conflict between Levels in Blake's Visions of the Daughters of Albion." Recovering Literature 6.2 (1976): 39-49. Print.

Clark, Steve H. Sordid Images: The Poetry of Masculine Desire. London: Routledge, 1994. Print.

Clark, Steve and Masashi Suzuki, eds. The Reception of Blake in the Orient. London: Continuum, 2006. Print. 
Clark, Steve and David Worrall, eds. Historicizing Blake. New York: St. Martins Press, 1994. Print.

Clute, John. "Oliver, Chad." The Encyclopedia of Science Fiction. Ed. John Clute et al. Gollancz, 9 May 2014. Web. 23 July 2014.

Cooke, Michael G. Acts of Inclusion: Studies Bearing on an Elementary Theory of Romanticism. New Haven: Yale UP, 1979. Print.

Connolly, Tristanne J. "The Authority of the Ancients: Blake and Wilkins' Translation of the Bhagvat-Geeta." Clark and Suzuki 145-158.

Cooper, Andrew. William Blake and the Productions of Time. Farnham: Ashgate, 2013. Print.

Cox, Stephen. Love and Logic: The Evolution of Blake's Thought. Ann Arbor: U of Michigan P, 1992. Print.

Damon, S. Foster. A Blake Dictionary: The Ideas and Symbols of William Blake. Providence: Brown UP, 1965. Print.

Davies, Keri, and Marsha Keith Schuchard. "Recovering the Lost Moravian History of William Blake's Family.” Blake: An Illustrated Quarterly 38.1 (2004): 36-43. Print.

de Waal, Edmund. "Homo Orientalis: Bernard Leach and the Image of the Japanese Craftsman.” Journal of Design History 10.4 (1997): 355-362. Web. JSTOR. 31 May 2014.

Duerkson, Roland A. “The Life of Love: Blake's Oothoon.” Colby Quarterly 13.3 (1977): 186-194. Web. Colby Digital Commons. 3 Nov. 2014.

Eaves, Morris, Robert Essick, and Joseph Viscomi, eds. The William Blake Archive. Lib. of Cong., 28 Sept. 2007. Web. 2013.

Ellis, Helen. "Blake's 'Bible of Hell': Visions of the Daughters of Albion and the Song of Solomon." English Studies in Canada 12.1 (1986): 23-36. Print. Erdman, David. "Blake's Vision of Slavery.” Journal of the Warburg and Courtauld Institutes 15.3/4 (1952): 242-252. JSTOR. Web. 3 Nov. 2014.

---. Blake, Prophet Against Empire : A Poet's Interpretation of the History of His Own Times. Rev. ed. Princeton: Princeton UP, 1969. Print. 
Essick, Robert N. Commentary. Visions of the Daughters of Albion. By William Blake. Ed. Robert N. Essick. San Marino: Huntingdon Library, 2002. 1969. Print.

Ferber, Michael. The Social Vision of William Blake. Princeton: Princeton UP, 1985. Print.

Fordyce, James. The Character and Conduct of the Female Sex... A Discourse, in Three Parts, Delivered in Monkwell-Street Chapel. $2^{\text {nd }}$ Ed. London, 1776. Google eBook. Web. 18 Sep. 2014.

---. Sermons to Young Women. $3^{\text {rd }}$ Ed. Philadelphia: Carey, 1809. Internet Archive. Web. 18 Sep. 2014.

Fox, Susan. “The Female as Metaphor in William Blake's Poetry.” Critical Inquiry 3.3 (1977): 507-519. JSTOR. Web. 31 Jul 2013.

Frye, Northrop. Fearful Symmetry: A Study of William Blake. Princeton: Princeton UP, 1947. Print.

Gavey, Nicola. Just Sex? The Cultural Scaffolding of Rape. London: Routledge, 2005. Print.

George, Diana Hume. Blake and Freud. Ithaca: Cornell UP, 1980. Print.

Gillham, D. G. "Blake: Visions of the Daughters of Albion.” Wascana Review 3.1 (1968): 41-59. Print.

Godart, G. Clinton. 'Tezuka Osamu's Circle of Life: Vitalism, Evolution, and Buddhism.' Mechademia 8: Tezuka’s Manga Life. Ed. French Lunning. Minneapolis: U of Minnesota P, 2013. 34-47. Print.

Goethe, Johann Wolfgang von. The Sorrows of Young Werther. 1774. Trans. Michael Hulse. London: Penguin, 1989. Print.

Goldman, Emma. 'Mary Wollstonecraft, Her Tragic Life and Her Passionate Struggle for Freedom.” 1911. Ed. Alice Wexler. Feminist Studies 7 (1981) 114-21. Print.

Goslee, Nancy Moore. "Slavery and Sexual Character: Questioning the Master Trope in Blake's Visions of the Daughters of Albion." ELH 57 (1990): 101128. JSTOR. Web. 25 Mar 2013. 
Gregory, John. A Father's Legacy to His Daughters. London, 1808. Internet Archive. Web. 18 Sep. 2014.

Hagstrum, Jean. The Romantic Body: Love and Sexuality in Keats, Wordsworth, and Blake. Knoxville: U of Tennessee P, 1985. Print.

Haigwood, Laura Ellen. “Blake's Visions of the Daughters of Albion: Revising an Interpretive Tradition.” San Jose Studies 11 (1985): 77-94. Rpt. in William Blake: Contemporary Critical Essays. Ed. David Punter. London: Macmillan, 1996. 94-107. Print.

Hampsey, John C. Paranoia and Contentment: A Personal Essay on Western Thought. Charlottesville: U of Virginia P, 2005. Print.

Harper, George Mills. The Neoplatonism of William Blake. Chapel Hill: U of North Carolina P, 1961. Print.

Heffernan, James A. W. "Blake's Oothoon: The Dilemmas of Marginality. Studies in Romanticism 30 (1991): 3-18. JSTOR. Web. 25 Mar 2013.

Hill, Christopher. Liberty Against the Law: Some Seventeenth-Century Controversies. London: Penguin, 1996. Print.

Hilton, Nelson. “An Original Story.” Unnam'd Forms: Blake and Textuality. Ed. Nelson Hilton and Thomas A. Vogler. Berkeley: U of California P, 1986. 69-104. Print.

Hinkel, Howard H. "From Energy and Desire to Eternity: Blake' Visions of the Daughters of Albion." Papers on Language \& Literature 15 (1979): 27889. Print.

Hisamori, Kazuko. “'Intercultural ‘Connection’: Bernard Leach’s Encounter with Three Painters: Whistler, Van Gogh, and Ryusei." NASSR Romantic Connections. Tokyo University, Tokyo. 14 June 2014. Panel Presentation. Hoerner, Fred. "Prolific Reflections: Blake's Contortion of Surveillance in Visions of the Daughters of Albion.” Studies in Romanticism 35 (1996): 119-150. JSTOR. Web. 25 Mar 2013.

Hutchings, Kevin. Imagining Nature: Blake's Environmental Poetics. Montreal: McGill-Queens UP, 2002. Print. 
---. "Pastoral, Ideology, and Nature in William Blake's Visions of the Daughters of Albion.” Interdisciplinary Studies in Literature and Environment 9.1 (2002): 1-24. Oxford Journals. Web. 16 Aug 2013.

---. "Ecocriticism in British Romantic Studies." Literature Compass 4.1 (2007): 172-202. Web. John Wiley. 4 Dec. 2014.

Hutchinson, Rachael. "Sabotaging the Rising Sun: Representing History in Tezuka Osamu's Phoenix.” Manga and the Representation of Japanese History. Ed. Roman Rosenbaum. Abingdon: Routledge, 2013. 18-39. Web. EBSCO. 15 July 2015.

Irigaray, Luce. This Sex Which Is Not One. Trans. Catherine Porter. Ithaca: Cornell UP, 1985. Print.

Itō, Gō.'Tezuka Is Dead: Manga in Transformation and Its Dysfunctional Discourse.” Trans. Miri Nakamura. Mechademia 6: User Enhanced. Ed. Frenchy Lunning. Minneapolis: U of Minnesota P, 2011. 69-82. Print. Trans. and abridged from Tezuka izu deddo: Hirakareta manga no hyōgenron e. Tokyo: NTT Shuppan, 2005.

Kaplan, Cora. 'Wild Nights: Pleasure/Sexuality/Feminism.' Formations of Pleasure. Ed. Frederic Jameson. London: Routledge and Kegan Paul, 1983. Print.

Keogh, Annette. "Oriental Translations: Linguistic Explorations into the Closed Nation of Japan.” The Eighteenth Century 45.2 (2004): 171-191. Web. JSTOR. 4 Dec. 2015.

Kitson, Peter J. "'Bid him bow down to that which is above him': The 'kowtow controversy' and Representations of Asian Ceremonials in Romantic Literature." Coleridge: Romanticism and the Orient: Cultural Negotiations. Ed. David Vallins, Kaz Oishi and Seamus Perry. New York: Bloomsbury, 2013. 19-37 Print.

Knott, Sarah, and Barbara Taylor, eds. Women, Gender and Enlightenment. Basingstoke: Palgrave Macmillan, 2005. Print. 
Kurosawa, Akira. Something Like An Autobiography. Trans. Audie E. Bock. New York: Knopf Doubleday, 2011. Print.

Larrissey, Edward. William Blake. New York: Blackwell, 1985. Print. Rereading Lit.

---. Rev. of The Reception of Blake in the Orient, ed. Steve Clark and Masashi Suzuki. Romanticism 13.3 (2007): 293-295. Print.

Lattin, Vernon E. "Blake's Thel and Oothoon: Sexual Awakening in the Eighteenth Century.” Literary Criterion 16 (1981): 11-24. Print.

Leach, Bernard. "Notes on William Blake.” Shirakaba 5 (1914): 462-471. Print.

---. Beyond East and West. New York: Watson-Guptill, 1978. Print.

---. Introduction. The Unknown Craftsman: A Japanese Insight into Beauty. By Sōetsu Yanagi. Adapt. Bernard Leach. 1972. First U.S. Edition. New York: Kodansha USA, 2013. 87-100. Print.

Lee, Debbie. Slavery and the Romantic Imagination. U of Pennsylvannia P, 2004. Print.

Linkin, Harriet Kramer. “Revisioning Blake’s Oothoon.” Blake: An Illustrated Quarterly 23 (1990): 184-94. Print.

Locke, John. Essay Concerning Human Understanding. 1689. Ed. Peter H. Nidditch. Oxford: Clarendon Press, 1975. Print.

Lucken, Michael. “The Endless Pursuit of Inner Desires: Yanagi Sōetsu before Mingei." Cipango - French Journal of Japanese Studies, English Selection 1 (2012): n. pag. Web. 6 Aug. 2014.

Lunning, Frenchy, ed. Mechademia 8: Tezuka's Manga Life. Minneapolis: U of Minnesota P, 2013. Print.

Lussier, Mark. "Blake, Deleuze and the Emergence of Ecological Consciousness." Ecocritical Theory: New European Approaches. Ed. Axel Goodbody and Kate Rigby. Charlottesville: U of Virginia P, 2011. Print.

---. "Blake’s Deep Ecology." Studies in Romanticism 35.3 (1996): 393-408. JSTOR. Web. 31 July 2013. 
MacWilliams, Mark W. “Revisioning Japanese Religiosity: Osamu Tezuka's Hi no tori (The Phoenix).” Global goes Local: Popular Culture in Asia. Ed. Timothy J. Craig and Richard King. Vancouver: UBC Press, 2002. Print.

Makdisi, Saree. William Blake and the Impossible History of the 179os. Chicago: U of Chicago P, 2003. Print.

Markley, Robert. The Far East and the English Imagination, 1600-1730. Cambridge: Cambridge UP, 2006. Print.

Margoliouth, H. M. William Blake. London: Oxford U P, 1951. Print.

Matthews, Susan. Blake, Sexuality and Bourgeois Politeness. Cambridge: Cambridge UP, 2011. Print.

McCalman, Iain. Radical Underworld: Prophets, Revolutionaries and Pornographers in London, 1795-1840.Cambridge: Cambridge UP, 1988.

McGann, Jerome J. Towards a Literature of Knowledge. Oxford and Chicago: Oxford UP and Chicago UP, 1989. Print.

Mee, John. Dangerous Enthusiasm: William Blake and the Culture of Radicalism in the 1790s. Oxford, Clarendon P, 1992. Print.

---. "Is there an Antinomian in the House? William Blake and the After-Life of a Heresy." Clark and Worrall 43-58.

Mellor, Anne K. Blake’s Human Form Divine. Berkeley: U of California P, 1974. 58-64. Print.

---. "Sex, Violence and Slavery: Blake and Wollstonecraft.” Huntington Library Quarterly 58.3/4 (1995): 345-370. JSTOR. Web. 24 Mar 2013.

Moran, Mary Catherine. "Between the Savage and the Civil: Dr John Gregory's Natural History of Femininity.” Knott and Taylor 829.

Morton, A.L. "The Everlasting Gospel: A Study in the Sources of William Blake." History and the Imagination: Selected Writings of A.L. Morton. Ed. Margot Heinemann and Willie Thompson. London: Lawrence, 1990. Print. 
Moss, John G. "Structural Form in Blake's Visions of the Daughters of Albion."

Bulletin de L'Association Canadienne des Humanités. 22.2 (1971): 9-18.

Print.

Niccol, Allardyce. William Blake and His Poetry. London: Harrap, 1922. Print.

Ōe, Kenzaburo. “History Repeats.” The New Yorker. Condé Nast, 28 March 2011.

Web. 12 July 2014.

Oishi, Kazuyoshi. “An Ideological Map of (Mis)reading: William Blake and Yanagi Muneyoshi in early-twentieth-century Japan.” Clark and Suzuki 181-194.

Onoda Power, Natsu. God of Comics: Osamu Tezuka and the Creation of Post-

World War II Manga. Jackson, MS: Mississippi UP, 2009. Print.

Ostriker, Alicia. “Desire Gratified and Ungratified.” Blake: An Illustrated Quarterly 16 (1982-83): 156-65. Print.

Otto, Peter. Blake's Critique of Transcendence: Love, Jealousy, and the Sublime in The Four Zoas. Oxford: Oxford UP, 200o. Print.

---. "Nebuchadnezzar's Sublime Torments: William Blake, Arthur Boyd and the East.” Clark and Suzuki 260-271.

Peterson, Jane E. "The Visions of the Daughters of Albion: A Problem of Perception.” Philological Quarterly 52.2 (1973): 252-64. Print.

Plumwood, Val. "Nature in the Active Voice." Australian Humanities Review 46 (2009): n. pag. Web. 3 March 2014.

Punter, David. "Blake, Trauma and the Female.” New Literary History 15.3 (1984): 475-490. Print.

Raine, Kathleen. Blake and Tradition. 2 vols. Princeton: Princeton UP, 1968.

Print.

“rape, n.3.” OED Online. Oxford University Press, December 2014. Web. 14 Jan 2015 .

“ravish, v.” Oxford University Press, December 2014. Web. 14 Jan 2015.

Richie, Donald. "William Blake, Well-Travelled Through the Imagination of All." Rev. of The Reception of Blake in the Orient, ed. Steve Clark and Masashi Suzuki. Japan Times 28 May 2006: n. pag. Web. 18 May 2014. 
Rigby, Kate. "Minding (about) Matter: On the Eros and Anguish of Earthly Encounter.” Rev. of For Love of Matter: A Contemporary Panpsychism and Reinhabiting Reality: Towards a Recovery of Culture, by Freya Mathews. Australian Humanities Review 38 (2006): n. pag. Web. 13 Jan 2015 .

Rousseau, Jean-Jacques. The Social Contract and the First and Second Discourses. Ed. and trans. Susan Dunn. New Haven: Yale UP, 2002. Print.

---. Politics and Arts: Letter to M D'Alembert on the Theatre. 1758. Ed. and trans. Allan Bloom. New York: Cornell UP, 1968. Print.

---. Emile, or, On Education. 1762. London: Penguin, 1991. Print.

Said, Edward. Orientalism. London: Penguin, 2003. Print.

Schorer, Mark. William Blake: The Politics of Vision. New York: Vintage, 1959. Print.

Shaffer, Elinor. Afterword. Clark and Suzuki 301-302.

Shakespeare, William. "A Midsummer Night's Dream.” 1595. Comedies. Ed. Sylvan Barnet. London: Everyman’s Library, 1995. Print.

---. The Rape of Lucrece. 1594. The Poems. Ed. John Roe. Cambridge: Cambridge UP, 1992. Print.

Snow, C.P. The Two Cultures and the Scientific Revolution. New York: Cambridge UP, 1959. Print.

Sontag, Susan. “On Style.” Against Interpretation and Other Essays. London: André Deutsch, 1987. Print.

Soper, Kate. "Feminism and Enlightenment Legacies.” Knott and Taylor 705-715. Spivak, Gayatri Chakravorty. "In a Word: Interview." Outside in the Teaching Machine. New York: Routledge, 1993. 1-26. Google Book Search. Web. 18 Jan 2015 .

Stevenson, W.H. Introduction and Notes. Blake: The Complete Poems. Ed. W. H. Stevenson. $2^{\text {nd }}$ ed. London: Longman, 1989. Print.

Suvin, Darko, and John Clute. "Lem, Stanislaw." The Encyclopedia of Science Fiction. Ed. John Clute et al. Gollancz, 9 July 2014. Web. 23 July 2014. 
Swearingen, James E. “The Enigma of Identity in Blake’s Visions of the Daughters of Albion." The Journal of English and Germanic Philology 91.2 (1992): 203-215. JSTOR. 25 Mar 2013. Web.

Swedenborg, Emanuel. The Wisdom of Angels, Concerning Divine Love and Divine Wisdom. Trans. N. Tucker. $2^{\text {nd }}$ ed. London: Hodson, 1816. Google ebook. Web. 16 Feb 2015.

Swift, Simon. "Mary Wollstonecraft and the 'Reserve of Reason," SiR 45 (2006): 3-24. Print.

Taylor, Barbara. Mary Wollstonecraft and the Feminist Imagination. Cambridge: Cambridge UP, 2001. Print.

---. "Feminists versus Gallants: Manners and Morals in Enlightenment Britain." Knott and Taylor 30-52.

---. Introduction. "Feminism and Enlightened Religious Discourses." Knott and Taylor 410-415.

Taylor, Irene. "The Woman Scaly." The Bulletin of the Midwest Modern Language Association 6.1 (1973): 74-87. JSTOR. 3 Nov. 2014.

Tezuka, Osamu. Phoenix: A Tale of the Future. Trans. Dadakai. San Francisco: Viz, 2004. Print. Vol. 2 of Phoenix (Hi no tori). 12 vols.

Thompson, E. P. Witness Against the Beast: William Blake and the Moral Law. Cambridge: Cambridge UP, 1993. Print.

Tomaselli, Sylvana. "Remembering Mary Wollstonecraft on the Bicentenary of the Publication of $A$ Vindication of the Rights of Woman." Mary Wollstonecraft. Ed. Jane Moore. Farnham: Ashgate, 2012. Print. Veselka, Vanessa. “The Collapsible Woman: Cultural Responses to Rape and Sexual Abuse.” 1999. BITCHfest: Ten Years of Cultural Criticism from the Pages of Bitch Magazine. Ed. Lisa Jervis and Andi Zeisler. Basingstoke: Macmillan, 2006. 56-61. Print.

Vine, Steven. “'That Mild Beam': Enlightenment and Enslavement in William Blake's Visions of the Daughters of Albion.” The Discourse of Slavery. Ed. Carl Plasa and Betty J. Ring. London: Routledge, 1994. 40-63. Print. 
Viscomi, Joseph. Blake and the Idea of the Book. Princeton: Princeton UP, 1993. Print.

Vogler, Thomas. "In Vain the Eloquent Tongue.” Critical Paths: Blake and the Argument of Method. Ed. Dan Miller, Mark Bracher, and Donald Ault. Durham: Duke UP, 1987. 271-309. Print.

Wada, Ayako. “Blake’s Oriental Heterodoxy: Yanagi's Perception of Blake.” Clark and Suzuki 162-163.

Wagenknecht, David. Blake's Night: William Blake and the Idea of the Pastoral. Cambridge: Belknap-Harvard UP, 1973.

Waxler, Robert P. “The Virgin Mantle Displaced: Blake’s Early Attempt.” Modern Language Studies 12 (1982): 45-53. Web. JSTOR. 3 Nov. 2014.

Webster, Brenda S. Blake's Prophetic Psychology. Athens: U of Georgia P, 1983.

Welch, Dennis M. “Essence, Gender, Race: William Blake’s Visions of the Daughters of Albion." Studies in Romanticism 49 (2010). 105-131. Web. JSTOR. 12 Jul 2013.

Wilkie, Brian. Blake's Thel and Oothoon. English Literary Studies. Victoria: U of Victoria, 1990. Print.

Williams, Nicholas M. Ideology and Utopia in the Poetry of William Blake. Cambridge: Cambridge UP, 1998. Print.

Wollstonecraft, Mary. The Works of Mary Wollstonecraft in Seven Volumes. Ed. Janet Todd and Marilyn Butler. London, 1989. Print.

---. A Vindication of the Rights of Woman, with Strictures on Moral and Political Subjects (1792). Works, vol. 5.

---. A Vindication of the Rights of Men, in a Letter to the Right Honourable Edmund Burke (1790). Works, vol. 5.

---. The Wrongs of Woman, or Maria (1798). Works, vol. 1.

Worrall, David. Radical Culture: Discourse, Resistance and Surveillance, 179o1820. Hemel Hempstead: Harvester Wheatsheaf, 1992. Print. 
Yanagi, Muneyoshi. Letter to Bernard Leach. 8 Nov. 1915. Japanese Folk Craft Museum, Tokyo. Reproduced in William Blake: Great Encounter, Yanagi and Blake, by Blake et al. 93 .

Zamyatin, Yevgeny. We. Trans. Clarence Brown. London: Penguin, 1993. Print. 